On the Response of the GPHS Fueled Clad to Various Impact Environments

\author{
M. Eck and M. Mukunda
}

July 1988

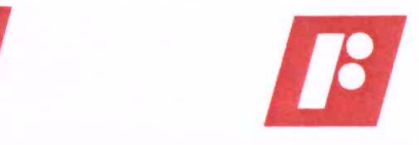




\section{DISCLAIMER}

This report was prepared as an account of work sponsored by an agency of the United States Government. Neither the United States Government nor any agency Thereof, nor any of their employees, makes any warranty, express or implied, or assumes any legal liability or responsibility for the accuracy, completeness, or usefulness of any information, apparatus, product, or process disclosed, or represents that its use would not infringe privately owned rights. Reference herein to any specific commercial product, process, or service by trade name, trademark, manufacturer, or otherwise does not necessarily constitute or imply its endorsement, recommendation, or favoring by the United States Government or any agency thereof. The views and opinions of authors expressed herein do not necessarily state or reflect those of the United States Government or any agency thereof. 


\section{DISCLAIMER}

Portions of this document may be illegible in electronic image products. Images are produced from the best available original document. 
FSC-ESD-217/88/427

\title{
On the Response of the GPHS Fueled Clad to Various Impact Environments
}

\author{
M. Eck and M. Mukunda
}

July 1988 


\section{INTRODUCTION AND SUMMARY}

The General Purpose Heat Source (GPHS) was developed by Department of Energy personnel and their contractors to provide a safe and mass efficient method of packaging the radioactive isotope $238 \mathrm{PuO}_{2}$ for use in space power systems. The characteristics of this heat source and its development history are well documented in numerous reports and papers and will not be revisited here. An exploded view of a GPHS module is shown in Figure 1 for reference.

Most of the GPHS Safety Verification Tests (SVT) which were conducted during the course of the program focused on demonstrating the ability of the modules to survive launch-abort explosions and fires, reentry heating, and post-reentry impact on rigid surfaces. The Challenger (STS-51L) accident demonstrated that Solid Rocket Motor (SRM) casing failure could produce large, high velocity fragments. At the time of the accident, the ability of the GPHS modules to withstand impacts of fragments of this caliber and velocity had not been demonstrated either by analysis or test. Once the magnitude of this problem was assessed, DOE management initiated a program to determine the response of the GPHS-RTG to the impact of SRM casing fragments of the type and velocity witnessed in the $51 \mathrm{~L}$ event(1),(2). This program required the designers to use analysis and test in a serial manner to make the best use of the available hardware and test facilities. Using existing gas-gun facilities, the maximum velocity at which $238 \mathrm{PuO}_{2}$ fueled clads could be tested in a constrained module configuration was $120 \mathrm{~m} / \mathrm{s}$. The maximum fragment size which could be tested was $30.5 \times 40.6 \mathrm{~cm}$. The $51 \mathrm{~L}$ event showed that SRM quadrant sized fragment having velocities of approximately $200 \mathrm{~m} / \mathrm{s}$ were generated at a Mission Elapsed Time (MET) of 110 seconds. The rocket sleds which were available to test fragments of this size were not in contained facilities; hence, they could not be used to test $238 \mathrm{puO}_{2}$ fueled modules. It then became obvious that the extrapolation of the results obtained in tests of $238 \mathrm{UO}_{2}$ fueled clad would be required to predict the response of $238 \mathrm{PuO}_{2}$ fueled clads. 


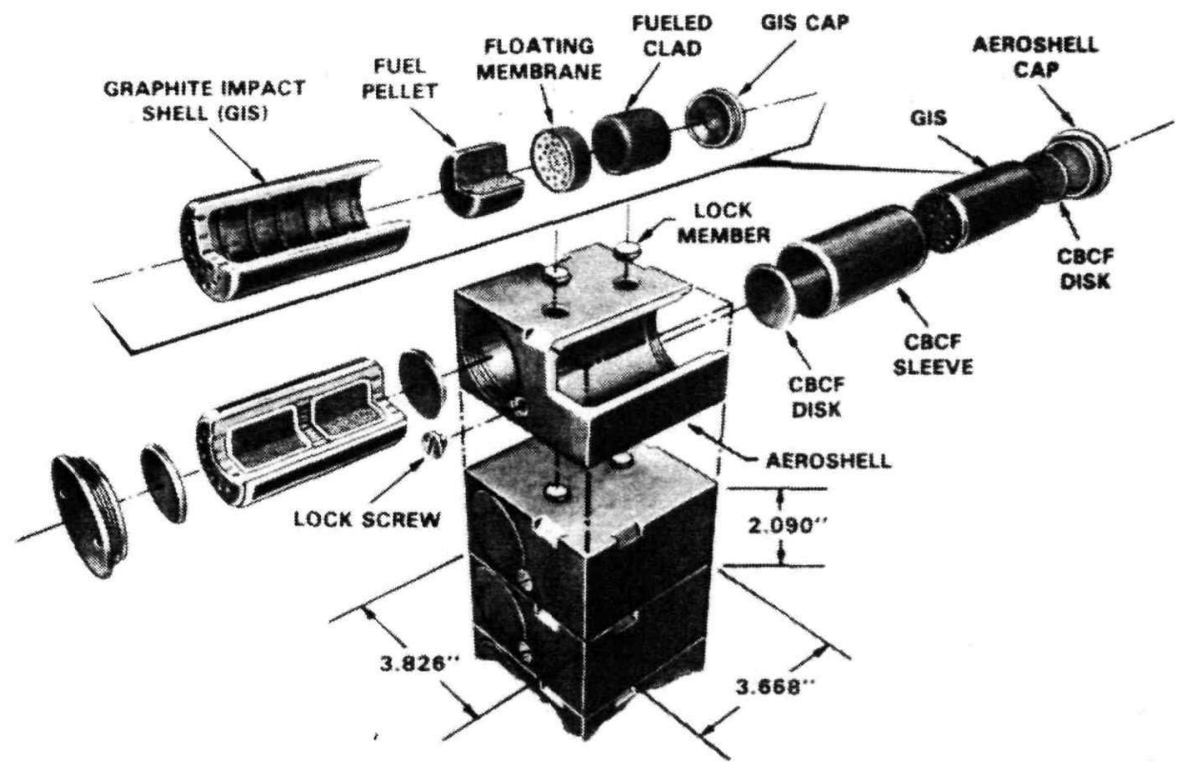

Figure 1. General Purpose Heat Source 
The subject of this report is the analytical process used to perform macro calibrations of analytical models and their application to predict the modules' response to serially increasing levels of test environment complexity. The analytical process proceeded in the following manner:

1) Constitutive equations were developed for the fuel, fuel simulant and iridium.

2) The distortion resulting from the impact of bare fueled clads on concrete or steel targets was predicted for a number of velocities.

3) Tests were conducted using $238 \mathrm{PuO}_{2}$ and a $238 \mathrm{uO}_{2}$ simulant and the results of the experimental observations were compared to the predictions.

4) The above procedure was repeated for impacts of longitudinally constrained modules on a $30.5 \times 40.6 \mathrm{~cm}$ fragment of an STS-SRM casing in a contained gas-gun facility.

5) The above procedure was repeated for rocket sled driven impacts of a $142 \mathrm{~cm}$ square STS-SRM casing fragment on a one-half length section of a GPHS-RTG using $238 \mathrm{UO}_{2}$ simulant only.

6) The results which would have been observed had the $238 \mathrm{UO}_{2}$ simulant been the ${ }^{238} \mathrm{PuO}_{2}$ fuel were predicted analytically.

7) Sensitivity studies were performed to generate a fueled-clad-distortionresponse statistical data base for use in a Monte carlo based fuel release analysis.

A flow chart showing how the test and analytical phases interacted is shown in Figure 2. The "Test" branch shown in Figure 2 is subdivided into pre- and post-51L data bases. This distinction is made to show how the results of the $51 \mathrm{~L}$ event impacted on the planned test program.

The first step in the modeling process was to develop a set of materials constitutive equations for plutonia and urania. Because of the variability in test results, it rapidly became clear that a single set of material properties could not be used. It then became necessary to develop material constitutive equations which would bracket the results obtained from the planned experiments. The terms "weak" and "strong" describe the material property sets which provided upper and lower bounds to the fueled clad deformation 


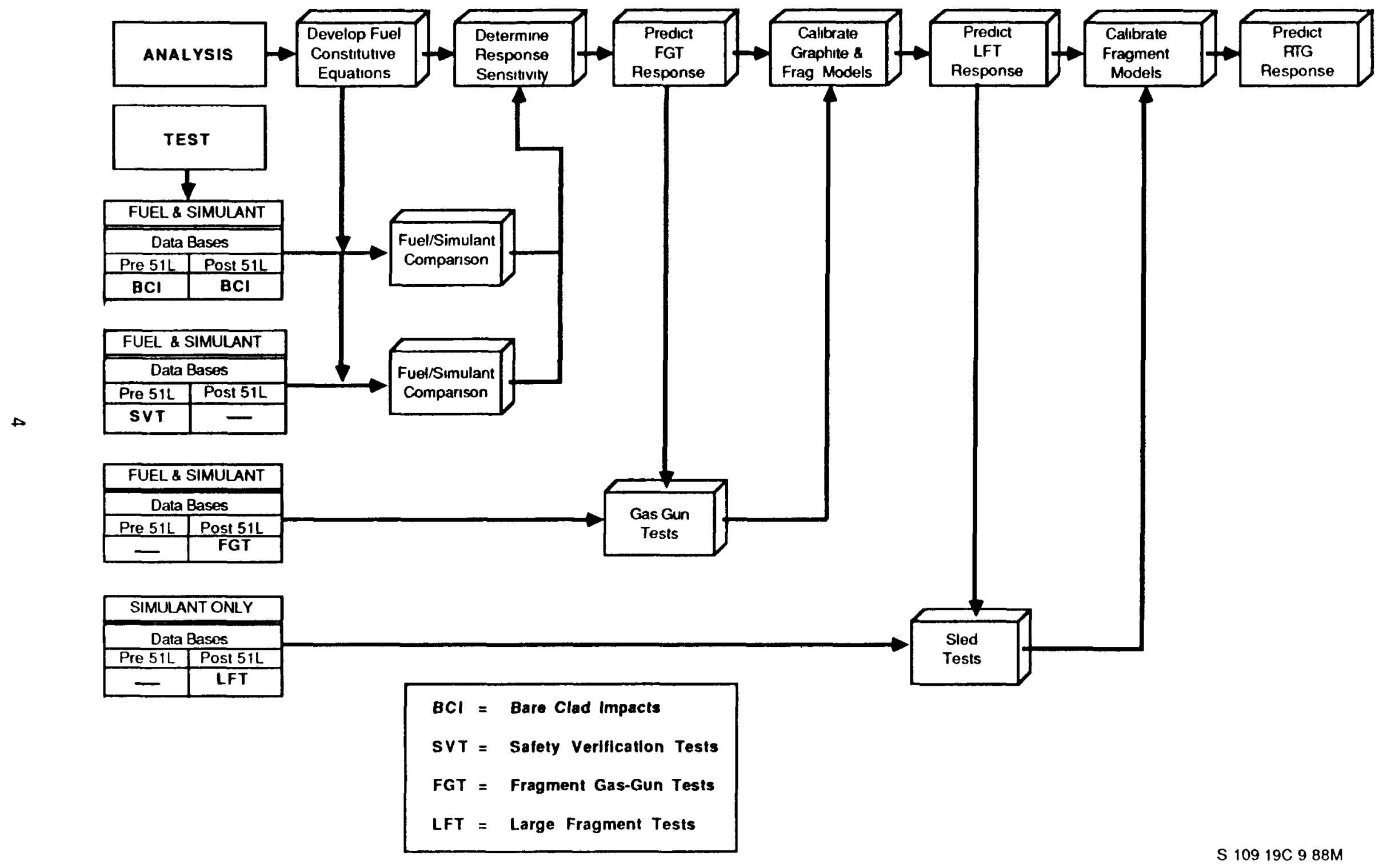

Figure 2. Analysis/Test Interaction Flow Chart 
response observed in the experimental program. The development of acceptable fuel and simulant constitutive equations was necessary because of test facility limitations. As was earlier mentioned, the planned Large Fragment Test (LFT) series could not use live fuel for safety reasons. As a result, it was critical that a pathway be developed to connect the simulant data base derived from the LFT to the live-fuel single-module Fragment Gas-Gun Tests (FGT). The reader may find repeated reference to figure 2 useful throughout the following development.

The protocol for the experimental program required that an analytical prediction be made prior to performing a test. As a result, with the exception of the $54 \mathrm{~m} / \mathrm{s}$ Bare Clad Impact (BCI) test series, the authors made their analytical predictions before they knew the corresponding experimental results. This was purposely done to provide a single blind experiment. Comparison of analytical predictions and test results showed that the analytical methods employed produced an accurate picture of the various impact test results.

More than 200 cases were run using the methods developed. The results of these calculations were used to create a statistical data base for a Mante Carlo based risk analysis performed by others. The cases used to develop the risk analysis data base investigated the effects of fragment velocity; fragment spin rate; effective fragment mass and stiffness; and RTG impact point on the fragment. Additional analyses were performed to predict the response of the plutonia fueled clads to impacts on Shuttle bay doors, concrete and wet sand. The results of several fueled clad multiple impact scenarios were also predicted.

A principal finding of this study was that, for SRM fragment impacts, fueled clad distortion was a function only of point velocity over approximately 90 percent of the fragment surface.

A second major finding was that the fueled clad distortion resulting from fragment impacts on intact RTGs was relatively constant over a large range of point velocities. This finding differs from the results obtained in the BCI 
and FGT events and is due to the longitudinal constraint offered by the inertia of the adjacent modules in the RTG stacked configuration.

The analyses showed that the iridium fueled clads in the GPHS-RTG have high resistance to distortion induced by the impact of large, high velocity, SRM casing fragments. It was concluded that the impact of large SRM fragments will cause little clad disruption at early MET, and that the effects of these impacts will be less severe than had initially been believed. It was also found that fueled clad multiple impacts tend to be less disruptive than some had predicted. This conclusion was supported by subsequent test results. These test results showed that plutonia fueled clads could absorb 37 percent distortion without failure and fuel release. These results are consistent with the authors' long stated position that fueled clad failure is pathway dependent and, at low rates of momentum transfer, fueled clads will accommodate 40 percent distortion before cracking through.

Test results showed that, in the LFT geometry, the length of the fueled clads increases with increasing impact velocity. At some point the threedimensional nature of the fueled clad flow will become important and the efficacy of the two-dimensional modeling used in this study will require reexamination. However, we have shown that the onset of a requirement for three-dimensional analysis will occur at a velocity significantly above 212 meters per second. 


\section{TECHNICAL DISCUSSION}

This chapter is divided into five sections: review of the analytical techniques used in these analyses; calibration and verification of these techniques by comparison of predictions to experimental results; use of these techniques to predict the fueled clad response to test events which cannot be simulated experimentally; use of these techniques to generate a data base for a Monte Carlo treatment of the fuel release which might occur from a number of abort events; and an evaluation of the effect of initial distortion on the fueled clad distortion which may result from secondary impacts. Each of the above topics will be discussed in turn.

\section{A. Numerical Modeling}

A number of hydrocode analyses have been performed to predict the deformation resulting from fueled clad impacts on various media. Hydrocodes were developed by weapons program analysts to predict the distortion resulting from the high velocity collision of materials. These codes solve material constitutive equations while simultaneously conserving mass, momentum and energy. A brief discussion of the mechanics of hydrocode analyses is presented in the following sections.

\section{Continuum Definition}

The initial geometry used to define the continua in the Bare Clad Impact ( $B C I$ ) events is shown in Figure 3 for illustrative purposes. All impact calculations discussed in this paper were performed in a twodimensional (2-D) Lagrangian coordinate system using translational symmetry arguments. In Lagrangian coordinates, the vertices (grid points) of a zone respond to applied forces. The zone vertices define a volume which contains a constant mass of material which moves and distorts in space and time. The motion of all the zones taken together approximates the motion of the continuum of zones. This coordinate system is very useful when it is desirable to define and display motions resulting from the interactions of 


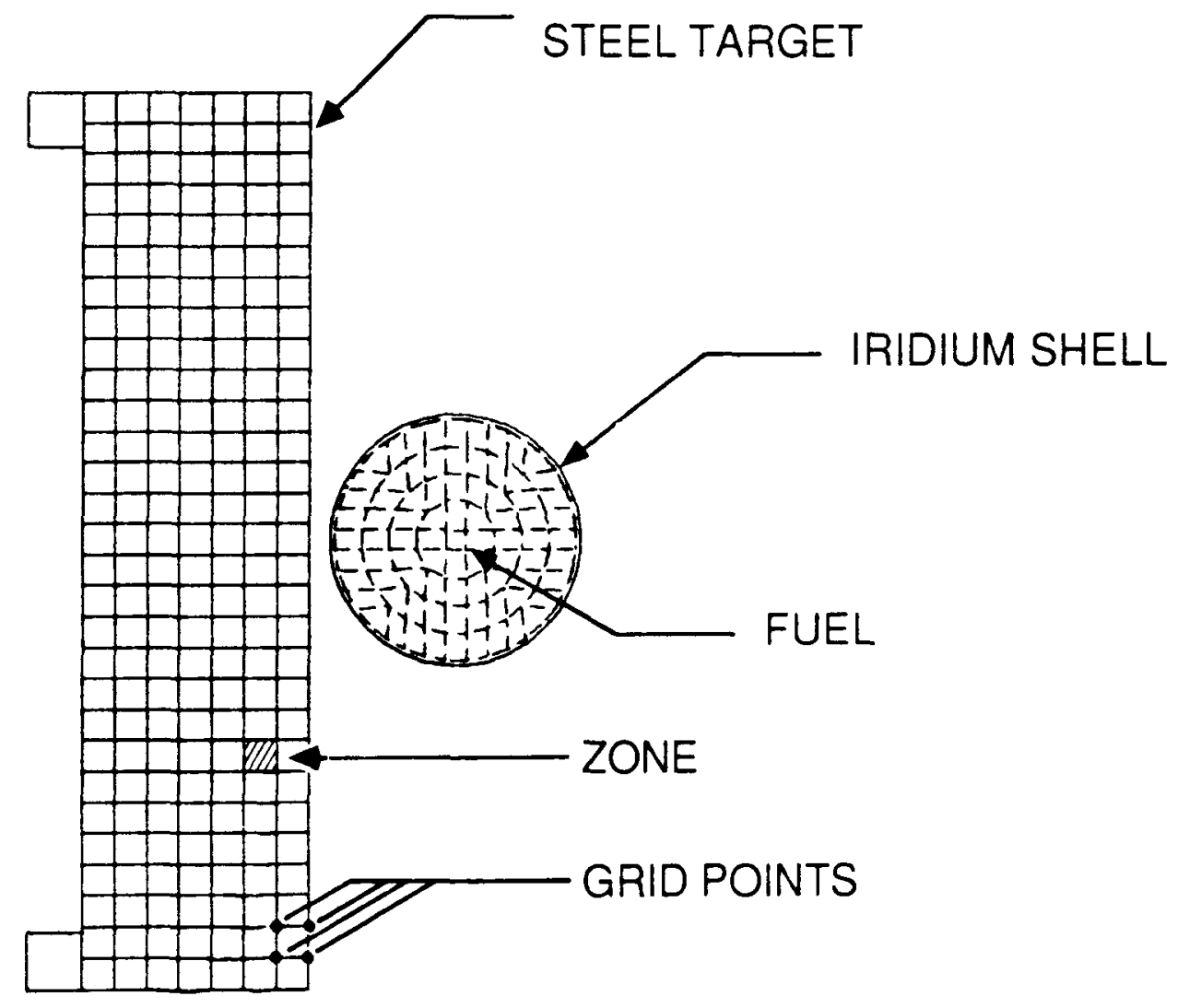

Figure 3. Zone Representation of the Continua Defined by the $\mathrm{BCl}$ Test Geometry 
solid bodies. Mass $(\rho V)$ is automatically conserved in Lagrangian coordinates since it remains constant at its initial values $\left(\rho_{0} \cdot v_{0}\right)$.

The volume of the mass in a zone may be calculated at any time from the geometry of deformation. Hence, the zone density at any time is:

$$
\rho=\frac{m}{V}=\frac{\rho_{0} V_{0}}{V}
$$

\section{Constitutive Equations}

Inertia and material constitutive equations control the trace of the zone distortion which occurs when continua (materials) are acted upon by external forces. In addition to initial and boundary conditions, each material requires equations to define: the zone internal pressure change which occurs in response to zone volume and internal energy changes (An equation of state; see Figure 4.); the resistive forces which are developed in response to strain (A material model; see figure 5.); and, tractive forces (friction) generated at continua interfaces. The material models and the values of material properties used to define all continua are presented in Table I.

\section{Lagrangian Processing}

The basic Lagrangian computing method used in PISCES was developed for the Hemp code and was described by Mark Wilkins of LLNL in UCRL-7322, Rev. 1. In this method, the momentum equations are integrated explicitly in time using a cycle which consists of the following steps:

1. Compute accelerations, new velocities, and new positions of grid points (zone vertices) from forces and masses.

2. Compute strain rates in a zone from the corner velocities.

3. For each zone use a material model to compute new stresses from predicted strain increments.

4. Compute the forces exerted on grid points by the surrounding zones. 
From the above, it is clear that the equations for the conservation of momentum must be related to the material response model through the concept of a stress tensor.

To develop this concept, the partial differential equations expressing the laws of conservation of mass, momentum and energy must be cast in Lagrangian coordinates. When these equations are combined with a material model relating stress to deformation, and with a set of initial and boundary conditions, they give a complete description of the motion of a continuum. It has been previously shown that conservation of mass is assured in Lagrangian coordinates since:

$$
\rho=\frac{m}{V}=\frac{\rho_{0} V_{0}}{V}
$$

Under plane strain and plane stress conditions conservation of momentum may be related to a continuum thru the material model.

$$
\begin{aligned}
& \rho \ddot{x}=\frac{\partial}{\partial x} T_{x x}+\frac{\partial}{\partial y} T_{x y} \\
& \rho \ddot{y}=\frac{\partial}{\partial x} T_{x y}+\frac{\partial}{\partial y} T_{y y}
\end{aligned}
$$

For plane strain the stress tensor may be separated into hydrostatic pressure and a stress deviator tensor. Upon decomposition the stress tensor becomes:

$$
\begin{aligned}
& T_{x x}=-P+S_{x x} \\
& T_{y y}=-P+S_{y y} \\
& T_{\theta \theta}=-P+S_{\theta \theta} \\
& T_{x y}=S_{x y}
\end{aligned}
$$




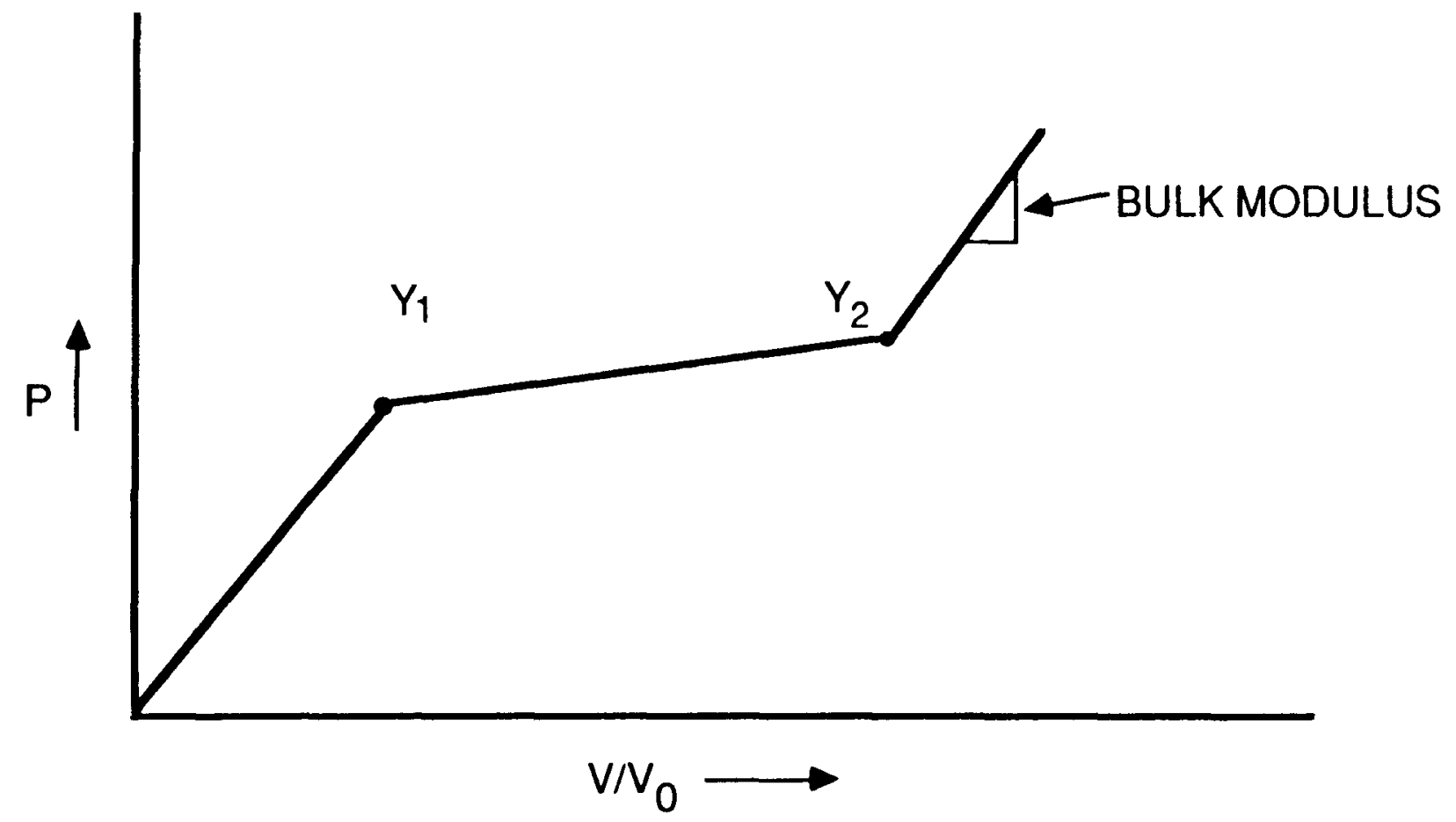

Where:

$\mathrm{P}=$ Pressure within a zone

$Y_{1}=$ Compressive yield strength of the uncompacted material

$Y_{2}=$ Compressive yield strength of the compacted material

$\mathrm{V}=$ Current zone volume

$V_{0}=$ Initial zone volume

Figure 4. Trace of a Generalized P- $\alpha$ Compaction Equation of State 

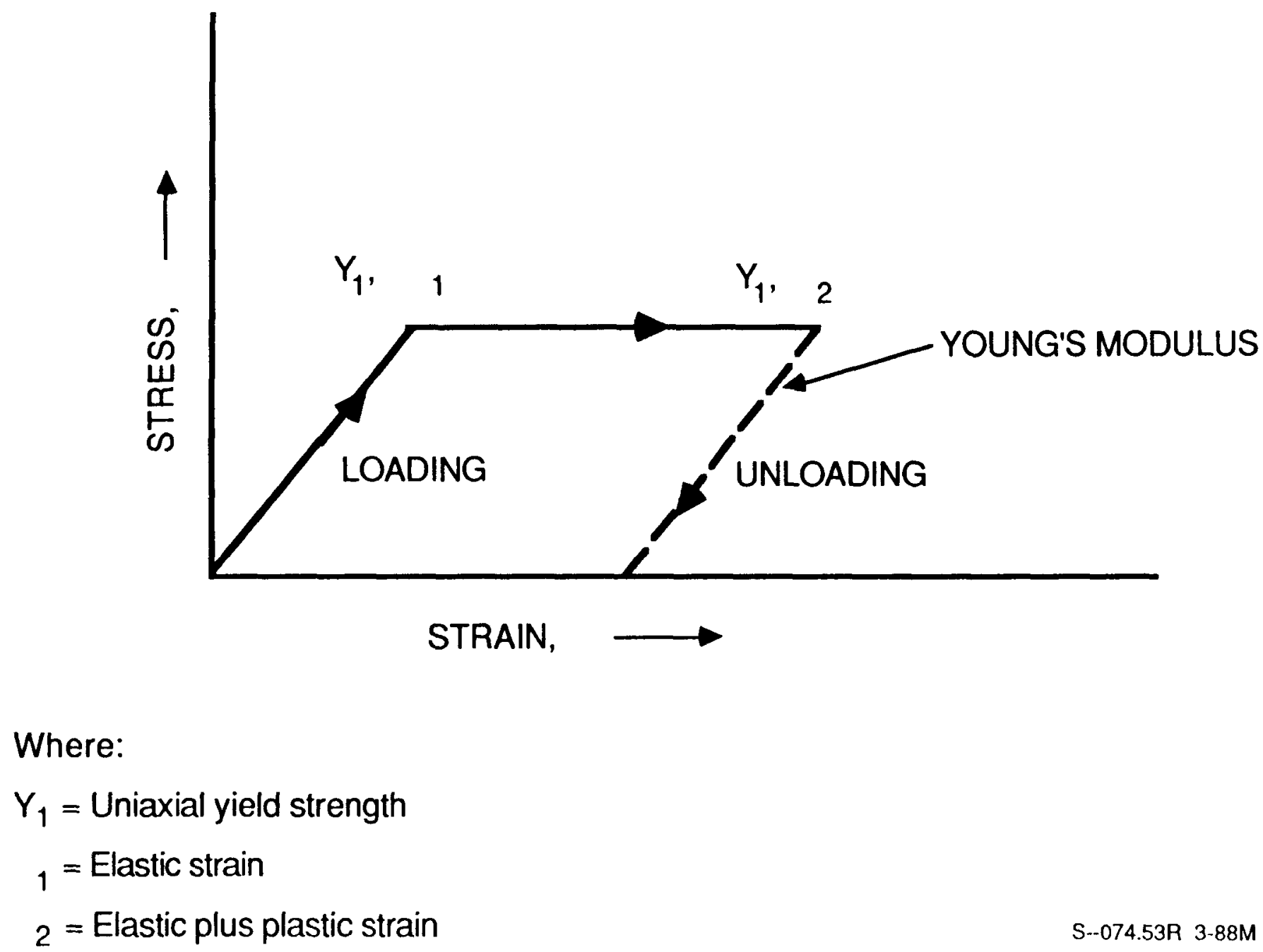
Table I. Summary of Material Properties Used in the SRM Fragment Impact Analyses

\begin{tabular}{|c|c|c|c|c|c|c|c|c|c|c|c|}
\hline \multirow[t]{2}{*}{ MATERIAL } & \multicolumn{6}{|c|}{ EQUATION OF STATE } & \multicolumn{3}{|c|}{ YIELD MODEL } & \multirow[b]{2}{*}{\begin{tabular}{|l|} 
SPALL \\
STRENGTH
\end{tabular}} & \multirow[t]{2}{*}{ DATA SOURCE } \\
\hline & TYPE & (1) & $\mid \begin{array}{c}\text { BULK } \\
\text { MODULUS } \\
\text { KBAR }\end{array}$ & $\begin{array}{c}Y_{1} \\
\text { KBAR }\end{array}$ & $\begin{array}{c}\mathrm{Y} 2 \\
\text { KBAR }\end{array}$ & $\begin{array}{c}\text { REF } \\
\text { DENSITY } \\
(\rho 0) \\
\mathrm{gm} / \mathrm{cc}\end{array}$ & TYPE & $\begin{array}{c}\text { SHEAR } \\
\text { MODULUS } \\
\text { KBAR }\end{array}$ & $\begin{array}{c}\text { YIELD } \\
\text { STRENGTH } \\
\text { KBAR }\end{array}$ & & \\
\hline WEAK PLUTONIA (PU2HGH) & $\mathrm{P}-\boldsymbol{a}$ & 084 & 730 & 0677 & 133 & 115 & $\begin{array}{l}\text { VON } \\
\text { MISES }\end{array}$ & 270 & 0677 & 0200 & \multirow{2}{*}{$\begin{array}{l}\text { LOS ALAMOS DATA SHEETS } \\
\text { MAY } 1986\end{array}$} \\
\hline STRONG PLUTONIA (PUAH 13H) & $\mathrm{P}-a$ & 084 & 730 & 130 & 133 & 115 & $\begin{array}{l}\text { VON } \\
\text { MISES } \\
\end{array}$ & 270 & 130 & 0400 & \\
\hline WEAK URANIA (UGH 11H) & $p-a$ & 087 & 1370 & 110 & 122 & 110 & $\begin{array}{c}\text { VON } \\
\text { MISES } \\
\end{array}$ & 598 & 110 & 0600 & \multirow{2}{*}{$\begin{array}{l}\text { LOS ALAMOS DATA SHEETS } \\
\text { MAY } 1986\end{array}$} \\
\hline STRONG URANIA (U8H 12H) & P- $a$ & 087 & 1370 & 120 & 122 & 110 & $\begin{array}{c}\text { VON } \\
\text { MISES } \\
\end{array}$ & 598 & 120 & 0800 & \\
\hline POCO GRAPHITE & \begin{tabular}{|l} 
POLY- \\
NOMIAL \\
\end{tabular} & - & 301 & - & - & 198 & $\begin{array}{c}\text { VON } \\
\text { MISES }\end{array}$ & 20 & 050 & 10 & \multirow{2}{*}{$\begin{array}{l}\text { WW TARBELL (1979) } \\
\text { AFWL-TA-79-38 }\end{array}$} \\
\hline 3-D GRAPHITE & SHOCK & - & 259 & - & - & 195 & $\begin{array}{l}\text { VON } \\
\text { MISES } \\
\end{array}$ & 20 & 100 & 10 & \\
\hline IRIDIUM & \begin{tabular}{|l} 
POLY- \\
NOMIAL \\
\end{tabular} & - & 3510 & & & 225 & $\begin{array}{l}\text { VON } \\
\text { MISES } \\
\end{array}$ & 1618 & 200 & 1000 & $\begin{array}{ll}\text { ORNL-5611 APRIL } 1980 & \text { (3) } \\
\text { FSAR GESP 7200 AUGUST } 1985 \\
\end{array}$ \\
\hline INSULATION-TIE & $p-a$ & 059 & 89 & & & 090 & $\begin{array}{l}\text { VON } \\
\text { MISES } \\
\end{array}$ & 67 & 100 & 01 & $\begin{array}{l}\text { GE MEMO (2) } \\
\text { C J EARDLEY } 1 / 7 / 188 \\
\end{array}$ \\
\hline ALUMINIUM & \begin{tabular}{|l} 
POLY \\
NOMIAL
\end{tabular} & - & 765 & - & - & 277 & $\begin{array}{c}\text { VON } \\
\text { MISES } \\
\end{array}$ & 2940 & 650 & 1000 & BAKKEN \& ANDERSON, SANDIA \\
\hline DEA STEEL & $\begin{array}{l}\text { POLY- } \\
\text { NOMIAL }\end{array}$ & - & 1670 & - & - & 786 & $\begin{array}{l}\text { VON } \\
\text { MiSES }\end{array}$ & 8160 & 129 & 1000 & $\begin{array}{l}\text { LADISH DATA SHEET } \\
\text { FSCM } 07703 \text { (1987) }\end{array}$ \\
\hline
\end{tabular}

(1) a- DENSITY OF UNCOMPACTED MATERIAL

(2) DERIVED FROM EXPEAIMENTS CONDUCTED AT GE AND MODIFIED BY FSC PERSONNEL TO ACCOUNT FOR THERMOELECTRIC ELEMENT INITIAL COMPRESSIVE STRENGTH

(3) YIELD CORRECTED FOR THE BIAXIAL TENSION CREATED BY THE ALMOST SPHERICAL NATURE OF THE IRIDIUM SHELL 
The term "hydrocode" is derived from the fact that many code applications are so driven by the hydrostatic component of the stress tensor that the stress deviators can be ignored. In translational symmetry, strain rates are related to the local velocity $(\dot{x}, \dot{y})$ by:

$$
\begin{aligned}
& \dot{\epsilon}_{x x}=\frac{\partial \dot{x}}{\partial x} \\
& \dot{\epsilon}_{y y}=\frac{\partial \dot{y}}{\partial y} \\
& \dot{\epsilon}_{\theta \theta}=0 \\
& \dot{\epsilon}_{x y}=\frac{1}{2}\left[\frac{\partial \dot{x}}{\partial y}+\frac{\partial \dot{y}}{\partial x}\right]
\end{aligned}
$$

The relative rate of change of volume at a point in the material is related to the strain rates by:

$$
\frac{\dot{V}}{V}=\dot{\epsilon}_{x x}+\dot{\epsilon}_{y y}+\dot{\epsilon}_{\theta \theta}
$$


Elastic changes in the stress deviators may be expressed:

$$
\begin{aligned}
& \dot{S}_{x x}=2 G\left[\dot{\epsilon}_{x x}-\frac{1}{3} \frac{\dot{V}}{V}\right] \\
& \dot{S}_{y y}=2 G\left[\dot{\epsilon}_{y y}-\frac{1}{3} \frac{\dot{v}}{V}\right] \\
& \dot{S}_{\theta \theta}=2 G\left[\dot{\epsilon}_{\theta \theta}-\frac{1}{3} \frac{\dot{V}}{V}\right] \\
& \dot{S}_{x y}=2 G \dot{\epsilon}_{x y}
\end{aligned}
$$

Where: $G=$ Shear Modulus

The hydrostatic pressure which was separated earlier from the stress tensor is related to density, $\rho$, and specific internal energy, $e$, through the equation of state:

$$
P=f(\rho, e)
$$

This expression must be solved simultaneously with an equation which expresses conservation of energy:

$$
\dot{e}=\frac{1}{\rho}\left[T_{x x} \dot{\epsilon}_{x x}+T_{y y} \dot{\epsilon}_{y y}+T_{\theta \theta} \dot{\epsilon}_{\theta \theta}+2 T_{x y} \dot{\epsilon}_{x y}\right]
$$

The plane stress equations are similar to the plane strain formulations except it is assumed that the stress, rather than the strain, normal to the $x-y p l a n e$ is zero. The constitutive equations which are used to describe a plane stress condition relate temporal increments in stress to the stress at a previous instant and a current strain increment. The constitutive relations used in PISCES are based on the incremental theory of plasticity. 
They assume the Von Mises condition and the associated flow rule. For biaxial stress, the Von Mises yield function takes the form:

$$
f=T_{x x}^{2}+T_{y y}^{2}-T_{x x} T_{y y}+3 T_{x y}^{2}-Y^{2}
$$

Where: TXX, TYY and TXY are the non-vanishing components of the stress tensor and $Y$ is the uniaxial yield stress. A typical trace of a Von Mises yield model was shown in figure 5 .

\section{B. Analytical Model Calibration}

\section{Bare Clad Impact Tests}

A Lagrangian model of the BCI continua was constructed using the techniques presented in the previous discussion. Representative material properties were selected for the urania, plutonia, iridium and steel target from published data on these materials. Trial predictions of the fueled clad distortion resulting from impacts on a one-inch thick steel target at $54 \mathrm{~m} / \mathrm{s}$ were conducted. Unfortunately, there was considerable scatter in the tests results and it was necessary to use a range of values for fuel compressive yield strength and spall strength to capture the BCI $54 \mathrm{~m} / \mathrm{s}$ data base. This range of properties data was then used to predict a range of results for those $B C I$ geometry tests which were to be conducted at velocities other than $54 \mathrm{~m} / \mathrm{s}$. Subsequent higher velocity BCI tests showed that the range of material property values chosen to predict $54 \mathrm{~m} / \mathrm{s}$ results would capture the entire BCI data base.

The results of the $B C I$ predictions are presented graphically for urania- and plutonia-fueled clads in Figures 6 and 7 . A tabulation of these results is also presented in Table II. Note that the high strength plutonia 


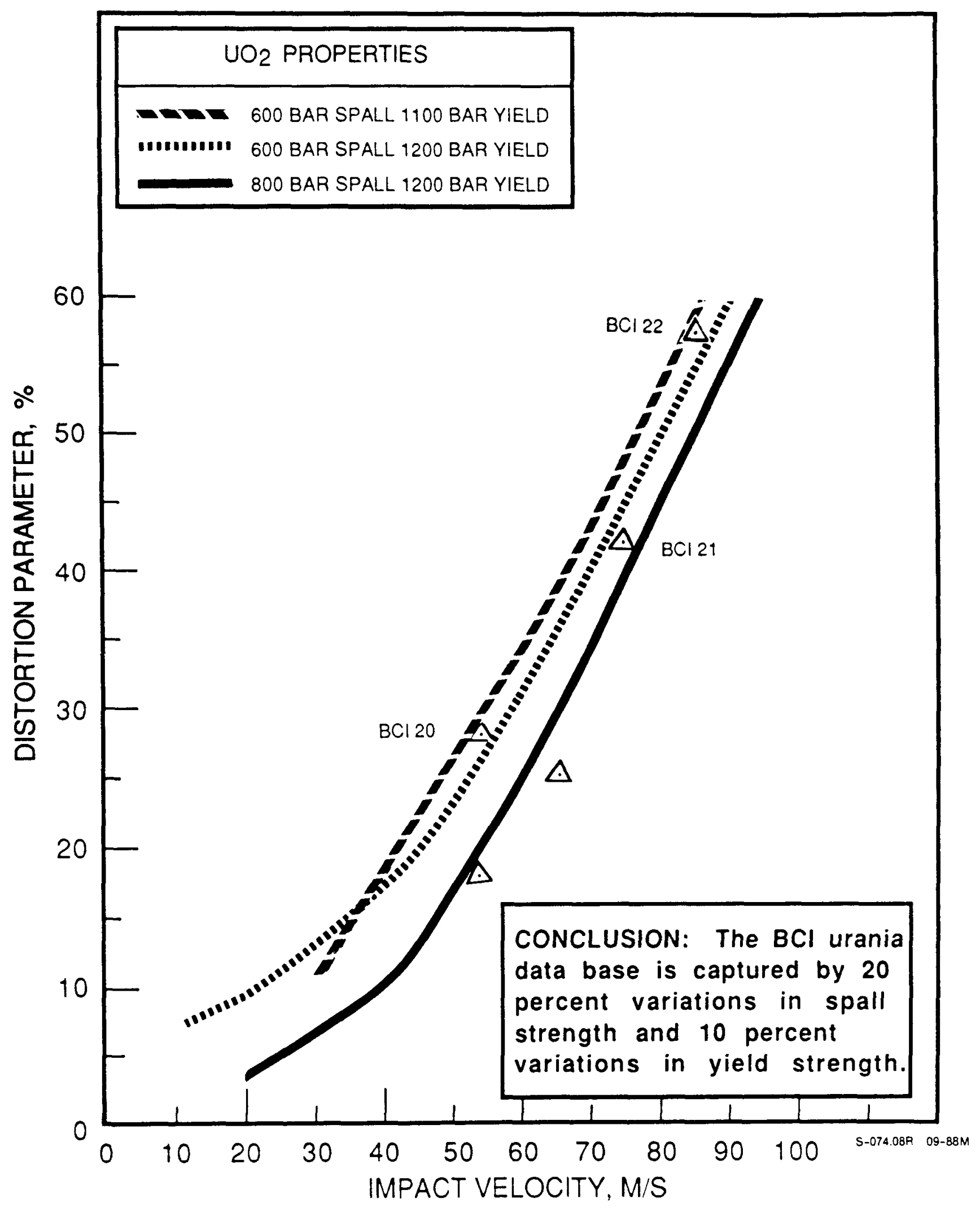

Figure 6. Bare Urania.Fueled Clad Response to Impact on a $2.54 \mathrm{~cm}$ Thick Steel Plate (BCl Geometry) 


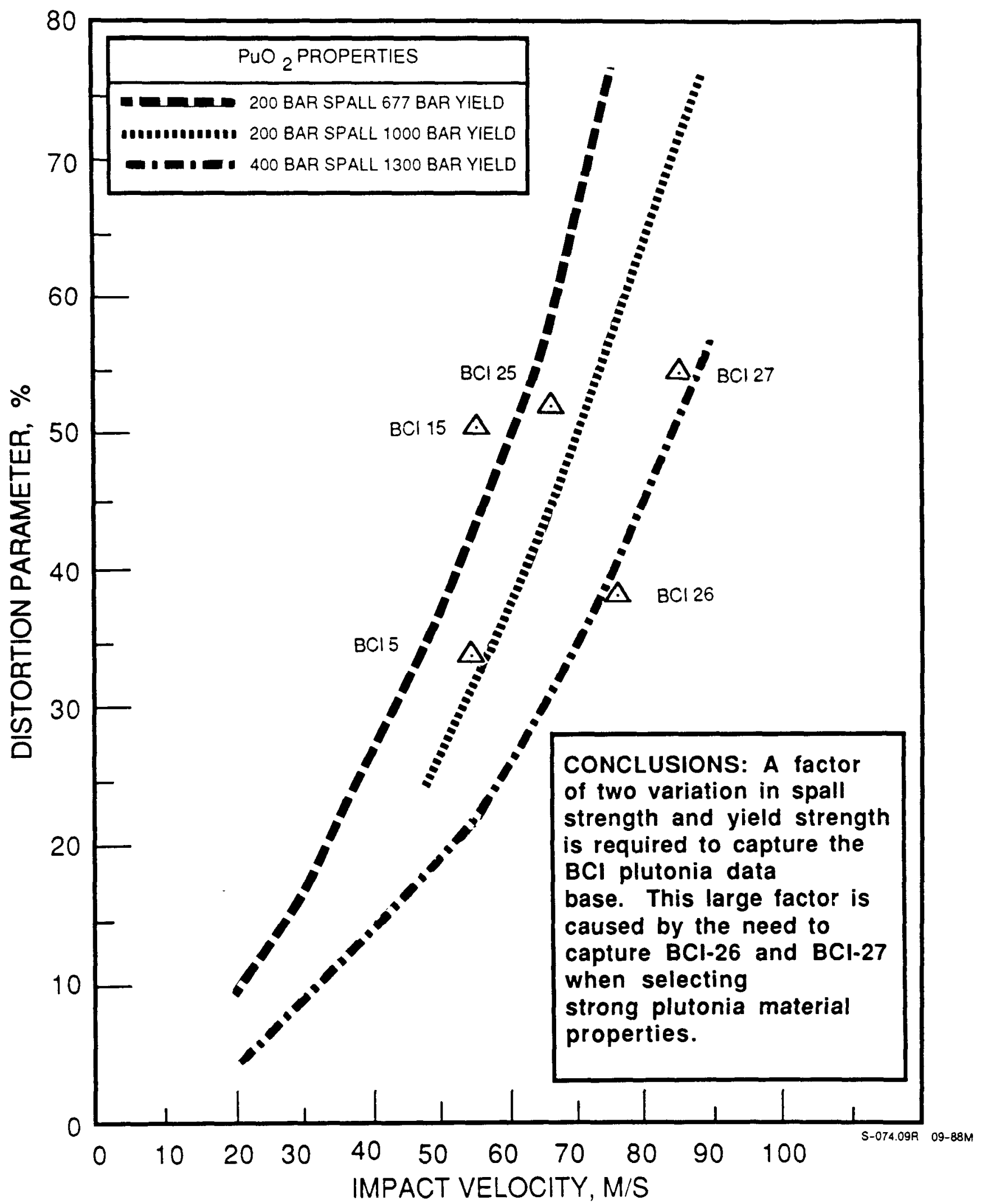

Figure 7. Plutonia.Fueled Bare GPHS Clad Response to Impact on a $2.54 \mathrm{~cm}$ Thick Steel Target (BCl Geometry) 
Table II. Effect of Fuel Properties and Impact Velocity on Predicted Fuel Clad Deformation in BCI Type Events

\begin{tabular}{|c|c|c|c|c|c|c|}
\hline DATA SETS & U02_*_6H11H & $\mathrm{U} 02_{-}{ }^{*}-6 \mathrm{H} 12 \mathrm{H}$ & U02_*_8H12H & PU_*_2H6H & $\mathrm{PU}_{-}{ }^{*}-2 \mathrm{H} 10 \mathrm{H}$ & $P U_{-}--4 H 13 H$ \\
\hline $\begin{array}{l}\text { IMPACT } \\
\text { VELOCITY }\end{array}$ & (Min Prop) & & (Max Prop) & (Min Prop) & & (Max Prop) \\
\hline$M / S$ & $\%$ & $\%$ & $\%$ & $\%$ & $\%$ & $\%$ \\
\hline 10 & - & 7.4 & - & - & - & - \\
\hline 20 & 9.8 & 9.0 & 3.3 & 10.0 & 6.9 & 3.7 \\
\hline 30 & 10.3 & 12.7 & - & 16.8 & 11.9 & 9.2 \\
\hline 35 & 15.6 & 15.8 & 7.7 & 22.6 & 17.1 & - \\
\hline 40 & 19.1 & 18.0 & - & 27.7 & 23.8 & 14.5 \\
\hline 45 & 21.9 & 19.8 & 12.8 & 31.5 & 27.0 & - \\
\hline 50 & 26.2 & 24.6 & - & - & 30.5 & - \\
\hline 54 & 29.2 & 27.0 & 20.5 & 43.6 & 32.2 & 21.0 \\
\hline 65 & 38.9 & 35.0 & 29.1 & 57.0 & 43.9 & - \\
\hline 75 & 49.6 & 45.3 & 44.0 & 79.5 & 58.2 & 39.8 \\
\hline 85 & 58.9 & 54.6 & 50.4 & - & 73.2 & 52.5 \\
\hline
\end{tabular}


properties are required by the results from BCI-26 and BCI-27. It is known that these clads were welded to their tantalum containers. It is not known if this caused anomalous distortion results. The concern is that the behavior shown in Figure 8 is a driver for the selection of the strong plutonia property values. Temporal variations in the predicted BCI geometry are shown in Figure 9. A comparison of predicted to observed post impact geometry was made as a sanity check. The geometry comparison shown in Figure 10 is for BCI-21, a $76 \mathrm{~m} / \mathrm{s}$ bare urania-fueled clad impact event. The agreement shown is typical of the agreement obtained between predicted and observed results. Based on these results, no further changes were allowed in the fuel, iridium, and interface friction properties used for subsequent, more geometrically complex, calculations.

\section{The Fragment Gas-Gun Test Events}

Urania and plutonia fueled modules having molybdenum mass simulants on either side and a simulated RTG section positioned in the direction of travel were impacted against a $30 \times 40 \times 1.24 \mathrm{~cm}$ section of STS-SRM at 100 and $120 \mathrm{~m} / \mathrm{s}$. The Fragment Gas-Gun Test (FGT) setup is shown in Figure 11. The results of the FGT events were used to verify the material property values first used for the 3-D and poco graphite in 1985 when similar calculations were performed to predict the results of the shock tube experiments. Also, it was found that no adjustments in the fuel, iridium, and friction properties used to predict the BCI test were required to capture the FGT data base. The graphic comparisons of predicted and observed fueled clad distortions shown in Figure 12 are the basis for the above conclusions. It should be noted that the observed distortion decreased with increased velocity as was predicted before the FGT series was conducted. This decrease is due to the fact that the front face of the aeroshell is driven into the space occupied by the low density CBCF before the high inertia fuel and clad can dilate into this volume. This effect becomes more apparent in the higher velocity, higher longitudinal constraint LFT series which will be discussed subsequently. Details of the graphically presented results are shown in Table III. Temporal variations in the predicted FGT-geometry are presented graphically in Figure 13. Comparisons 
Table III. Effect of Fuel Properties and Impact Velocity on Predicted Deformation in FGT Tpe Events

\begin{tabular}{|c|c|c|c|c|c|}
\hline DATA SET ${ }^{(1)}$ & VELOCITY & $\begin{array}{l}\text { SPALL } \\
\text { STRENGTH }\end{array}$ & $\begin{array}{c}\text { YIELD } \\
\text { STRENGTH }\end{array}$ & \multicolumn{2}{|c|}{ DISTORTION PARAMETER } \\
\hline & & & & FWD/CAP & AFT/CAP \\
\hline & M/S & BAR & BAR & $\%$ & $\%$ \\
\hline F1K_U6H11H_* & 100 & 600 & 1100 & 21.9 & 3.8 \\
\hline F1K_U6H11H_* & 125 & 600 & 1100 & 20.4 & 7.8 \\
\hline F1K_U6H11H_* & 150 & 600 & 1100 & 25.5 & 11.0 \\
\hline F1K_U8H12H_* & 100 & 800 & 1200 & 16.0 & 0. \\
\hline F1K_U8H12H_* & 125 & 800 & 1200 & 20.0 & 0. \\
\hline F1K_U8H12H_* & 150 & 800 & 1200 & 25.2 & 5. \\
\hline F1K_PU2H6H_" & 100 & 200 & 677 & 33.3 & 7.3 \\
\hline F1K_PU2H6H_* & 125 & 200 & 677 & 31.5 & 14.0 \\
\hline F1K_PU2H6H_* & 150 & 200 & 677 & 38.2 & 27.6 \\
\hline F1K_PU4H13H_* & 100 & 400 & 1300 & 11.9 & 0. \\
\hline F1K_PU4H13H_* & 125 & 400 & 1300 & 9.8 & 0. \\
\hline F1K_PU4H13H_* & 150 & 400 & 1300 & 14.3 & 1.8 \\
\hline
\end{tabular}

(1) A 3/4 INCH THICKNESS PLATE WAS USED AS A TARGET TO PROVIDE EQUIVALENT 2D STIFFNESS TO THE 3D $1 / 2$ INCH REAL TARGET. A $1 \mathrm{~K}$ BAR INSULATION YIELD WAS USED TO SIMULATE THE TIE ELEMENT FAILURE IN COMPRESSION. A 500 BAR POCO YIELD WAS USED FOR THE MASS SIMULANT CARBON BLOCKS. FUEL DISTORTION IS USED TO CALCULATE D.P.

* SUBSTITUTE VELOCITY FOR ASTERISK TO OBTAIN COMPLETE DATA SET NAME 


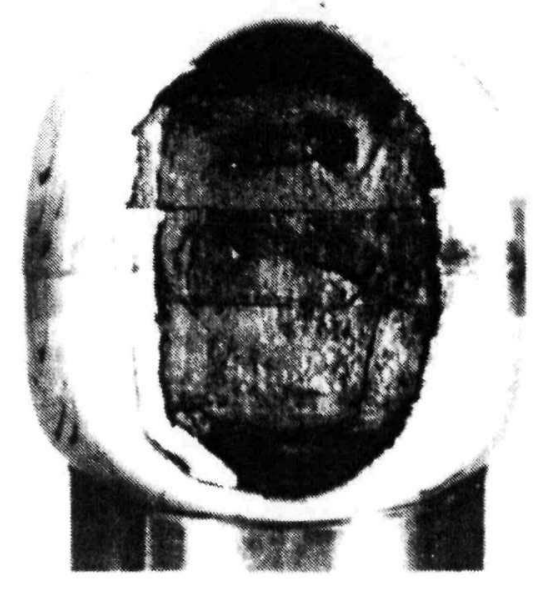

FC-297

IMPACT FACE

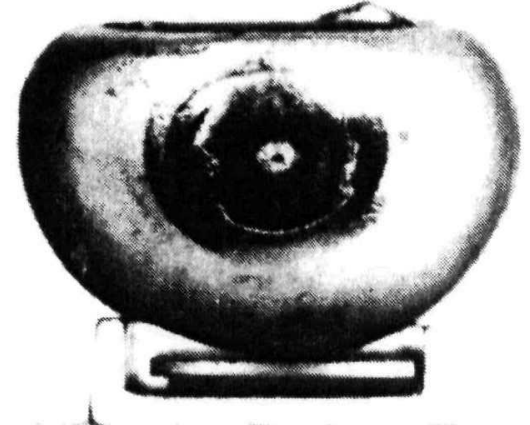

FC-297

VENT END PROFILE

CONCLUSION: The iridium clad welded to the tantalum containment vessel during impact

SPECULATION: This welding may have caused less clad distortion than would have occurred in the absence of welding

Figure 8. Post-Impact Geometry of the Plutonia-Fueled Clad from the $\mathrm{BCl}-27$ Event 


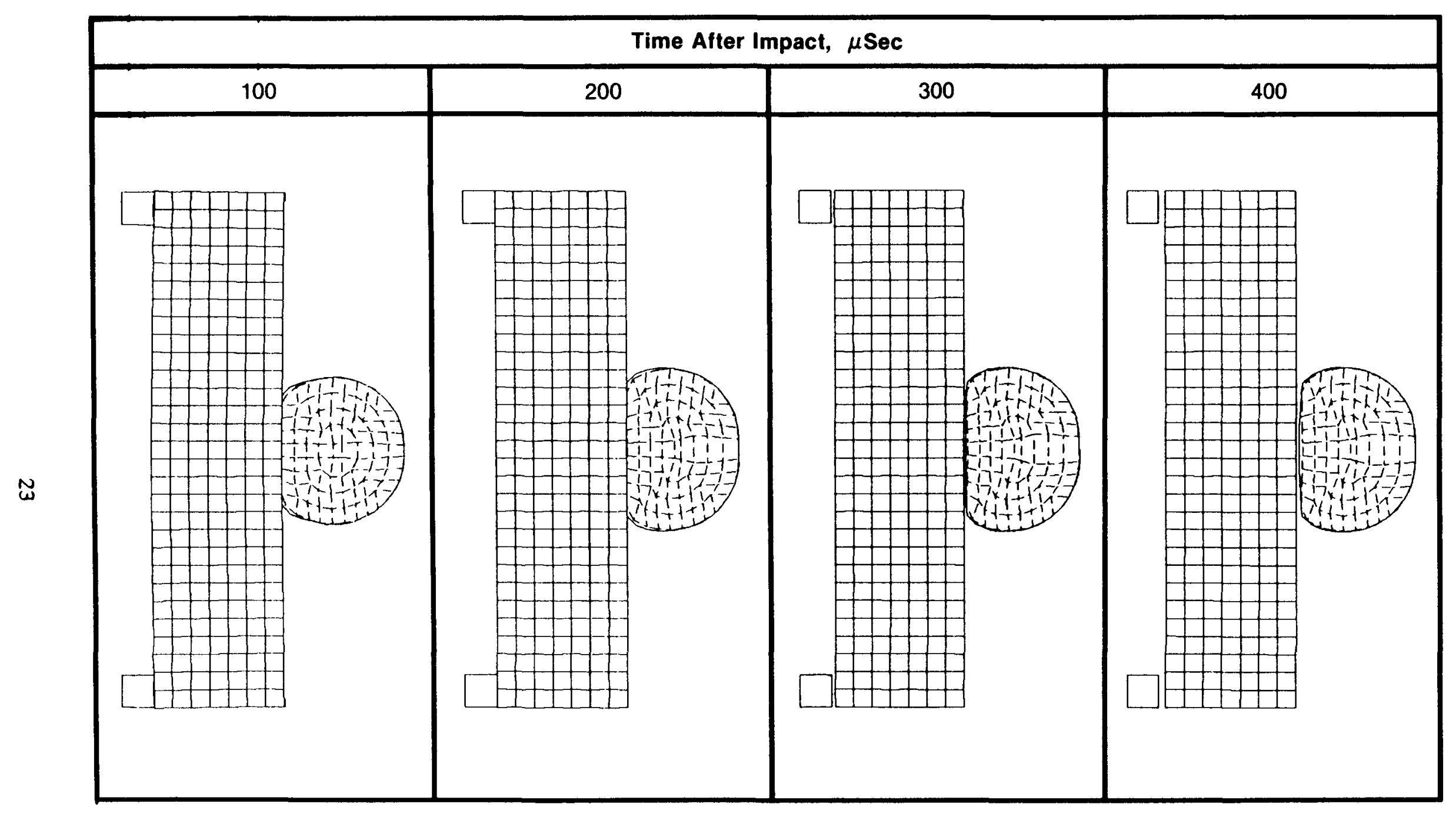

Figure 9. Predicted Response of a Urania-Fueled Clad in the $\mathrm{BCl} 21$ Event (76 M/S, $2.54 \mathrm{~cm}$ Thick Steel Target) 


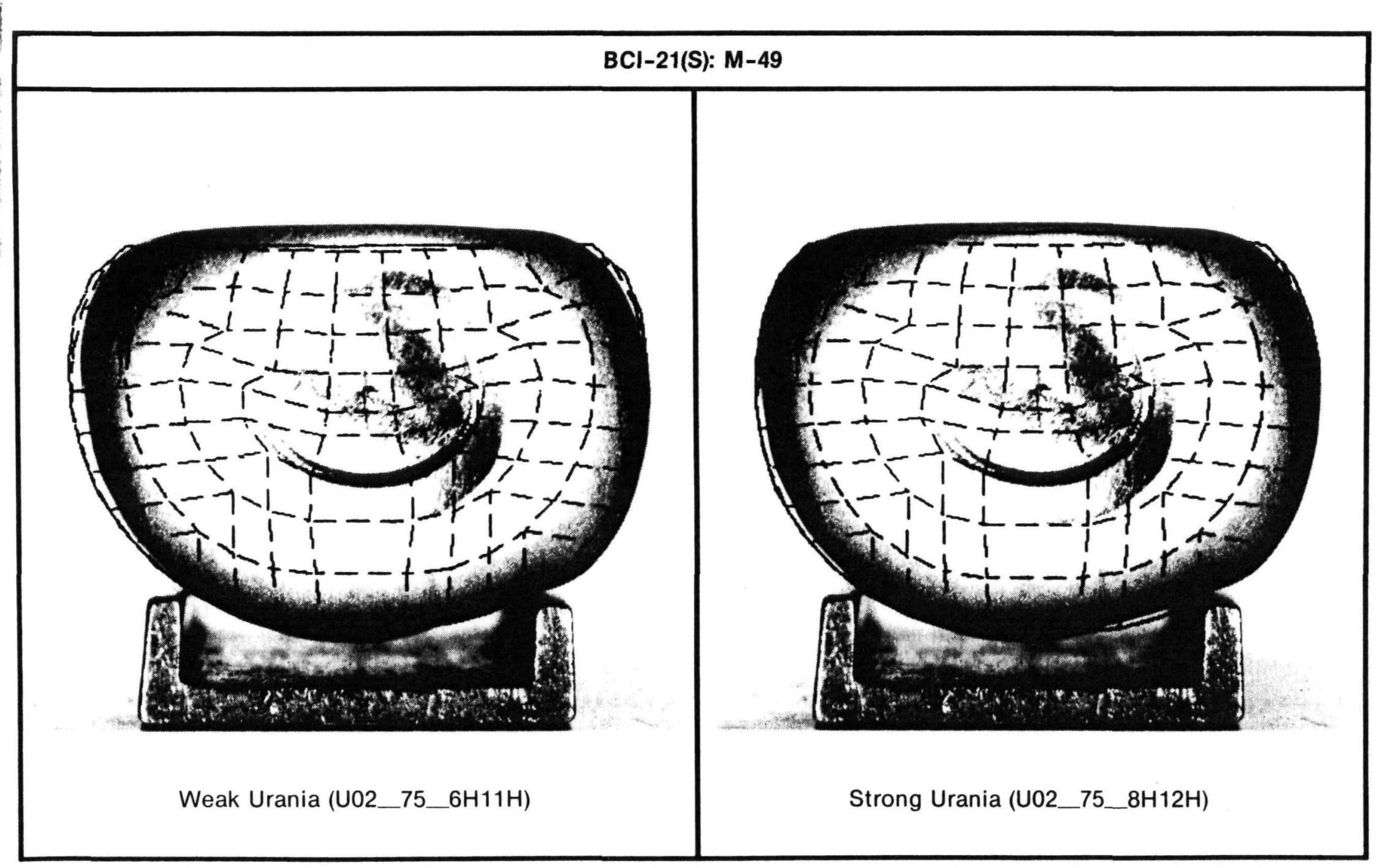

Figure 10. Comparison of Analytical and Experimental Bare Urania Fuel-Clad Response to Impact on a $2.54 \mathrm{~cm}$ Steel Target at $75 \mathrm{M} / \mathrm{S}$ in the BCl Geometry 


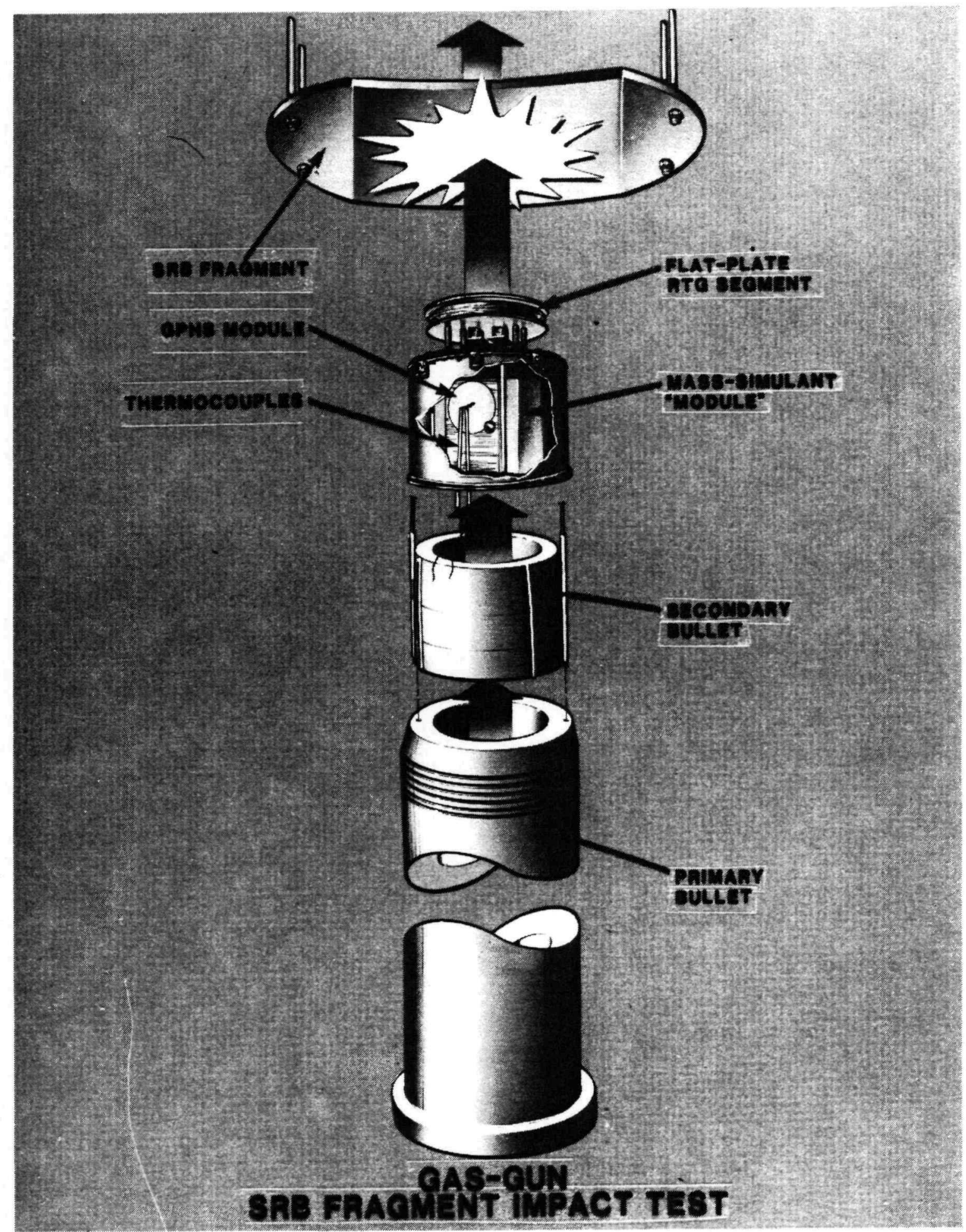

Figure 11. Fragment Gas-Gun Test (FGT) Arrangement-After Zocher ${ }^{(3)}$ 


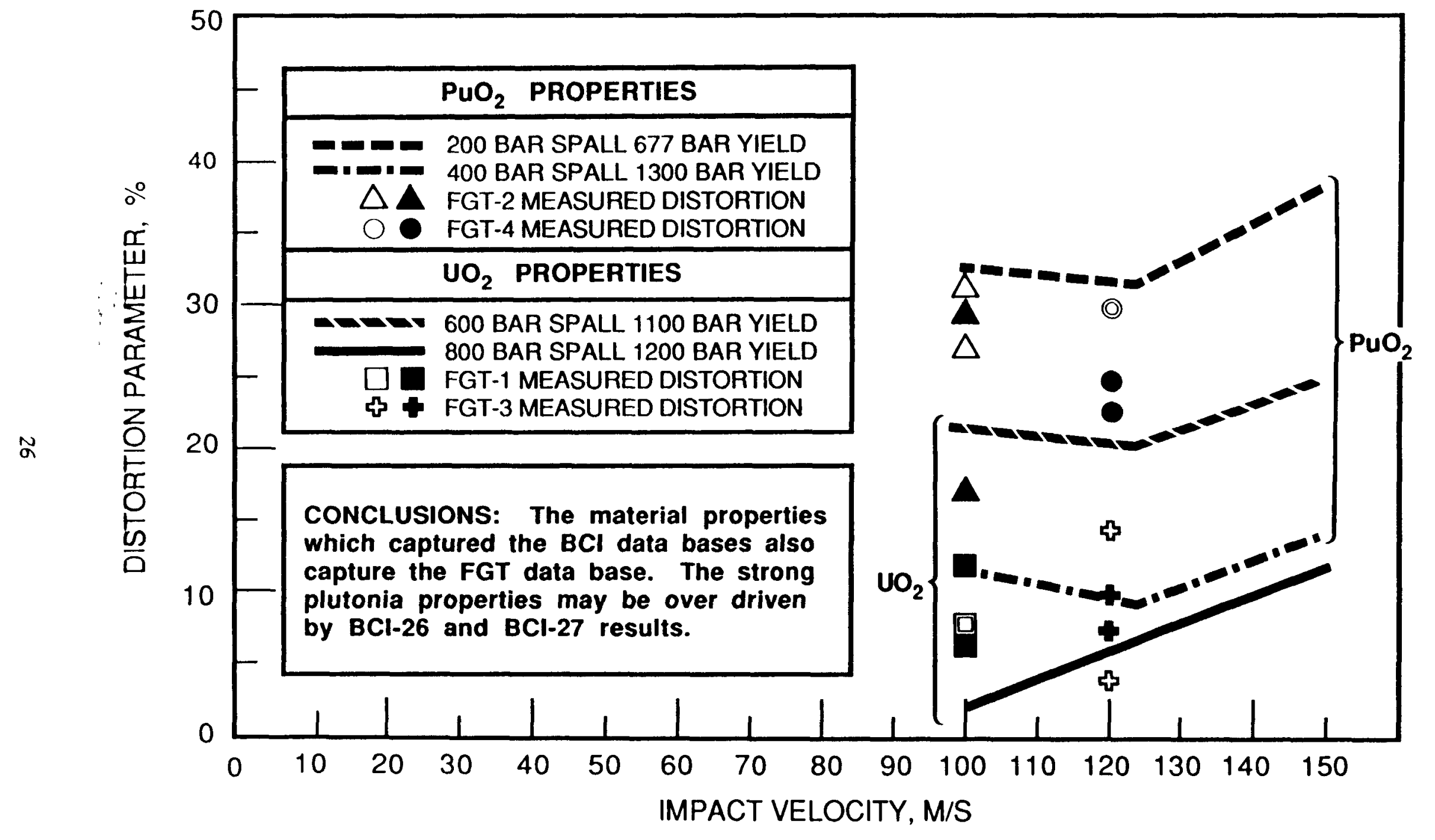

Figure 12. Effect of Fuel Properties, Impact Velocity, and Target Thickness on Predicted Forward GIS Fueled Clad Deformation in FGT-Type Events (Points are for Individial Cups). 


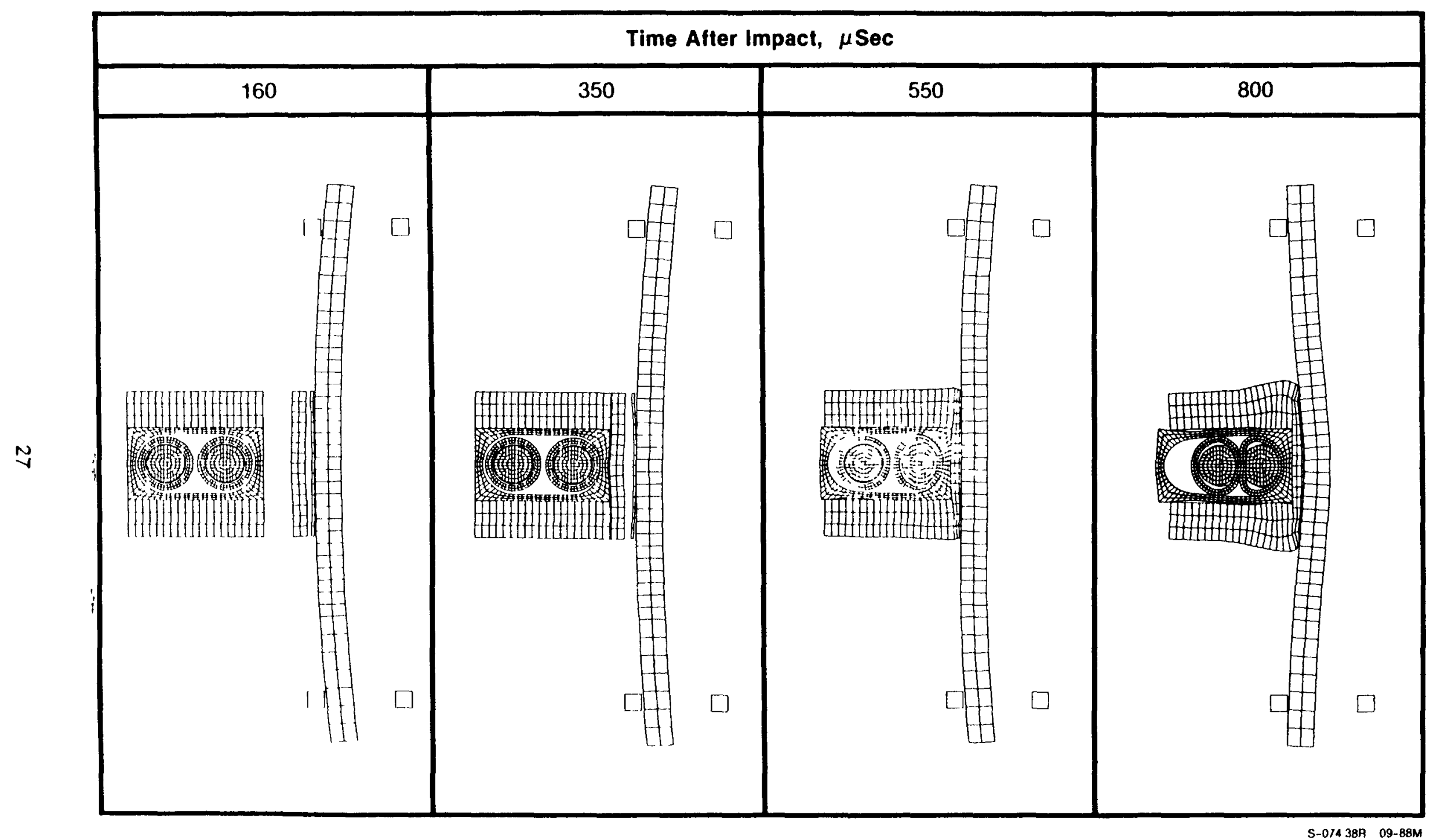

Figure 13. Predicted Response of the FGT-2 Stack to Impact at $100 \mathrm{M} / \mathrm{S}$ on a $16 \times 12 \times 1 / 2$ Inch D6A Steel Target 
of the predicted and observed fueled clad post impact geometry for the FGT-2 event are shown in Figures 14 and 15.

\section{Safety Verification Events}

A final verification of the analytical model was performed upon completion of the model calibration against the BCI and FGT events. This verification involved comparing the analytical predictions for the Safety verification Test (SVT) fueled clad distortion to the experimental observations obtained from these events. The verification protocol required that no change could be made to any of the parameters used to model the BCI and FGT events. The results presented in figures 16 and 17 show that the identical modeling parameters used to describe the BCI and FGT events capture both the module face-on impact and module edge-on impact SVT data base. Based on the above, the analytical model was judged operational and ready for use in a predictive mode.

\section{Analytical Predictions of Test Responses}

Tests were conducted to assess the response of the GPHS-RTG to face-on and edge-on impacts of $56 \times 56$ inch STS-SRM fragments. The face-on responses were evaluated on a one-half section of the GPHS Engineering unit. This was an actual convector which had been tested with an electrical heater. An assembly drawing of the GPHS-RTG is presented in Figure 18 for reference. The Engineering unit was cut in half at the plane of the mid span-support to provide two test articles for use in the LFT-1 and LFT-2 events. A general arrangement of the LFT Geometry is shown in figure 19. A detail of the GPHS convector half section is also shown in this figure.

Edge-on impact tests were conducted in the Ulysses geometry. These tests could not be modeled using the available 2-0 model, but the Ulysses configuration could be. Calculations to determine the predicted response of the GPHS module in the Ulysses geometry were performed and are included for reference. Comparisons of predicted and observed responses could not be 


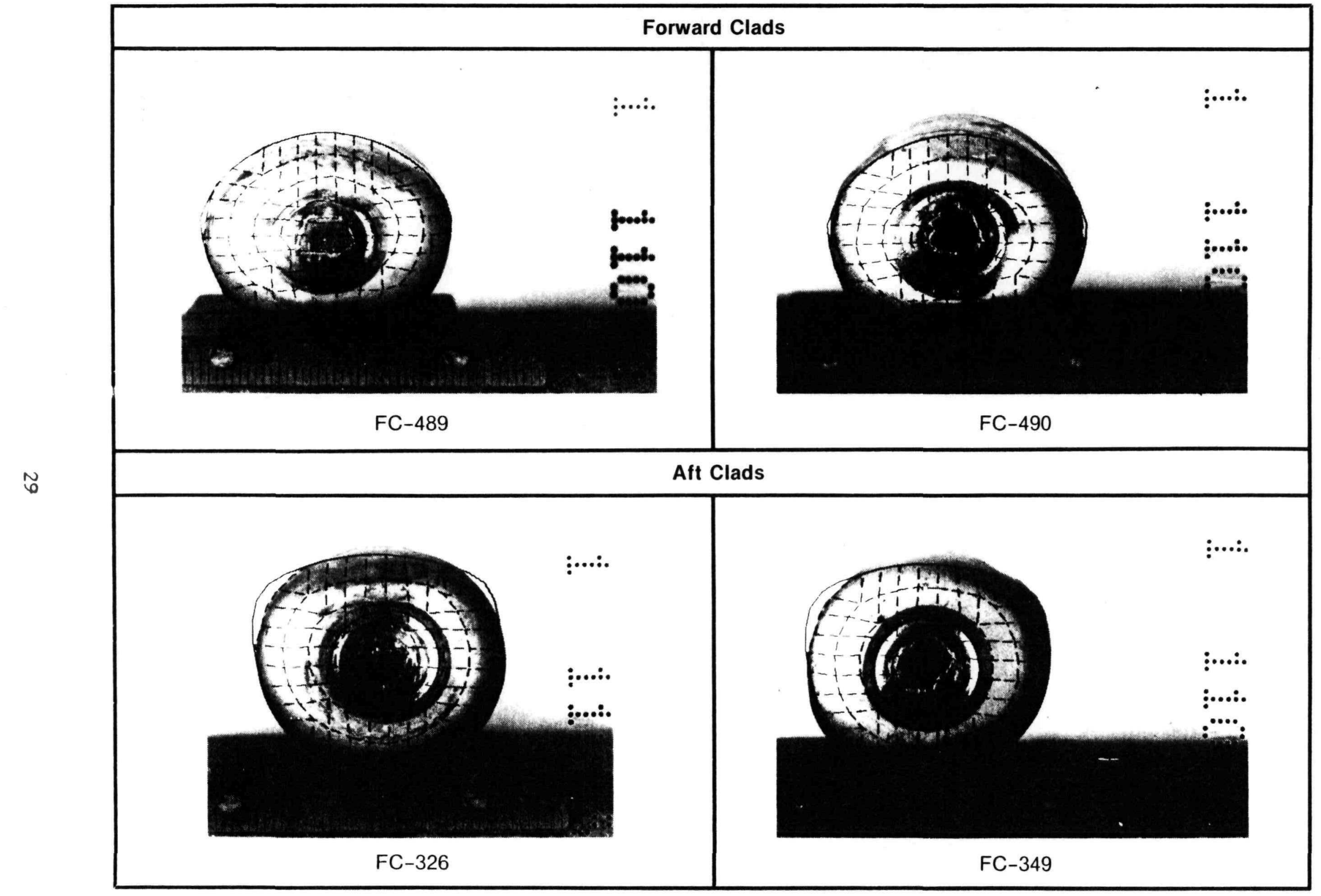

Figure 14. Comparison of Predicted and Observed Post FGT-2 Impact Fueled-Clad Geometry (100 M/S on a $16 \times 12 \times 1 / 2$ Inch D6A Steel Target, Weak Plutonia) 


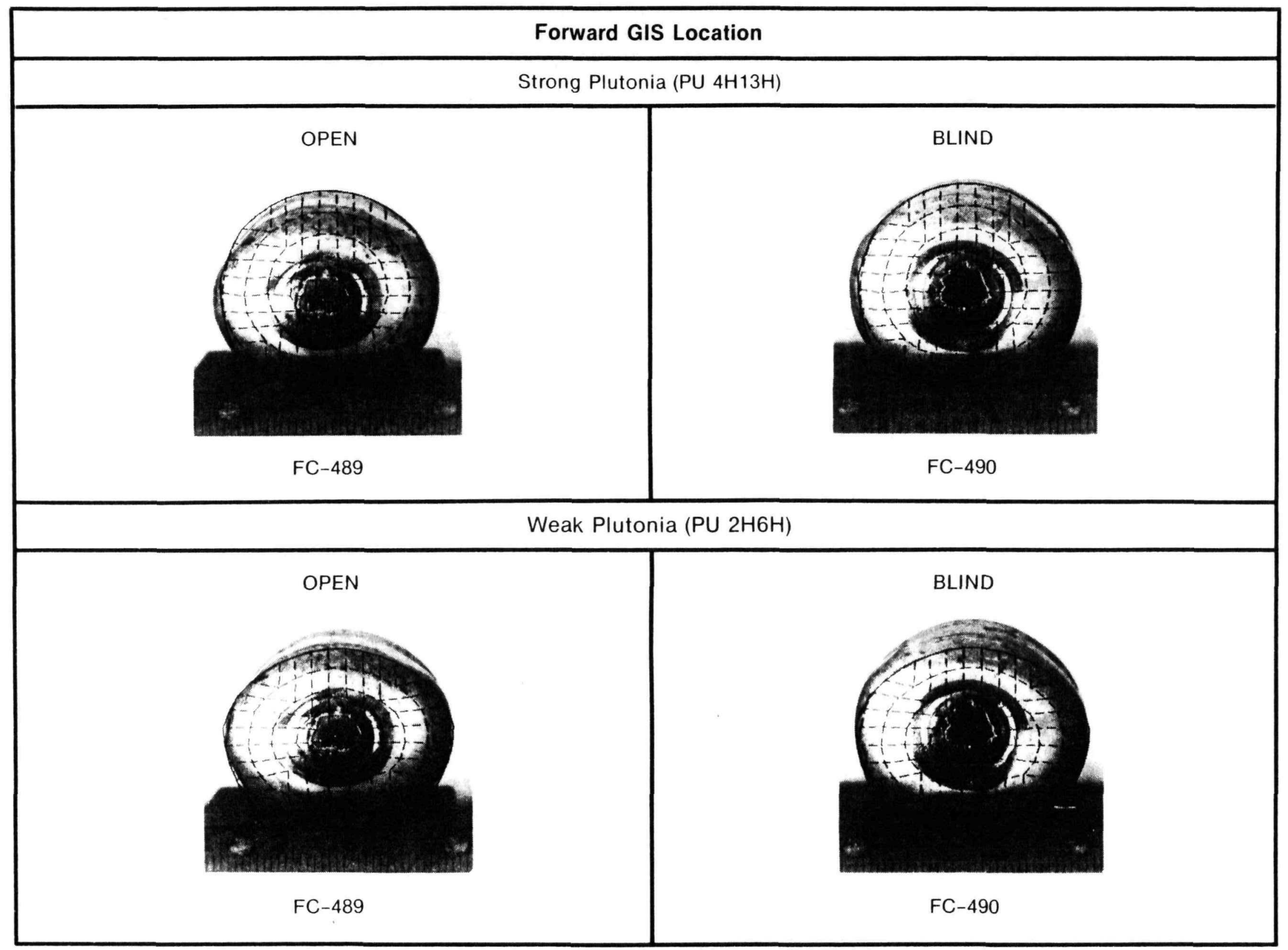

Figure 15. Comparison of the Predicted and Observed Post-Impact Geometries of the Forward GIS Plutonia-Fueled Clads from the FGT-2 Event 


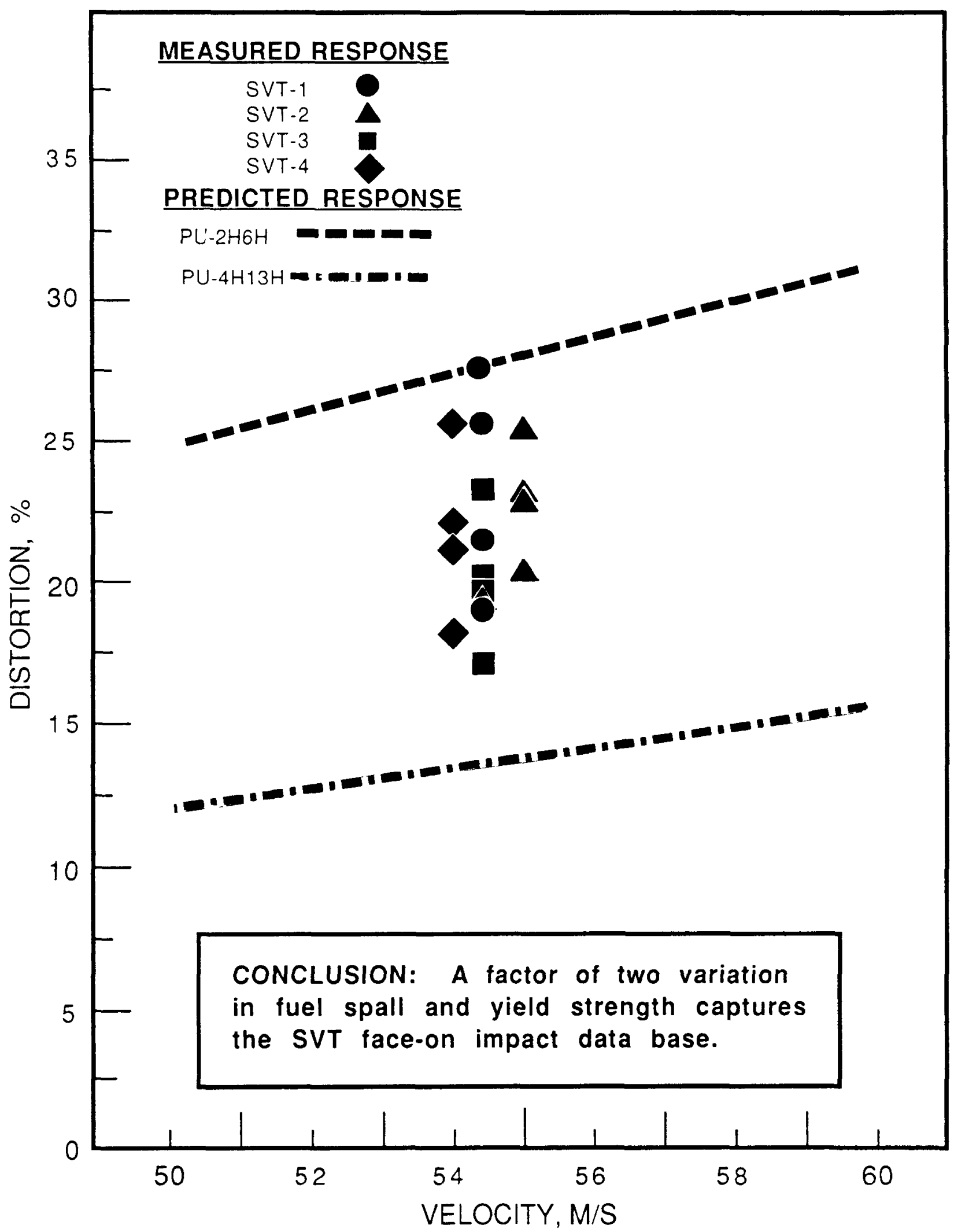

Figure 16. Response of a Plutionia-Fueled GPHS Module to a Face-On Impact on a Steel Target Having the SVT Geometry 


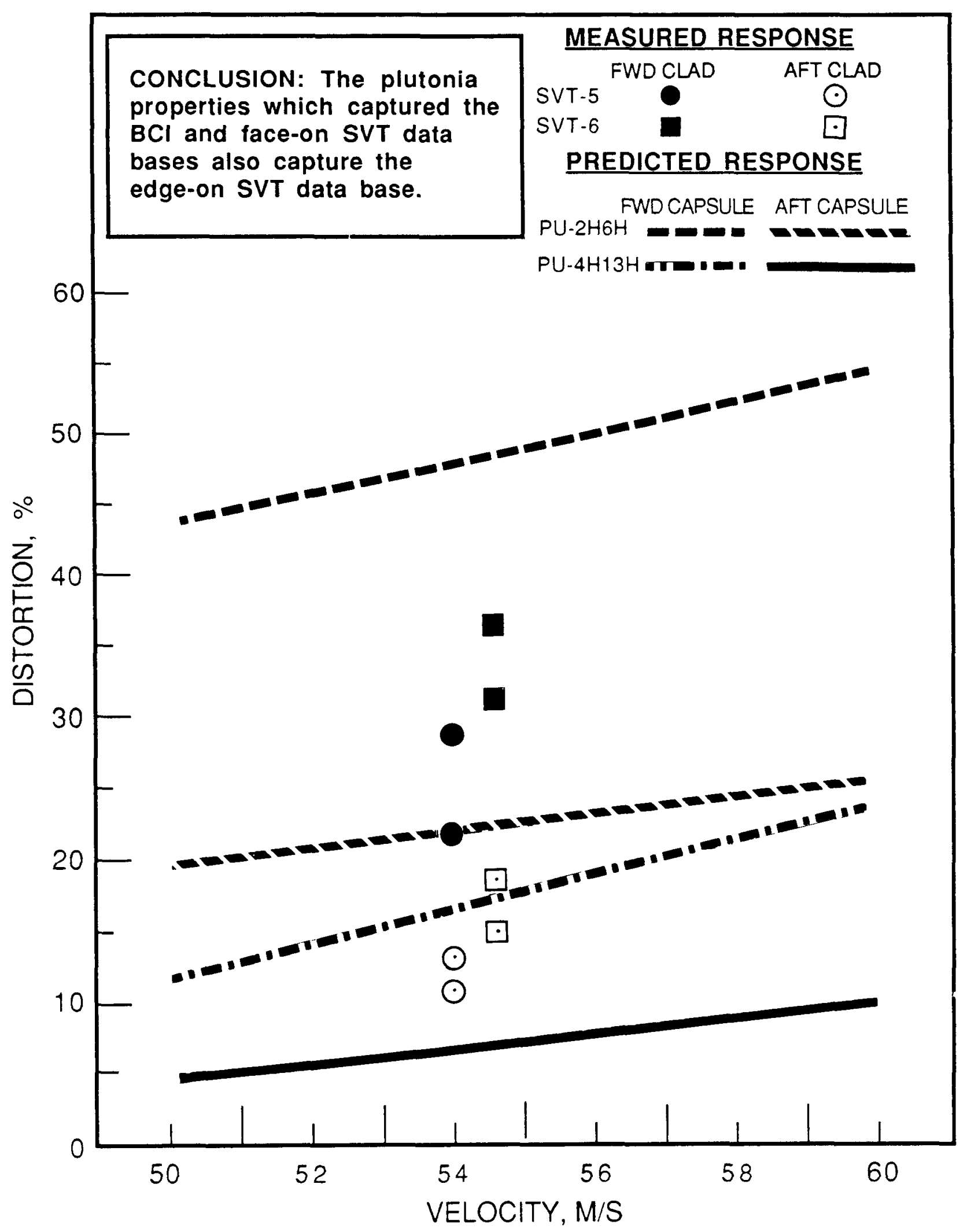

Figure 17. Response of Forward and Aft Plutonia-Fueled Clads to an Edge-On Module Impact on a Steel Target Having the SVT Geometry 


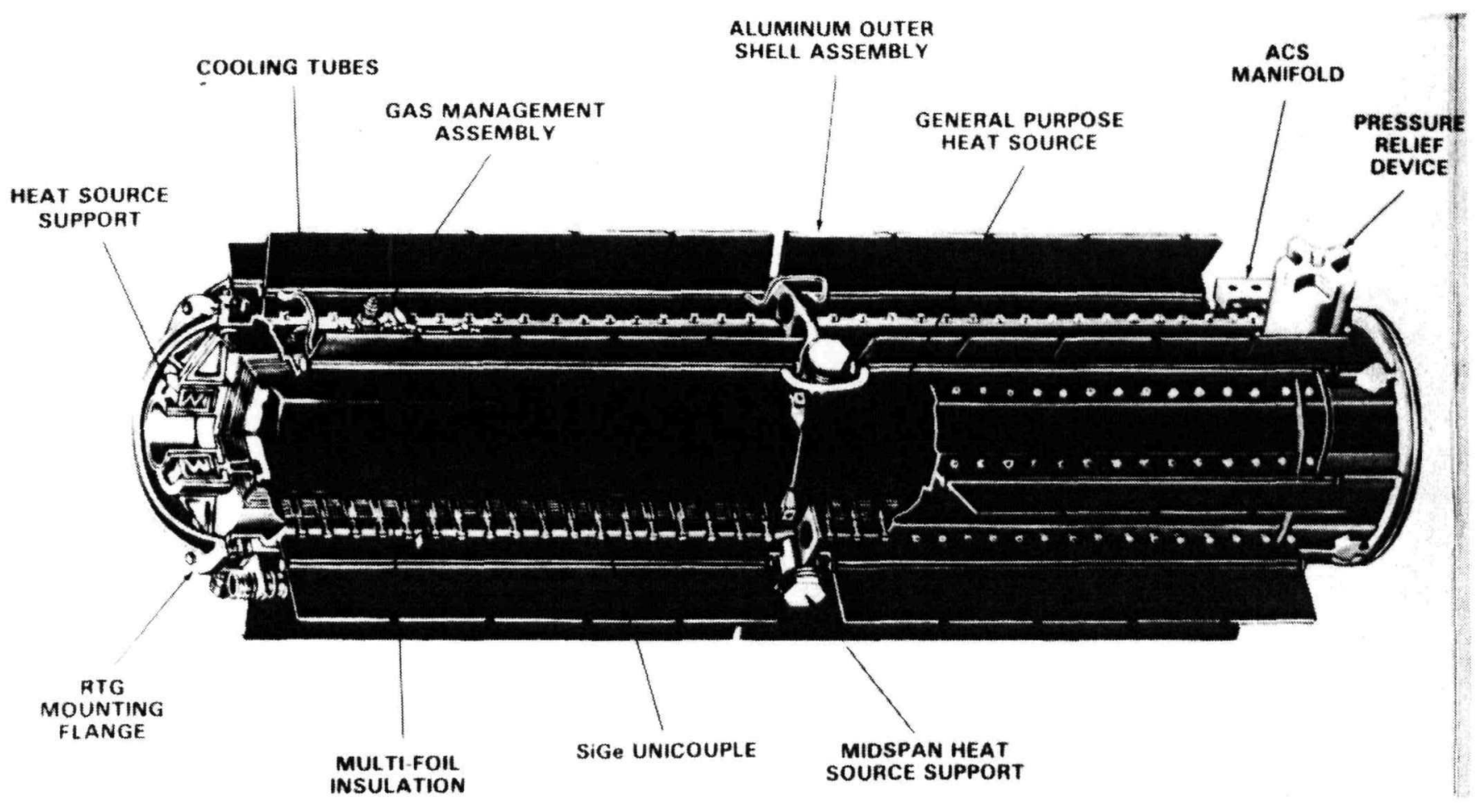

Figure 18. GPHS-RTG Assembly 


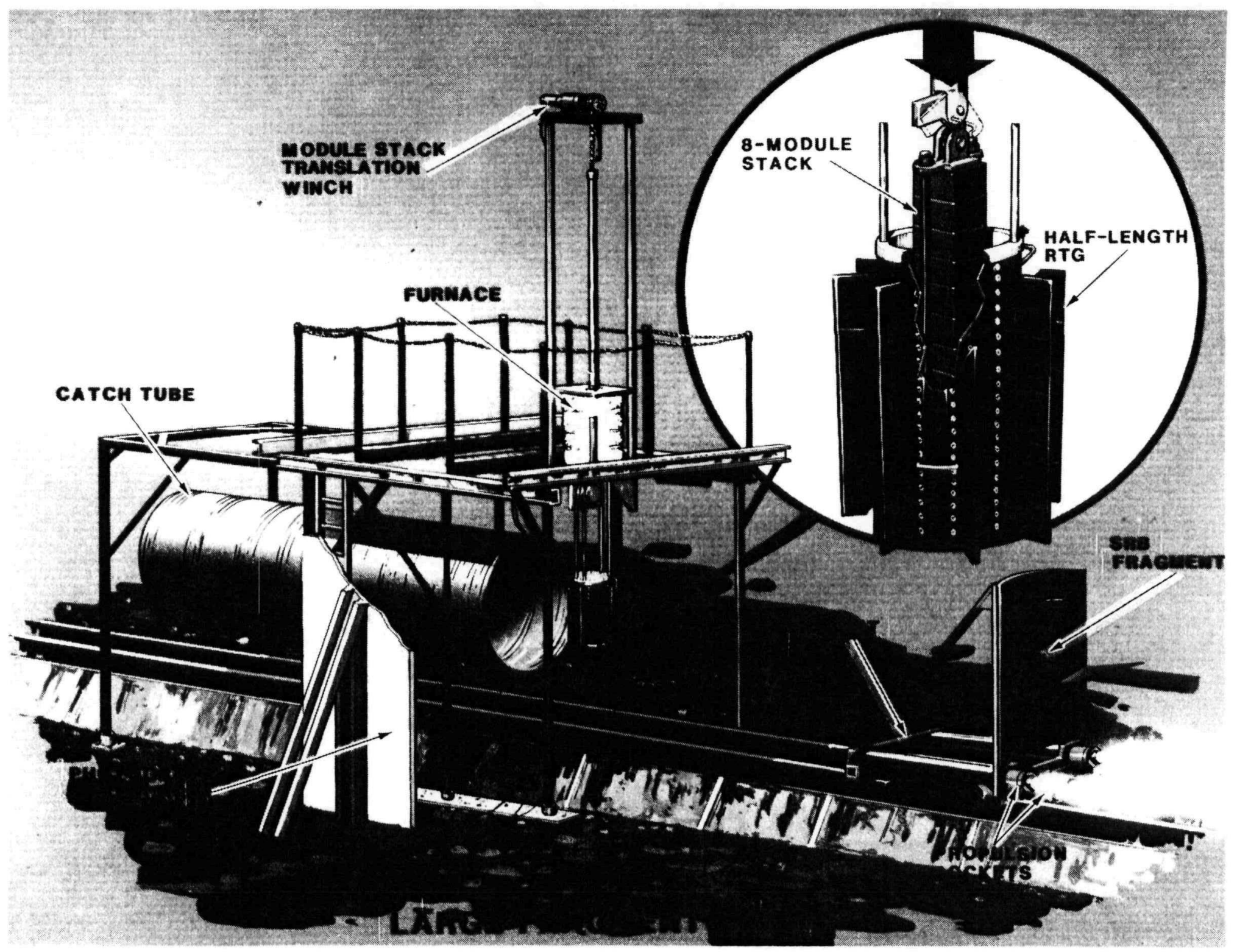

Figure 19. Large Fragment Test Set-Up (After Zocher ${ }^{(3)}$ ) 
made because of the difference in set-up Geometry. The results of the tests are included for reference.

1. Large Fragment Test. The first full scale predictive use of the calibrated analytical model was in connection with the first Large fragment Test (LFT-1). The geometry of the model used in the initial numerical simulations is shown in Figure 20. Although the internals of the simulated converter were well calibrated, some uncertainty remained in regard to the accuracy of the stiffness simulation used for the RTG housing and the $56 x$ $56 \times 1 / 2$ inch SRM fragment. The FGT events had shown that the simulated SRM fragment incurred some plastic deformation. Preliminary closed form calculations had shown that the SRM fragment should bow approximately four inches elastically along the impact surface before the onset of plastic deformation. The limitations inherent in the use of a 2-D code to simulate a 3-0 event required that the probable results be bracketed by the use of a range of fragment stiffness parameters.

A reprise of the FGT analyses was conducted to determine the sensitivity of the fueled clad distortion to target stiffness. The original FGT calibration had been performed using an equivalent $3 / 4$ inch thick plate to simulate the 3-D nature of the plate rather than the 2-D beam constraint imposed by the translational symmetry argument (refer to Theory of plates and Shells (4) for the justification of this approach). Examination of Figure 21 shows that use of a $1 / 2$ inch plate underestimates the amount of deformation likely to occur in an FGT event. It was concluded that the use of a $3 / 4$ inch plate having an overhanging mass seven times that of the simulated target (the test weight ratio) should be used as a first approximation of the SRM fragment stiffness.

The predicted information shown in Table IV was transmitted to the Safety Community in FSC-ESD-217/88/417 dated 2 March 1988. The LFT was conducted 4 March 1988. Also transmitted in that document was the following qualitative statement: ". . For an impact velocity of $100 \mathrm{~m} / \mathrm{s}$, modules subjected to the LFT-1 event environment are likely to undergo considerably less distortion than modules subjected to the FGT environment." A 


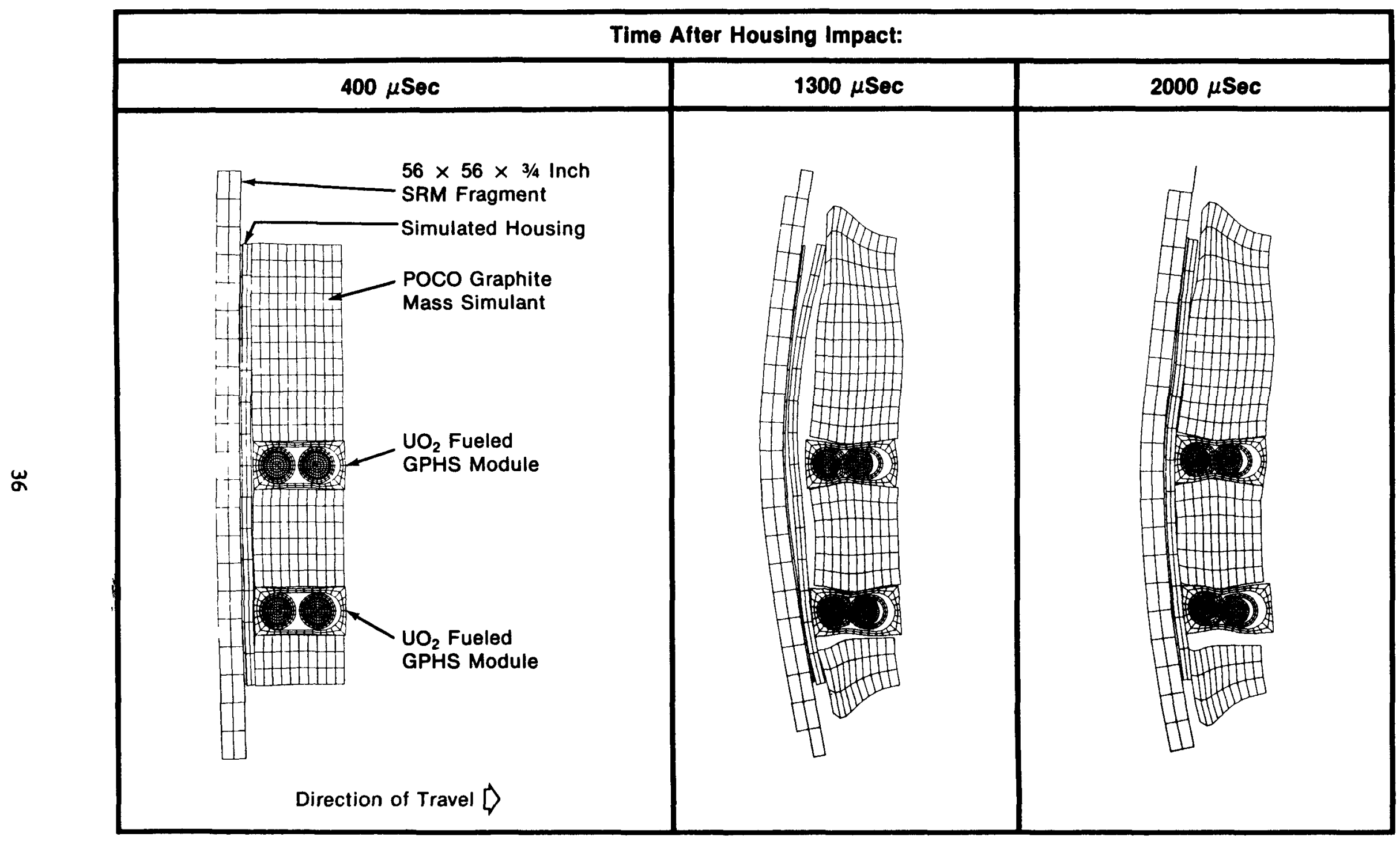

Figure 20. Predicted Deformation of the GPHS Module in the LFT-1 Environment 


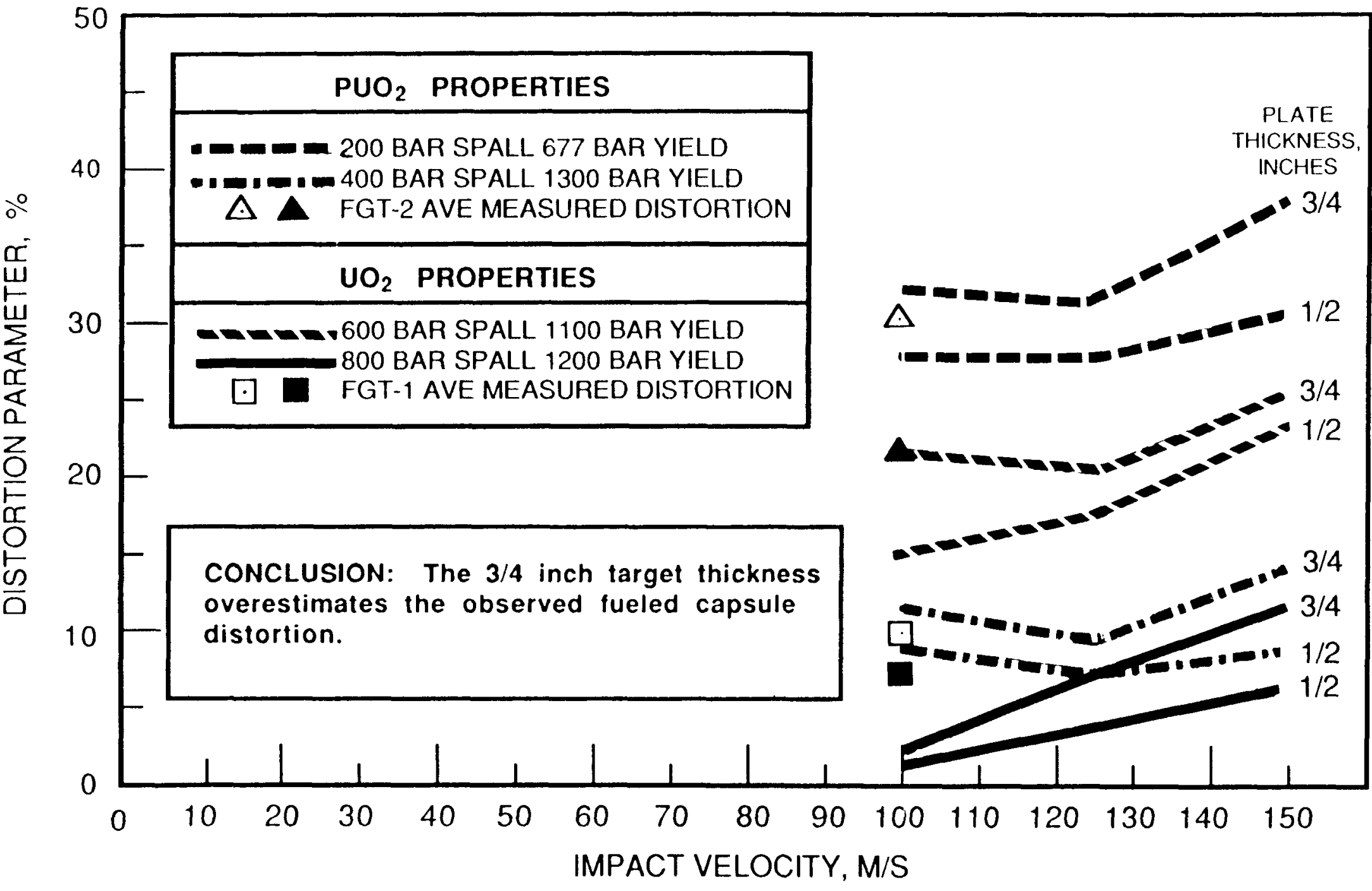

Figure 21. Effect of Fuel Properties, Impact Velocity, and Target Thickness on Predicted Forward GIS Plutonia-Fueled Capsule Deformation in FGT-Type Events 
Table IV. Upper And Lower Bound Estimation(1) of Fueled Clad Distortion Predicted for LFT Type Events at an Impact Velocity of $100 \mathrm{M} / \mathrm{S}$ Compared to Experimental Observations for a $115 \mathrm{M} / \mathrm{S}$ Impact Velocity

\begin{tabular}{|c|c|c|c|c|c|c|}
\hline \multirow[t]{3}{*}{ DATA SET } & \multirow{2}{*}{$\begin{array}{c}\text { SPALL } \\
\text { STRENGTH }\end{array}$} & \multirow{2}{*}{$\begin{array}{c}\text { YIELD } \\
\text { STRENGTH }\end{array}$} & \multicolumn{4}{|c|}{ AVERAGE DISTORTION PARAMETER (2) } \\
\hline & & & $\begin{array}{l}\text { FWD GIS } \\
\text { PREDICTED }\end{array}$ & $\begin{array}{l}\text { FWD GIS } \\
\text { OBSERVED } \\
(\text { LFT }-1)^{(3)(4)}\end{array}$ & $\begin{array}{c}\text { AFT GIS } \\
\text { PREDICTED }\end{array}$ & $\begin{array}{c}\text { AFT GIS } \\
\text { OBSERVED } \\
(\text { LFT }-1)^{(3)(4)}\end{array}$ \\
\hline & BAR & BAR & $\%$ & $\%$ & $\%$ & $\%$ \\
\hline YU_6H11H_100 & 600 & 1100 & 3.8 & 4.7 & 1.8 & 2.9 \\
\hline YU_8H12H_100 & 800 & 1200 & 1.9 & 4.7 & 0 & 2.9 \\
\hline
\end{tabular}

(1) THESE ESTIMATES ARE BASED ON A MODEL WHICH HAS 9 GPHS MODULES IN ONE HALF OF A GPHS GENERATOR HOUSING IMPACTING A $56 \times 56 \times 3 / 4$ INCH PLATE WITH A "PICTURE FRAME" MASS SEVEN TIMES THAT OF THE TEST ARTICLE. THE HIGHEST VALUES OF DISTORTION FOR EACH LOCATION WERE SELECTED FROM THE NUMBER TWO AND NUMBER FIVE SLOTS IN THE STACK.

(2) DISTORTION PARAMETER = [(DIAMETER/HEIGHT)-1]

(3) AVERAGE OF EIGHT CUPS IN FORWARD GIS AND EIGHT CUPS IN AFT GIS. AVERAGES ARE STRONGLY DRIVEN BY TWO HIGH VALUES WHICH MAY HAVE RESULTED FROM SECONDARY MODULE IMPACT (SEE FGT-1, LFT-1 COMPARISON TABLE.)

(4) NOTE THAT THIS IS A PREDICTION FOR $100 \mathrm{M} / \mathrm{S}$ COMPARED TO AN OBSERVATION FOR $115 \mathrm{M} / \mathrm{S}$. 
comparison of the fueled clad distortion observed in the FGT-1 and LFT-1 events is shown in Table $V$. It is reasonable to conclude that at $100 \mathrm{~m} / \mathrm{s}$ the LFT-1 event was, as predicted, less disruptive to the fueled clad than was the FGT-1 event.

Calculations were performed using the strong and weak urania fuel models and $1 / 2$ and $3 / 4$ inch thick, $56 \times 56$ inch SRM fragments. The temporal variation of geometry resulting from a typical simulated LFT-1 environment was shown in Figure 20 . The predictions were based on a central fragment impact area deflection of 6 to 8 inches. A request was made that the test conductors attempt to measure the amount of impact area deflection which occurred in the LFT-1 event. A comparison of the predicted and observed plate deflection is shown in Figure 22. A comparison of the predicted and observed average fueled clad distortion was shown in Tables IV and $V$.

\section{Model Refinements}

The LFT model uses gross approximations to the motions of the simulated-mass poco blocks. Examination of figure 23 shows that there is a different physical response to the detailed modeled modules when they are aligned serially rather than having poco blocks interposed. The initial poco block simulation used distributed mass rather than concentrating the mass in the molybdenum slugs. Since this formulation results in some collapsing of the GPHS aeroshell in an apparently non-physical manner, it was decided to pursue a more physically correct model which uses concentrated mass for the molybdenum slugs. A comparison of the early time geometry of the initial and final models may be made by comparing figure 24 to Figure 20 . This refined model was used to predict the response of the LFT-1 and LFT-2 events. The results of these predictions, as well as comparisons to the experimental observations, are presented in figures 25 , 26,27 , and 28 and Table VI.

The agreement between predictions and observations was adequate in the velocity regime where most impacts would occur and conservative at higher velocities. This overprediction occurs because of the 20 boundary condition 
Table V. Fueled Clad Distortion Observed in the FGT-1, FGT-2, and LFT-1 Events

\begin{tabular}{|c|c|c|c|c|c|c|}
\hline \multirow[t]{3}{*}{ TEST LOCATION } & \multicolumn{6}{|c|}{ DISTORTION PARAMETER } \\
\hline & \multirow{2}{*}{$\begin{array}{c}\text { FGT-1 } \\
\%\end{array}$} & \multirow{2}{*}{$\begin{array}{c}\text { FGT-2 } \\
\%\end{array}$} & \multicolumn{3}{|c|}{ LFT-1 } & \multirow[t]{2}{*}{ LFT-1/FGT- } \\
\hline & & & $\begin{array}{c}\text { MODULE } 2 \\
\%\end{array}$ & $\begin{array}{c}\text { MODULE } 5 \\
\%\end{array}$ & $\begin{array}{c}\text { AVERAGE } \\
\%\end{array}$ & \\
\hline \multicolumn{7}{|l|}{ FWD (A) GIS } \\
\hline $\begin{array}{l}\text { OPEN END } \\
\text { CLOSED CUP } \\
\text { VENT CUP }\end{array}$ & $\begin{array}{l}8.1 \\
6.7\end{array}$ & $\begin{array}{l}27.3 \\
33.9\end{array}$ & $\begin{array}{l}3.1 \\
3.9\end{array}$ & $\begin{array}{l}6.1 \\
5.9\end{array}$ & $\begin{array}{l}4.6 \\
4.9\end{array}$ & $\begin{array}{l}0.56 \\
0.73\end{array}$ \\
\hline $\begin{array}{l}\text { BLIND END } \\
\text { VENT CUP } \\
\text { CLOSED CUP }\end{array}$ & $\begin{array}{r}12.5 \\
7.7 \\
\end{array}$ & $\begin{array}{l}29.1 \\
17.9 \\
\end{array}$ & $\begin{array}{r}2.9 \\
3.2 \\
\end{array}$ & $\begin{array}{r}8.2 \\
4.4 \\
\end{array}$ & $\begin{array}{r}5.6 \\
3.8 \\
\end{array}$ & $\begin{array}{r}0.45 \\
0.43 \\
\end{array}$ \\
\hline AVERAGE & 8.73 & 27.1 & 3.3 & 6.2 & 4.8 & 0.54 \\
\hline \multicolumn{7}{|l|}{ AFT (C) GIS } \\
\hline $\begin{array}{l}\text { OPEN END } \\
\text { CLOSED CUP } \\
\text { VENT CUP }\end{array}$ & $\begin{array}{l}7.1 \\
7.9\end{array}$ & $\begin{array}{l}13.2 \\
12.4\end{array}$ & $\begin{array}{l}8.8 \\
4.4\end{array}$ & $\begin{array}{l}3.6 \\
1.6\end{array}$ & $\begin{array}{l}6.2 \\
3.0\end{array}$ & $\begin{array}{l}0.87 \\
0.38\end{array}$ \\
\hline $\begin{array}{l}\text { BLIND END } \\
\text { VENT CUP } \\
\text { CLOSED CUP }\end{array}$ & $\begin{array}{r}3.4 \\
3.0 \\
\end{array}$ & $\begin{array}{r}11.7 \\
9.2 \\
\end{array}$ & $\begin{array}{l}0.9 \\
1.5 \\
\end{array}$ & $\begin{array}{l}1.0 \\
1.1 \\
\end{array}$ & $\begin{array}{l}0.95 \\
1.3 \\
\end{array}$ & $\begin{array}{l}0.28 \\
0.43 \\
\end{array}$ \\
\hline AVERAGE & 5.4 & 11.6 & 3.9 & 1.8 & 2.9 & $\underline{0.49}$ \\
\hline
\end{tabular}




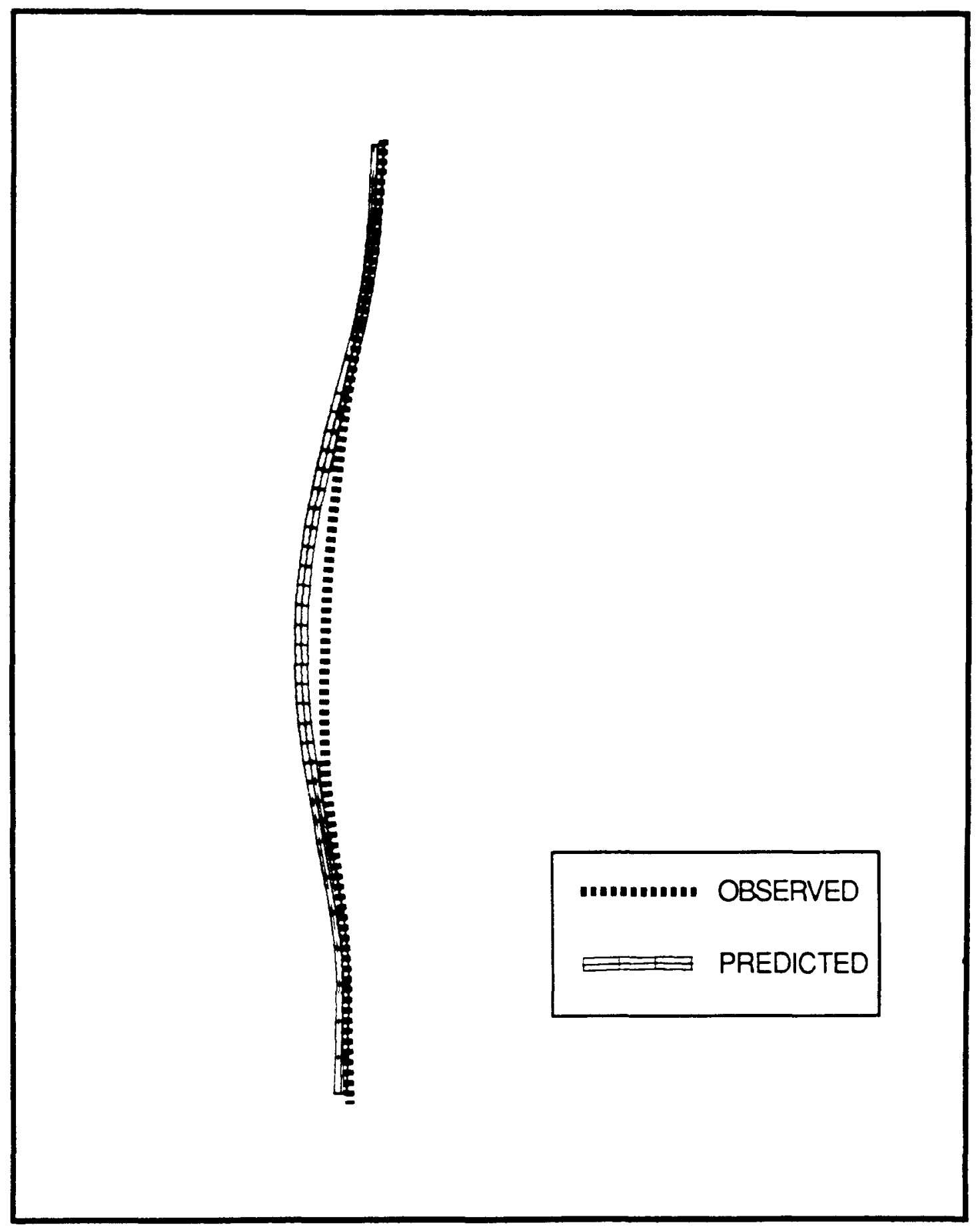

Figure 22. Comparison of Observed and Predicted Maximum Distortion of the $56 \times 56 \times t / 2$ inch SAm Fragment Occurring in the LFT-1 Event 


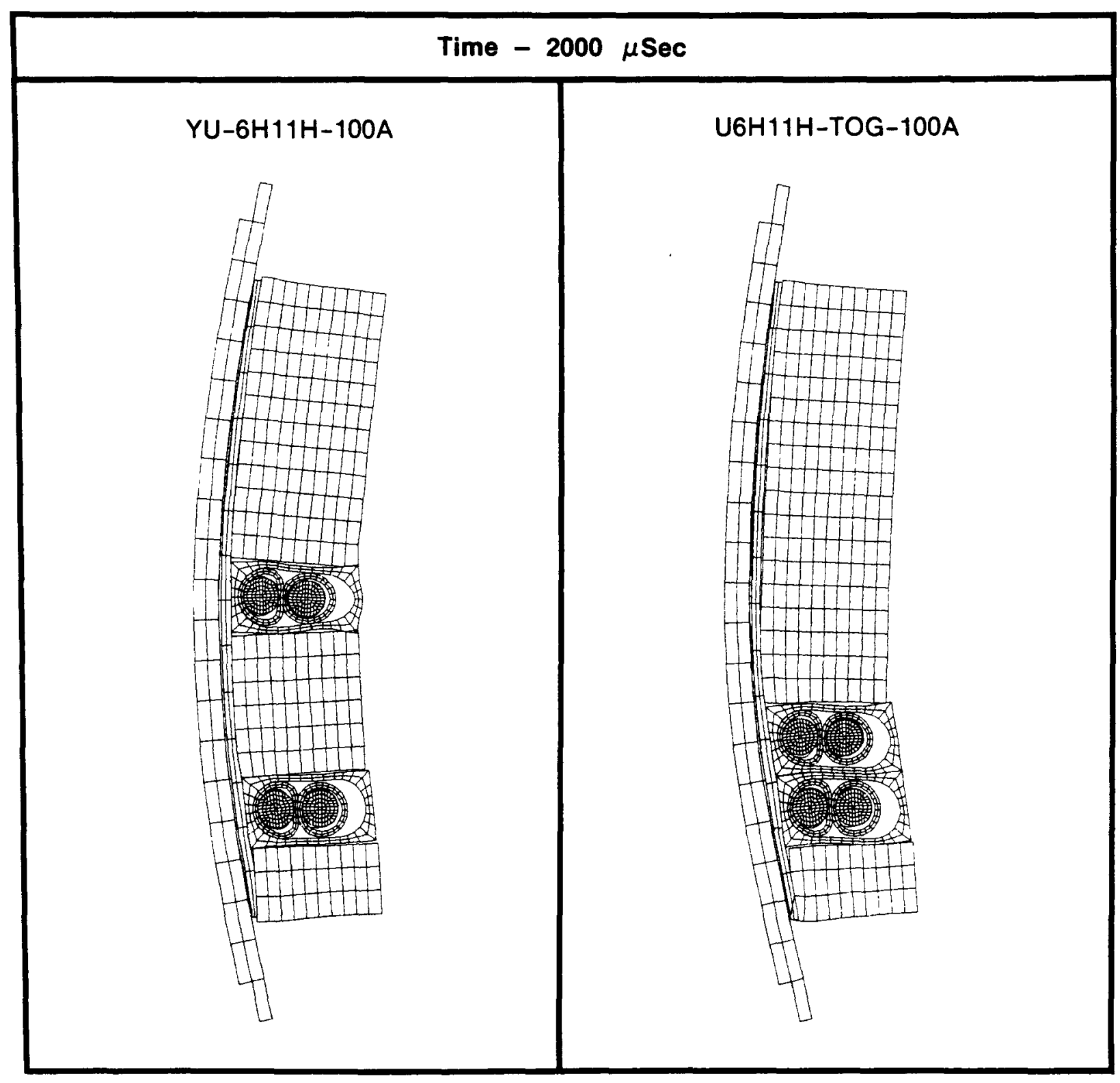

Figure 23. Comparison of Predicted Final Geometry for a Distributed Mass Model with Adjacent and Dispersed Detailed GPHS Module Simulations 


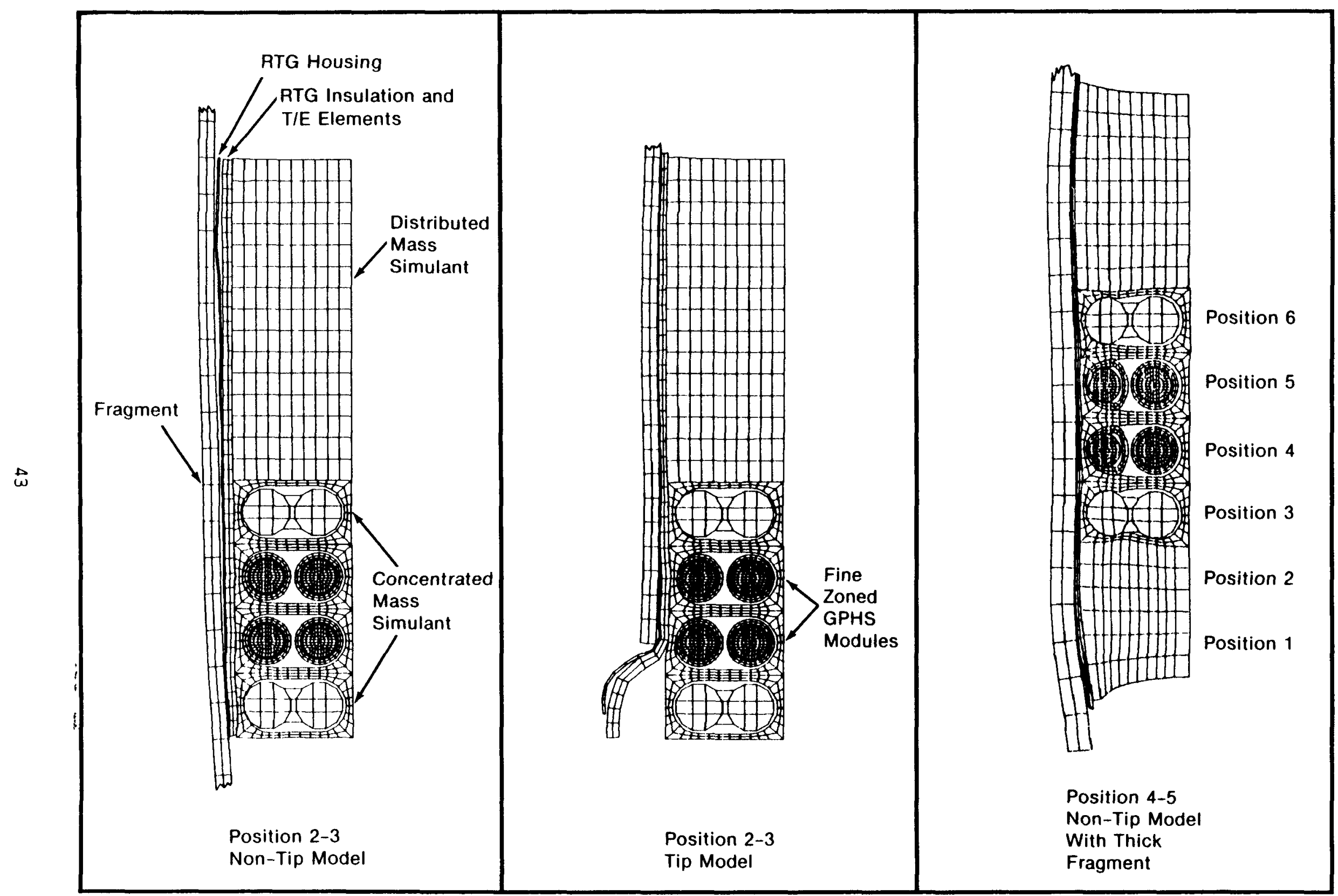

Figure 24. Models Used in Developing the SRM Fragment Data Base 


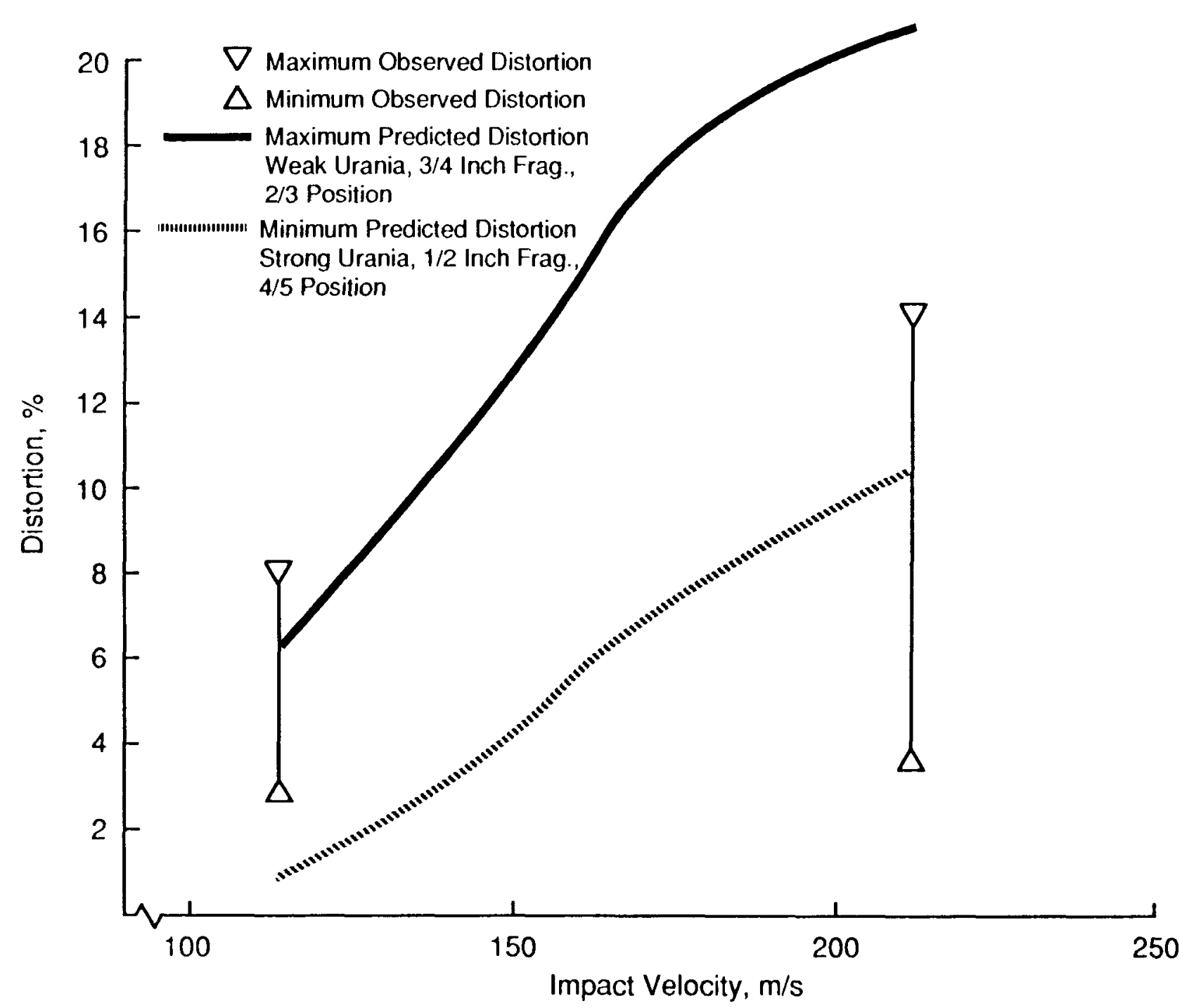

Figure 25. Comparison to the Predicted and Observed Distortion of Forward Cups from the LFT-1 and LFT-2 Events (1)

(1)LFT-1 Impact Velocity = $115 \mathrm{~m} / \mathrm{s}$; LFT-2 Impact Velocity = $212 \mathrm{~m} / \mathrm{s}$; Note That Maximum Observed Values Are Strongly Driven by Results Which were Caused by Secondary Impact. Calculation is very Conservative in Diameter Prediction due to Clad-Length Constraint $\left(\dot{\mathrm{E}}_{\pi}=0\right)$. 


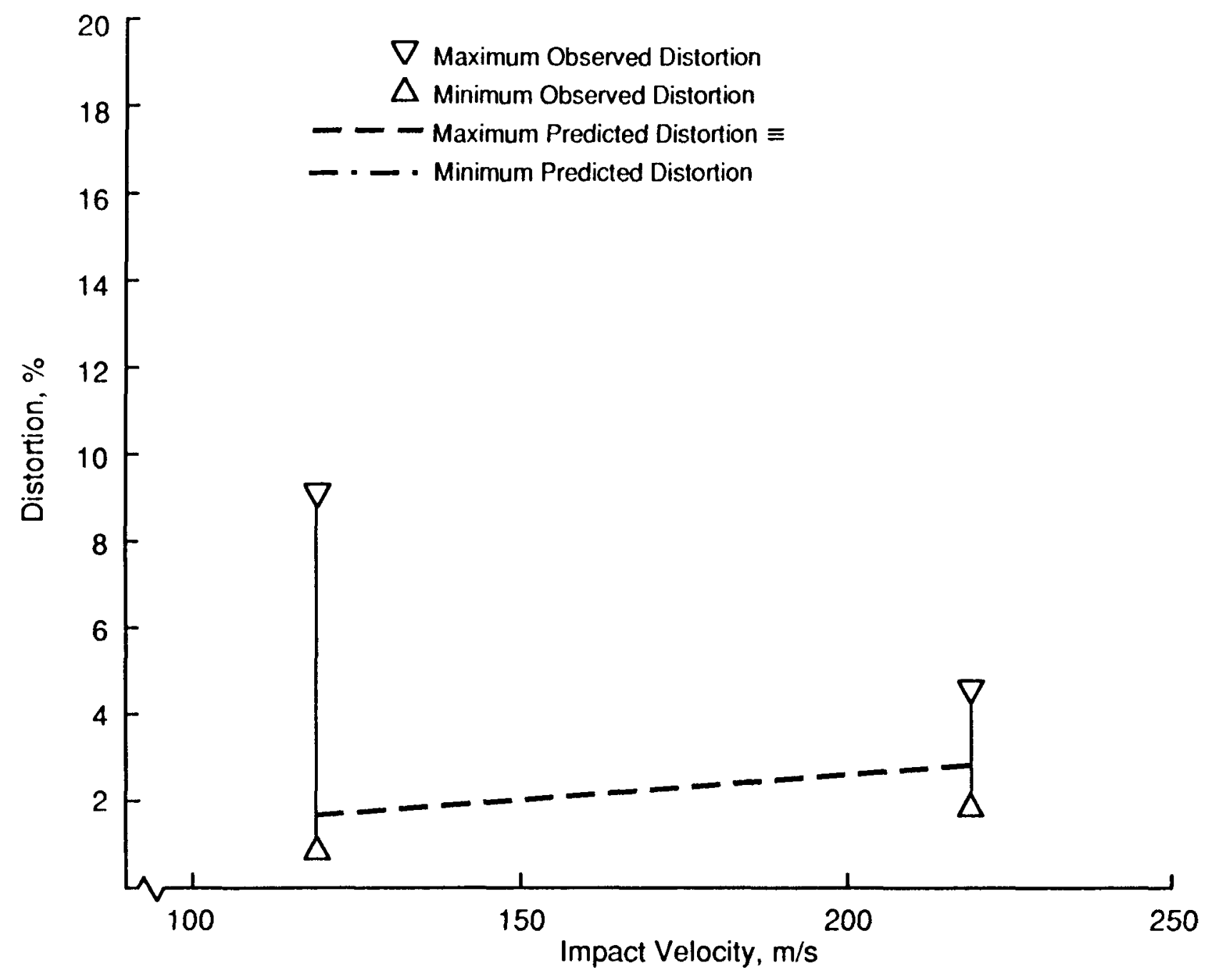

Figure 26. Comparison of the Predicted and Observed Distortion of Aft Cups From the LFT-1 and LFT-2 Events ${ }^{(1)}$

(1) LFT-1 Impact Velocity = $115 \mathrm{~m} / \mathrm{s}$; LFT-2 Impact Velocity = $212 \mathrm{~m} / \mathrm{s}$; Note That Maximum Observed Values Are Strongly Driven by Results Which Are Suspected to Have Been Caused by Secondary Impact 


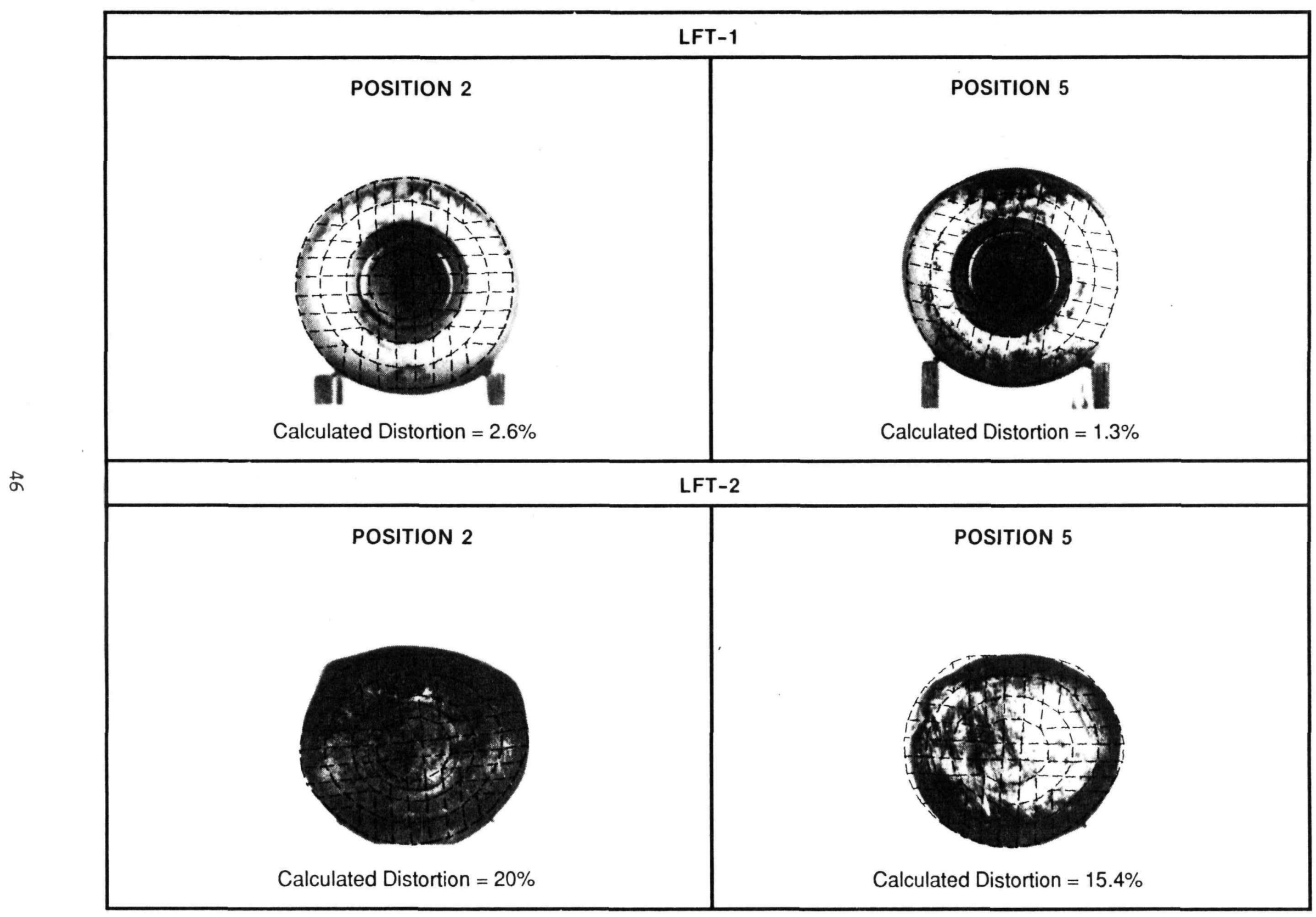

Figure 27. Forward Fueled Clad Post Impact Geometry for the LFT-1 and LFT-2 Events 


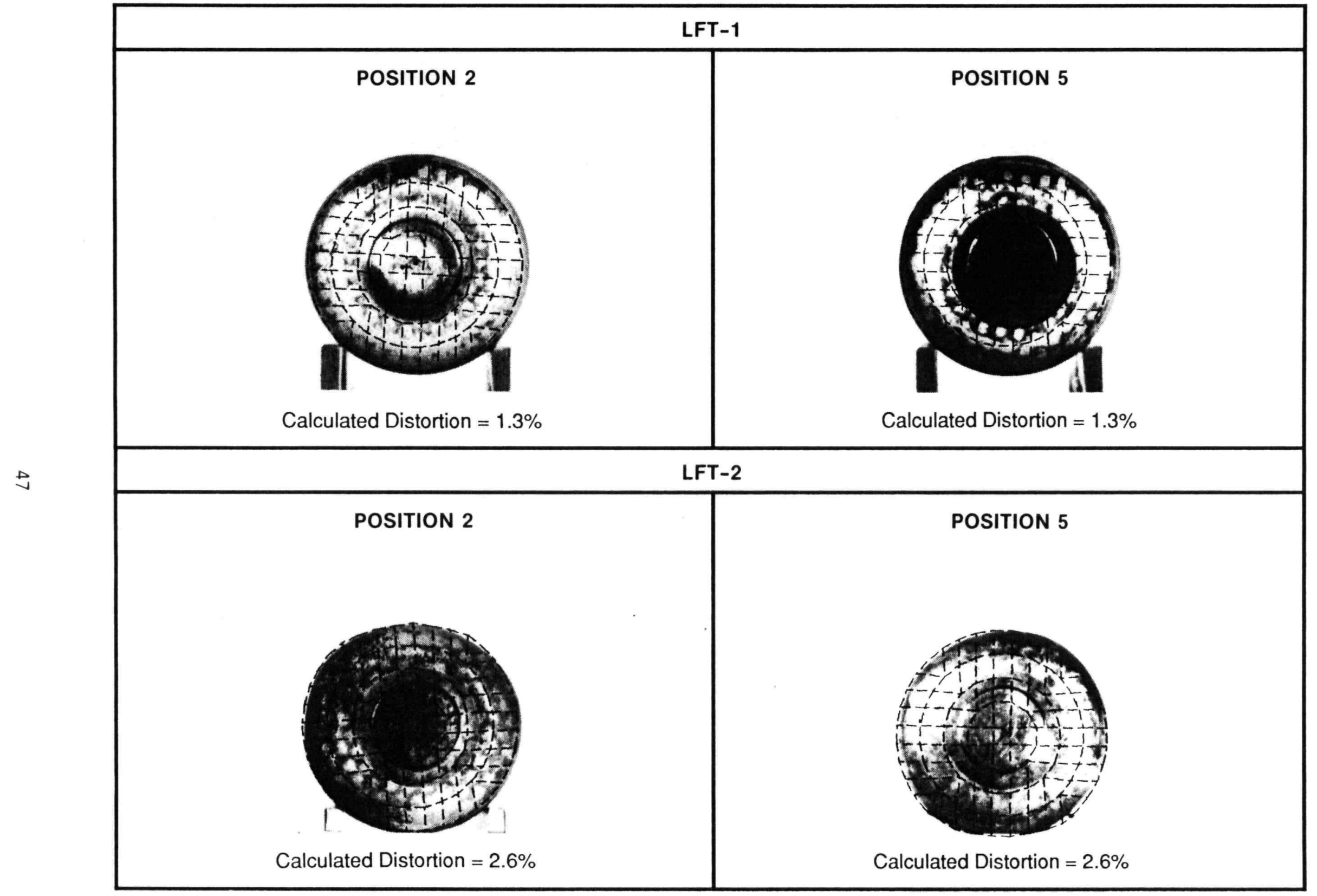

Figure 28. AFT Fueled Clad Post Impact Geometry for the LFT-1 and LFT-2 Events 
Table VI. Summary of the Large Fragment Test (LFT) Results and Comparison to Analytically Predicted Results (1)

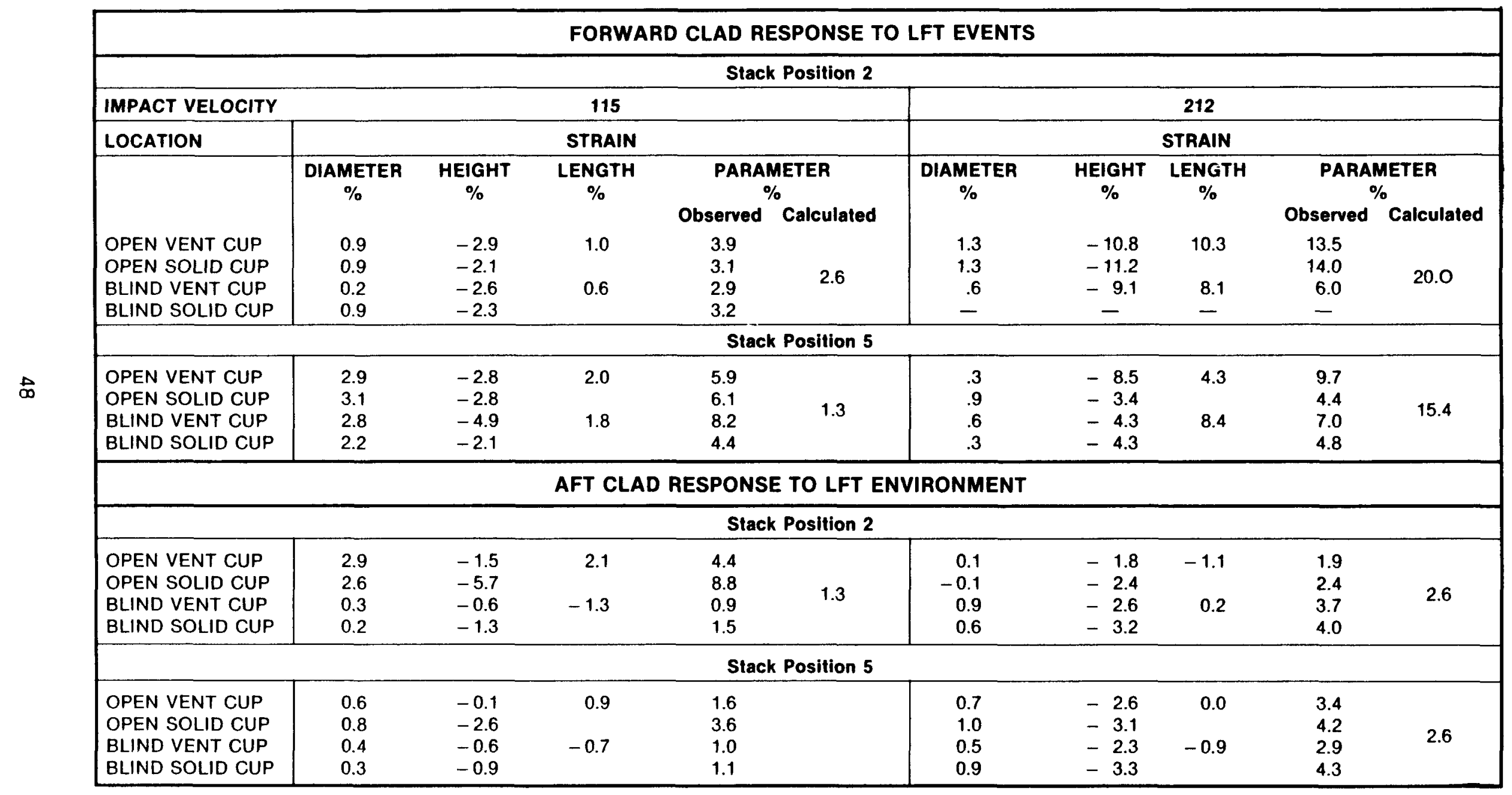

(1) Extreme Care Should be Used in Interpreting the Results of the Experiments. A Number of the Observed Distortions are Known to have Resulted from Secondary Inputs. Conclusions Drawn Without Reference to the Detailed Test Reports are Likely to be in Error. 
$\left(\dot{E}_{T T}=0\right)$ which prevents fueled clad length growth. Boundary constraint of fueled clad axial growth produces non-physical diametrial dilation. This results in an overprediction of the distortion parameter calculated for high velocity ( $>200 \mathrm{~m} / \mathrm{s}$ ) impacts. At some point a new failure mechanism will appear; i.e. weld failure due to axial flow of the fuel and clad. This point could be predicted by constructing a 2-D model in an orthogonal plane (or a 3-D model) and observing fueled clad longitudinal (length) growth. This was not pursued since there are few impacts (after structure attenuation) above $200 \mathrm{~m} / \mathrm{s}$. Based on this observation, the refined mode? was declared calibrated and operational for predicting the response of plutonia fueled clads to STS-SRM fragment impact.

\section{Fragment Edge-On Impacts}

Edge-on fragment impact tests were conducted on a mock-up of the GPHSRTG. The general arrangement of this fragment edge-on impact test is shown in Figure 29. The fueled clad distortion resulting from the edge-on impact of a $56 \times 56$ inch section of an STS-SRM at $95.4 \mathrm{~m} / \mathrm{s}$ is shown in Table VII. Analyses were conducted to determine weak-and strong-plutonia-fueled clad response to the edge-on impact of an SRM quadrant on the GPHS-RTG. These impacts were modeled in the LFT geometry with the fragment edge parallel to the GPHS module edge and with coincident fragment and fueled clad centerlines. The post impact geometry of a typical edge-on impact event is shown in Figure 30. The effect of velocity on the magnitude of the distortion parameter is shown in Figure 31 . It is seen that edge-on impacts at velocities greater than $60 \mathrm{~m} / \mathrm{s}$ can cause significant distortion to weak plutonia-fueled clads. It is also seen that the amount of distortion resulting from such an impact is an exponential function of impact velocity.

\section{Edge-On Angle of Attack Sensitivity}

Various assumptions concerning the fueled-clad-distortion parameter's sensitivity to edge-on fragment angle of attack have been made. Calculations to quantify this sensitivity were performed at angles of attack ranging from 50 to 90 degrees at $60 \mathrm{~m} / \mathrm{s}$ using strong and weak plutonia 


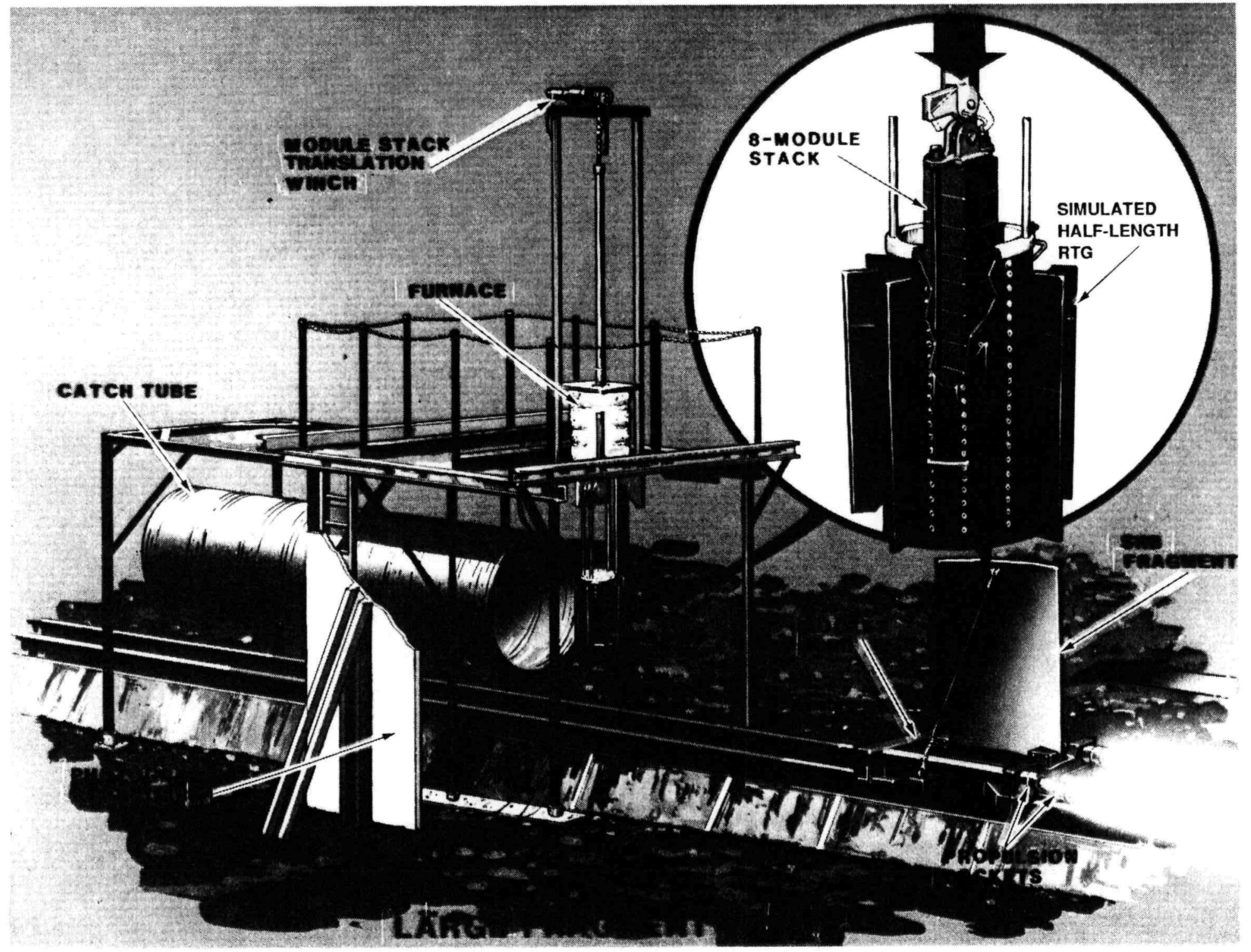

Figure 29. Large Edge-On Fragment Test Set Up 
Table VII. Urania Fueled Clad Distortion Resulting from a $95.4 \mathrm{M} / \mathrm{S}$ Edge-On Impact of a 56 X 56 Inch STS SRM Section on a Simulated GPHS RTG in the Galileo Configuration

\begin{tabular}{|ccc|}
\hline Location & $\begin{array}{c}\text { Forward Capsule } \\
\text { Observed } \\
\text { Distortion } \\
\%\end{array}$ & $\begin{array}{c}\text { Aft Capsule } \\
\text { Observed } \\
\text { Distortion } \\
\%\end{array}$ \\
\hline Position 2 & $(1)$ & -0.2 \\
Position 5 & $32^{(2)}$ & 0.6 \\
\hline
\end{tabular}

S. $10840 R 5,89 \mathrm{M}$

Note: The Predicted Value for Impact in the Ulysses Geometry was 15 to $30 \%$ for the Forward Capsule at an Input Velocity of $60 \mathrm{M} / \mathrm{S}$. Failure was Predicted at $70 \mathrm{M} / \mathrm{S}$.

(1) Separated at Weld and Lost $\sim 49 \mathrm{~g}$ of Fuel

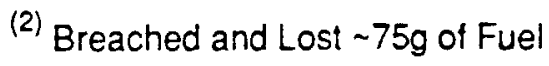




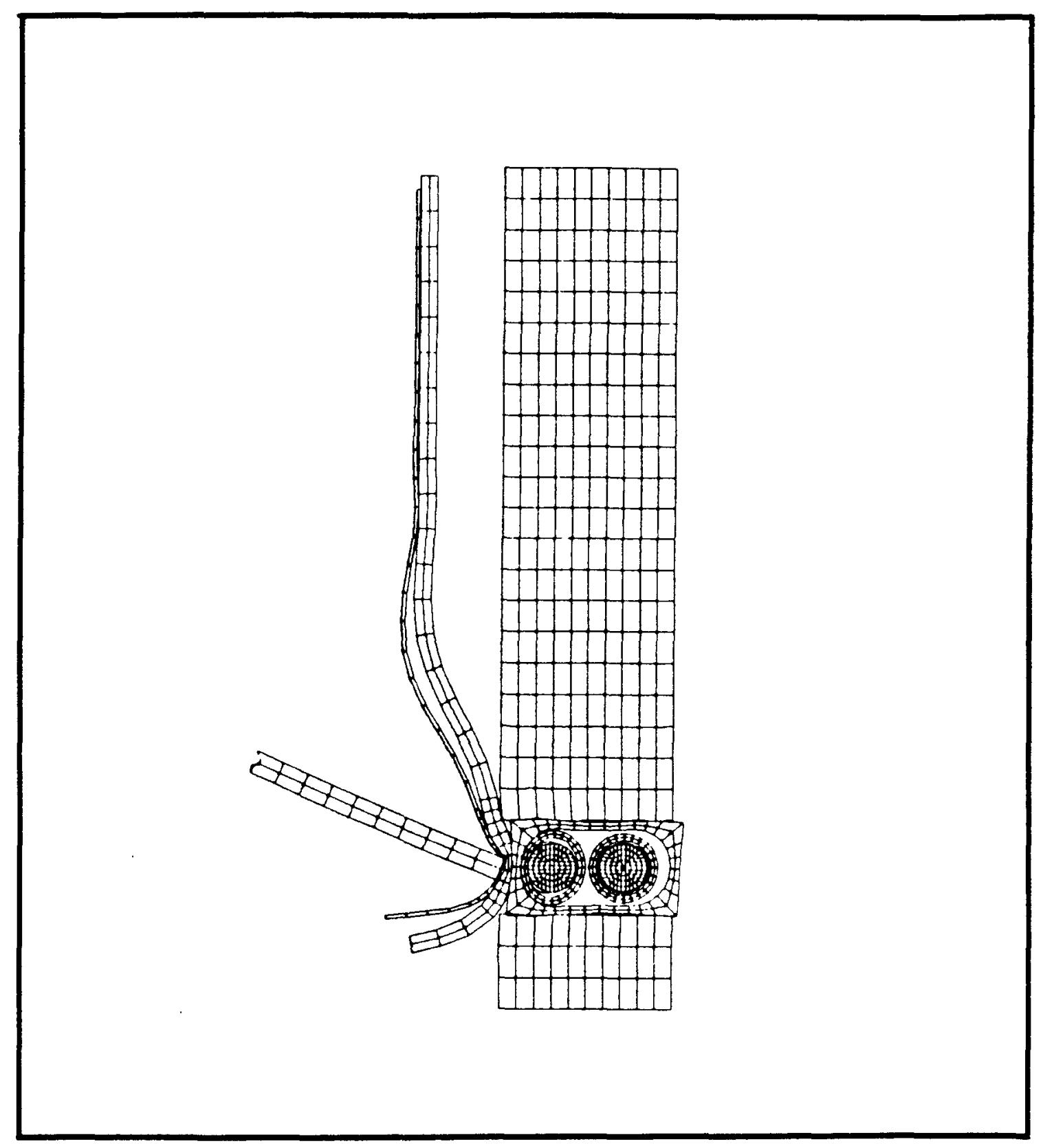

Figure 30. Post Impact Geometry of an Edge-On Quadrant Impact at $60 \mathrm{M} / \mathrm{S}$ and 70 Degree Angle of Attack Using the LFT Model 


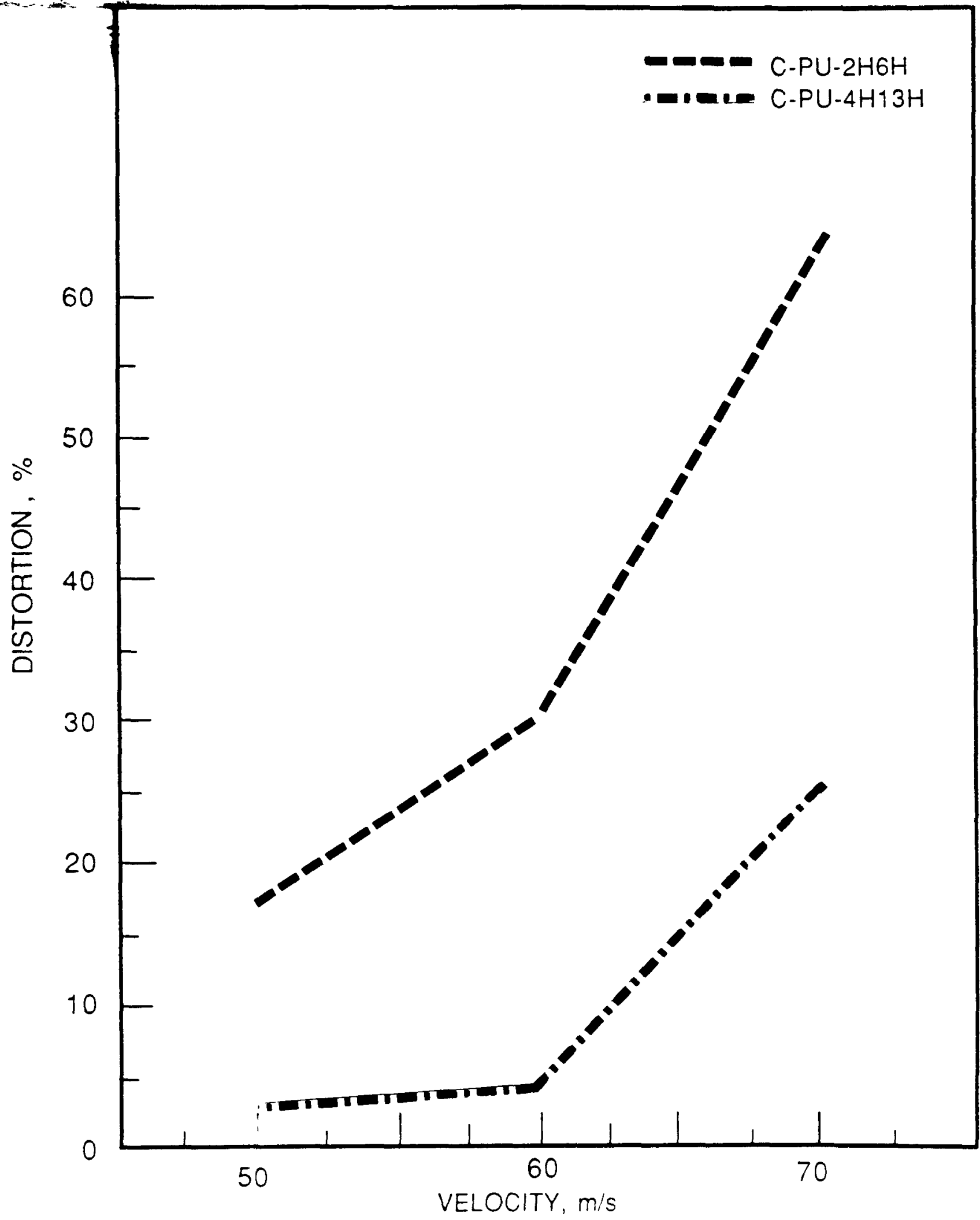

Figure 31. Effect of Fuel Properties and Velocity on the Response of a Plutonia.Fueled Clad to the $90^{\circ}$ Edge.On Impact of a SRM Quadrant in the LFT Stack Geometry 
properties and the LFT geometry. The results of these analyses are presented graphically in figure 32. It is seen that fragment angle of attack can have a large effect on the fueled clad distortion incurred under the assumed loading conditions.

It was recognized that the translational symmetry arguments used in the current LFT model may result in understating the RTG housing stiffness response to an edge-on fragment impact. The geometric model which was developed and calibrated for the earlier shock tube analyses was felt to have shown good agreement with those test results. This model geometry was reproduced and fitted with the current material properties. The model was exercised at various fragment angles of attack ranging from 50 to 90 degrees. The end point geometry of a 70 degree edge-on impact event is shown in Figure 33. A graphical comparison of these results to the previous results is shown in Figure 34 .

\section{Analytical Predictions Used for LASEP Analyses}

The material presented in this section constitutes the data base upon which the LASEP Program was exercised. This data base was generated using the calibrated hydrocode models described in sections $B$ and $C$. The LASEP Program is used to determine release probabilities for the GPHS fueled clads when they are subjected to a number of adverse events. Among these are:

1. Side-On Impaci oy Solid Rocket Motor (SRM) Fragments.

2. Edge-On Impact by SRM Fragments.

3. Impact of an Intact RTG Against the STS-Bay Door.

4. Impact of a Bare Module Against the STS-Bay Door.

5. Impact of a Bare Fueled Clad Against the STS-Bay Door.

6. Side-On Impact of a Bare GIS Against Concrete.

7. End-On Impact of an Intact RTG on Concrete. Stee 1 and wet Sand.

The results of calculations performed to describe the fueled clad distortion occurring in the above events are presented in this section. As 


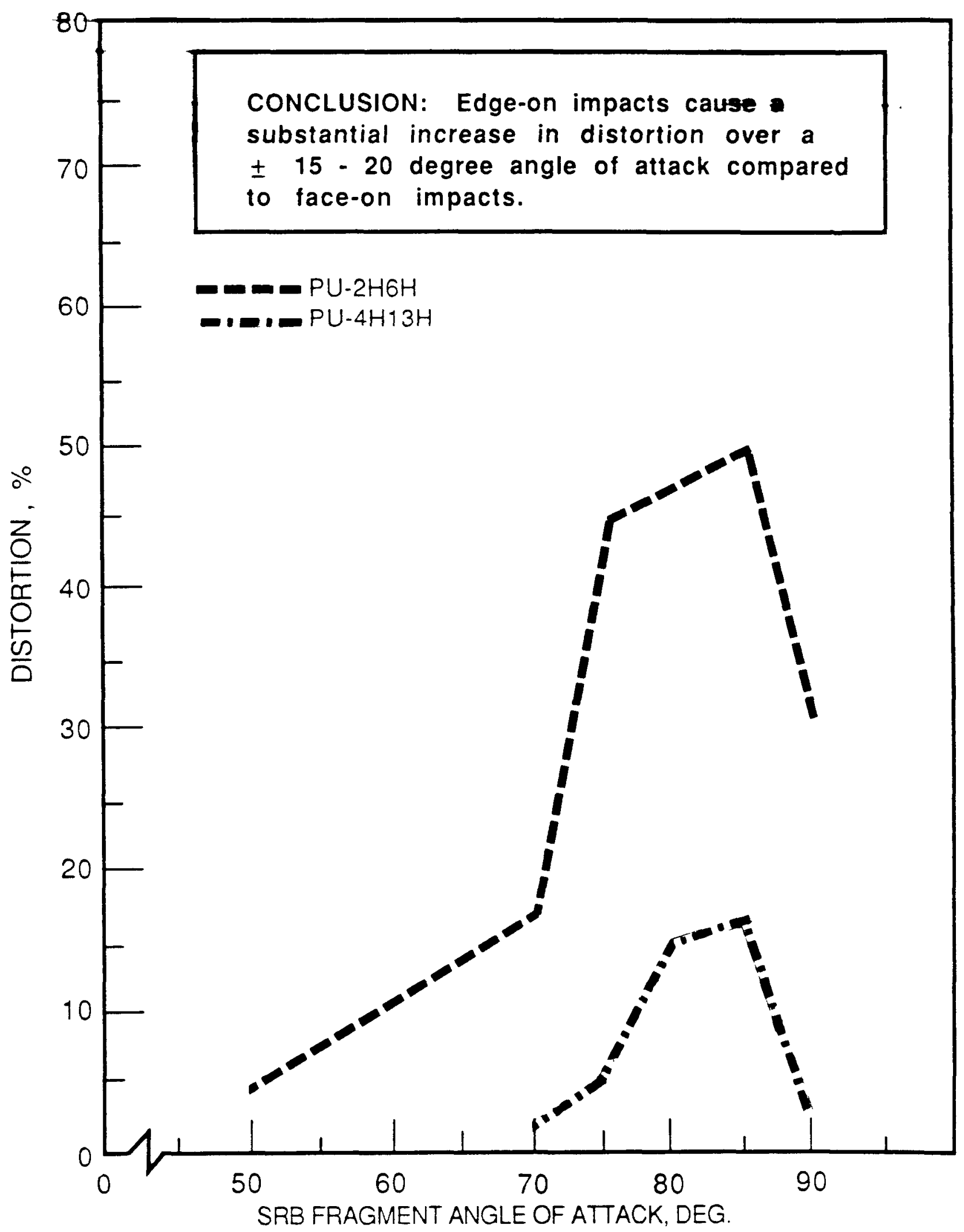

Figure 32. Effect of Fragment Angle of Attack on the Response of a Plutonia-Fueled Clad to the Edge-On Impact of a SRB Quadrant at $60 \mathrm{M} / \mathrm{S}$ in the LFT Geometry 


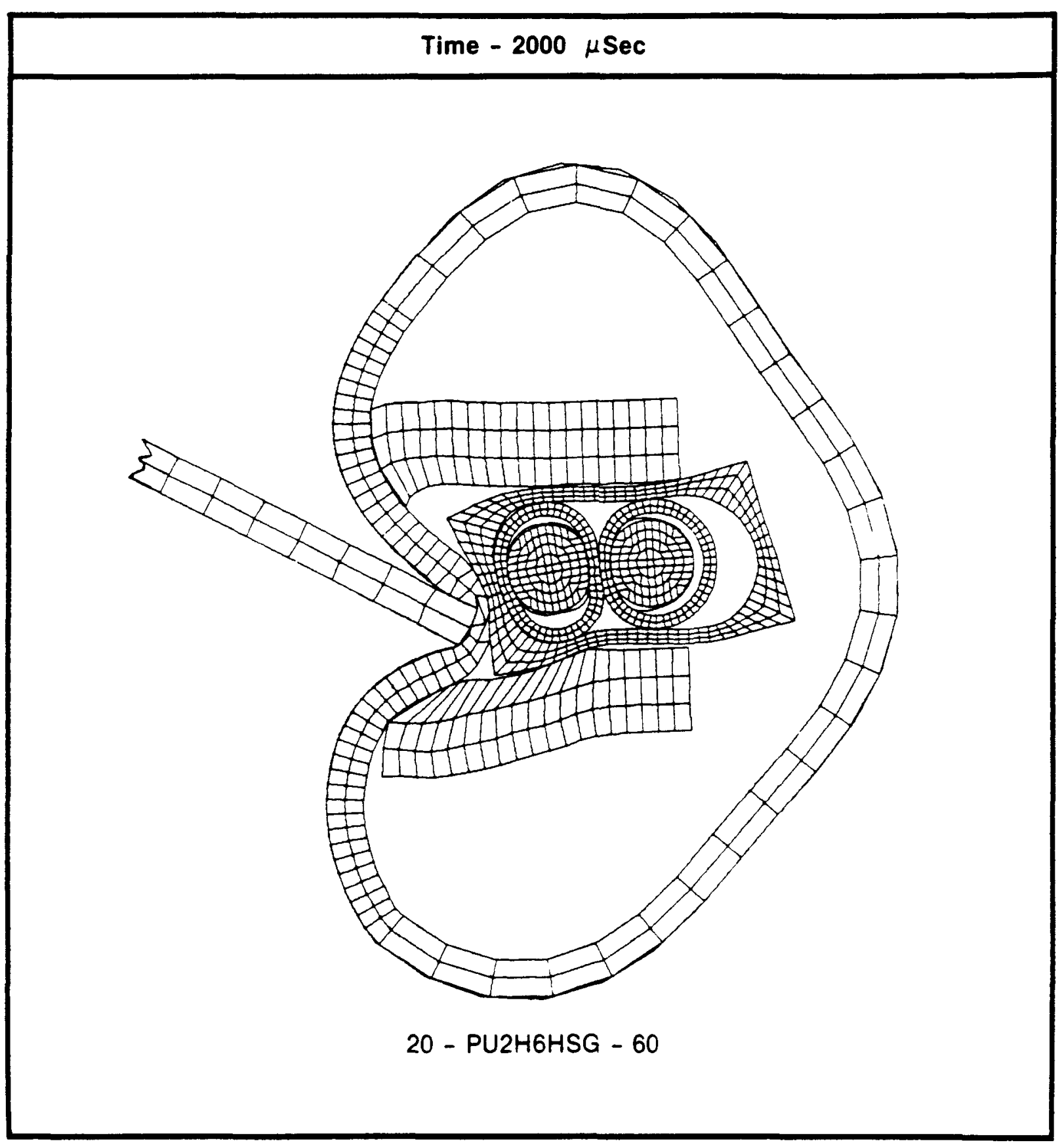

Figure 33. Post Impact Geometry of an Edge-On Quadrant Impact at $60 \mathrm{M} / \mathrm{S}$ and at 70 Degree Angle of Attack Using a Cylindrical Housing Model 


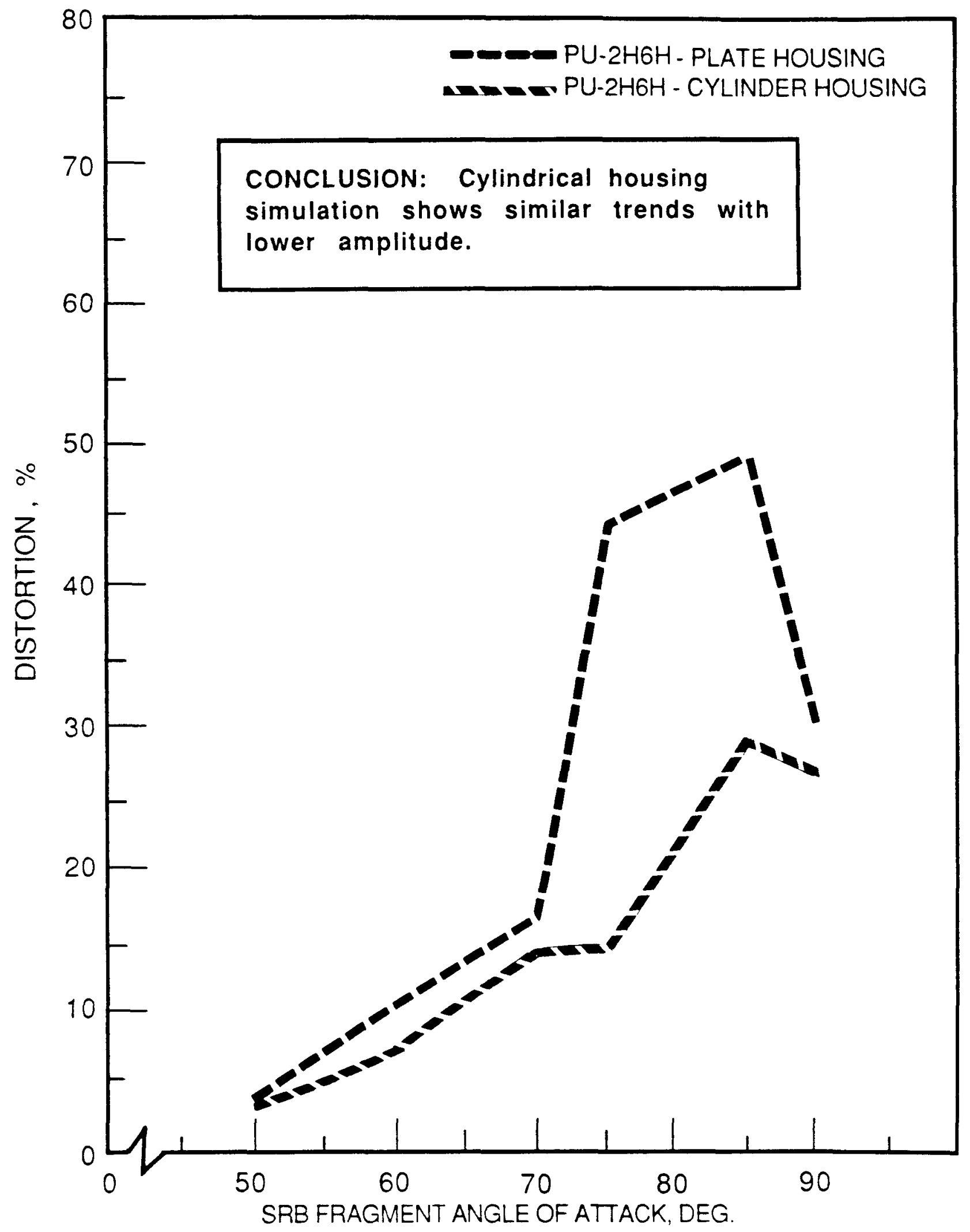

Figure 34. Effect of Housing Simulation Method on Distortion Parameter Change with Fragment Angle of Attack 
has been suggested previously, there is no way to test the plutonia-fueled clad in a full scale environiment. As a result, it was necessary to predict the distortion of the urania simulant used in the LFTs prior to predicting the potential plutonia results, and to establish material-response uncertainty bounds based on the results of the BCI and FGT plutonia fueled events. The results of the LFT series were presented in Table $V I$ for reference. A fueled clad impact sensitivity study was conducted after calibration of the analytical models. This study resulted in the data base referenced above.

\section{Side-On SRM Fragment Impact}

The material properties used for the models discussed in this section were presented in Table I. The analyses used a very detailed zoning of two GPHS modules with dummy mass concentrations on either side of these two fine zoned modules. The early time geometry of a typical RTG stack model was shown in figure 24. These snapshots were taken just as the fragmenthousing-insulation sandwich impacts the module stack. Also shown in Figure 24 is the device used for approximating the effects of modules at various longitudinal positions within the generator. Note that in the first panel of Figure 24 , the two modules with fine zoning are shown in the second and third position from the bottom of the stack and the mass simulants are located in the 1 and 4 positions. In the third pane 1 of figure 24, note that the active modules are in the 4 and 5 positions while the mass simulants are in the 3 and 6 positions. The remainder of the stack is simulated with distributed mass blocks having the mechanical properties of poco graphite. The thicker-than-actual plate used to investigate threedimensional fragment bending stiffness effects is also shown in the third panel of Figure 24 .

More than two hundred-fifty cases were calculated to provide a data base for the LASEP input. These calculations varied impact point on a fragment, fragment rotation rate and translational velocity, as well as plate thickness and the module location within the stack. It was noted early in the generation of this data base that the distortion predicted for 
any given stack location was a function of the point velocity of the fragment, i.e., the vector summation of its rotational velocity and its translational velocity at any point from the center of the fragment to 87 percent of the distance from the fragments center to its tip. Observed non-linearities occurred when the module of interest was impacted by the last twelve percent of the fragment's length. It appeared that the stiffness in both the $1 / 2$ and $3 / 4$ inch plate configurations was a factor only in the last 12 percent of the distance from the rotational center of the fragment to the tip of the fragment. This observation greatiy simplified the generation of the data base because it became necessary to look only at point velocities on the fragment, and any combination of distance and rotational speed could be modeled as a simple translational impact having that velocity. The special case which occurred for impacts on the final 12 percent of the fragment was handled as a separate set of calculations. The model used for these calculations was shown in the second panel of Figure 24.

Best results for correlation with the Large fragment Tests (LFT) were obtained using the model which was calibrated against the BCI tests and the FGT tests using weak urania (U6HIIH) and $1 / 2$ inch plate properties. During calibration, the bounds of these properties were shifted only in terms of the strength of the urania and the fragment thickness. The fragment thickness changes which were made to calibrate the model in the LFT-1 did not seem appropriate in the LFT-2. Therefore, it appears that the $1 / 2$ inch plate case using the weak plutonia (PU2H6H) model may be a better approximation of an upper bound than of the nominal event. (See figures 25 and 26.) Passible mechanisms for these differences were presented in the previous sections. This work was completed prior to running the LFT-2. As a result the $1 / 2$ inch thick plate, weak plutonia model was defined as the nominal rather than the worst case for the purposes of this effort.

A complete compilation of the side-on fragment impact data base developed using the PISCES code is presented in Table VIII. This data base was treated statisticaliy by $A$. Mowery of DOE and $R$. Vaughn of NUS, to determine the means and distributions of distortion as a function of the 
Table VIII (1 of 7). Data Base for Side-On Fragment Impact Events For Impacts from 0 to $87.5 \%$ of the Distance from Fragment Center to Fragment Tip (Non-Tip Cases)

\begin{tabular}{|c|c|c|c|c|c|c|c|}
\hline Data Set Name & $\begin{array}{c}\text { Stack } \\
\text { Location/ } \\
\text { FWD-AFT } \\
\text { Location }\end{array}$ & $\begin{array}{c}\text { Distance } \\
\text { From } \\
\text { Fragment } \\
\text { Center } \\
\%\end{array}$ & $\begin{array}{c}\text { Fragment } \\
\text { Thickness } \\
\text { INS }\end{array}$ & $\begin{array}{c}\text { Impact } \\
\text { Velocity } \\
\mathrm{m} / \mathrm{s}\end{array}$ & $\begin{array}{l}\text { Fuel } \\
\text { Type }\end{array}$ & $\begin{array}{c}\begin{array}{c}\text { Rotation } \\
\text { Rate }\end{array} \\
\mathrm{HZ}\end{array}$ & $\begin{array}{c}\text { Distortion } \\
\% \\
\end{array}$ \\
\hline 4R07_PU2H6H_100 & $2 F$ & 87.5 & 0.5 & 100 & WEAK & 7 & 26.0 \\
\hline 4RO7_PU2H6H__100 & $2 A$ & 87.5 & 0.5 & 100 & WEAK & 7 & 10.7 \\
\hline 4R07__PU2H6H_100 & $3 F$ & 87.5 & 0.5 & 100 & WEAK & 7 & 18.7 \\
\hline 4R07_PU2H6H_100 & $3 A$ & 87.5 & 0.5 & 100 & WEAK & 7 & 7.7 \\
\hline 4R12_PU2H6H_100 & $2 F$ & 87.5 & 0.5 & 100 & WEAK & 12 & 42.0 \\
\hline 4R12_PU2H6H_100 & $2 A$ & 87.5 & 0.5 & 100 & WEAK & 12 & 14.3 \\
\hline 4R12_PU2H6H_100 & $3 F$ & 87.5 & 0.5 & 100 & WEAK & 12 & 29.3 \\
\hline 4R12_PU2H6H_100 & $3 A$ & 87.5 & 0.5 & 100 & WEAK & 12 & 6.2 \\
\hline 4R17__PU2H6H_100 & $2 F$ & 87.5 & 0.5 & 100 & WEAK & 17 & 42.4 \\
\hline 4R17__ PU2H6H_ 100 & $2 A$ & 87.5 & 0.5 & 100 & WEAK & 17 & 14.7 \\
\hline 4R17__PU2H6H_100 & $3 F$ & 87.5 & 0.5 & 100 & WEAK & 17 & 14.9 \\
\hline 4R17_PU2H6H_100 & $3 A$ & 87.5 & 0.5 & 100 & WEAK & 17 & 27.7 \\
\hline 2R07_PU2H6H_100 & $2 F$ & 75.0 & 0.5 & 100 & WEAK & 7 & 25.1 \\
\hline 2R07_PU2H6H_100 & $2 A$ & 75.0 & 0.5 & 100 & WEAK & 7 & 10.8 \\
\hline 2R07_PU2H6H_100 & $3 F$ & 75.0 & 0.5 & 100 & WEAK & 7 & 16.1 \\
\hline 2R07_PU2H6H_100 & $3 A$ & 75.0 & 0.5 & 100 & WEAK & 7 & 8.0 \\
\hline 2R12_PU2H6H_100 & $2 F$ & 75.0 & 0.5 & 100 & WEAK & 12 & 38.1 \\
\hline 2R12_PU2H6H_100 & $2 A$ & 75.0 & 0.5 & 100 & WEAK & 12 & 12.5 \\
\hline 2R12_PU2H6H_100 & $3 F$ & 75.0 & 0.5 & 100 & WEAK & 12 & 25.8 \\
\hline 2R12_PU2H6H_100 & $3 A$ & 75.0 & 0.5 & 100 & WEAK & 12 & 9.7 \\
\hline 2R17_PU2H6H_100 & $2 F$ & 75.0 & 0.5 & 100 & WEAK & 17 & 40.4 \\
\hline 2R17_PU2H6H_100 & $2 \mathrm{~A}$ & 75.0 & 0.5 & 100 & WEAK & 17 & 18.1 \\
\hline 2R17_PU2H6H_100 & $3 F$ & 75.0 & 0.5 & 100 & WEAK & 17 & 27.5 \\
\hline 2R17_PU2H6H__ 100 & $3 A$ & 75.0 & 0.5 & 100 & WEAK & 17 & 7.9 \\
\hline 3R07_PU2H6H_100 & $2 F$ & 50.0 & 0.5 & 100 & WEAK & 7 & 22.0 \\
\hline 3R07_PU2H6H_100 & $2 A$ & 50.0 & 0.5 & 100 & WEAK & 7 & 11.2 \\
\hline 3R07_PU2H6H_100 & $3 F$ & 50.0 & 0.5 & 100 & WEAK & 7 & 12.6 \\
\hline 3R07_PU2H6H_100 & $3 A$ & 50.0 & 0.5 & 100 & WEAK & 7 & 7.8 \\
\hline 3R12_PU2H6H_100 & $2 F$ & 50.0 & 0.5 & 100 & WEAK & 12 & 30.6 \\
\hline $3 \mathrm{R} 12$ _ $\mathrm{PU} 2 \mathrm{H} 6 \mathrm{H} \_100$ & $2 A$ & 50.0 & 0.5 & 100 & WEAK & 12 & 15.6 \\
\hline 3R12_PU2H6H_100 & $3 F$ & 50.0 & 0.5 & 100 & WEAK & 12 & 19.8 \\
\hline 3R12_PU2H6H_100 & $3 A$ & 50.0 & 0.5 & 100 & WEAK & 12 & 10.2 \\
\hline 3R17_PU2H6H_100 & $2 F$ & 50.0 & 0.5 & 100 & WEAK & 17 & 40.8 \\
\hline 3R17_PU2H6H_100 & $2 A$ & 50.0 & 0.5 & 100 & WEAK & 17 & 15.7 \\
\hline 3R17_PU2H6H_100 & $3 F$ & 50.0 & 0.5 & 100 & WEAK & 17 & 29.5 \\
\hline 3R17_PU2H6H_100 & $3 A$ & 50.0 & 0.5 & 100 & WEAK & 17 & 11.4 \\
\hline
\end{tabular}


Table VIII (2 of 7). Data Base for Side-On Fragment Impact Events (Continued)

For Impacts from 0 to $87.5 \%$ of the Distance from Fragment Center to Fragment Tip (Non-Tip Cases)

\begin{tabular}{|c|c|c|c|c|c|c|c|}
\hline Data Set Name & $\begin{array}{l}\text { Stack } \\
\text { Location/ } \\
\text { FWD-AFT } \\
\text { Location }\end{array}$ & $\begin{array}{c}\text { Distance } \\
\text { From } \\
\text { Fragment } \\
\text { Center } \\
\% \\
\end{array}$ & $\begin{array}{c}\text { Fragment } \\
\text { Thickness } \\
\text { INS }\end{array}$ & $\begin{array}{c}\text { Impact } \\
\text { Velocity } \\
\mathrm{m} / \mathrm{s}\end{array}$ & $\begin{array}{l}\text { Fuel } \\
\text { Type }\end{array}$ & $\begin{array}{c}\text { Rotation } \\
\text { Rate } \\
\text { HZ }\end{array}$ & $\begin{array}{c}\text { Distortion } \\
\%\end{array}$ \\
\hline 5R07_PU2H6H_- 100 & $2 F$ & 25.0 & 0.5 & 100 & WEAK & 7 & 15.1 \\
\hline 5R07_PU2H6H__100 & $2 A$ & 25.0 & 0.5 & 100 & WEAK & 7 & 9.6 \\
\hline 5R07_PU2H6H_-100 & $3 F$ & 25.0 & 0.5 & 100 & WEAK & 7 & 12.1 \\
\hline 5R07__PU2H6H__ 100 & $3 A$ & 25.0 & 0.5 & 100 & WEAK & 7 & 4.2 \\
\hline 5R12_PU2H6H_ 100 & $2 F$ & 25.0 & 0.5 & 100 & WEAK & 12 & 20.9 \\
\hline 5R12_PU2H6H_100 & $2 A$ & 25.0 & 0.5 & 100 & WEAK & 12 & 7.9 \\
\hline 5R12_PU2H6H_100 & $3 F$ & 25.0 & 0.5 & 100 & WEAK & 12 & 10.5 \\
\hline 5R12_PU2H6H__100 & $3 A$ & 25.0 & 0.5 & 100 & WEAK & 12 & 5.6 \\
\hline 5R17_PU2H6H_100 & $2 F$ & 25.0 & 0.5 & 100 & WEAK & 17 & 23.4 \\
\hline 5R17_PU2H6H_- 100 & $2 A$ & 25.0 & 0.5 & 100 & WEAK & 17 & 12.9 \\
\hline 5R17_PU2H6H_100 & $3 F$ & 25.0 & 0.5 & 100 & WEAK & 17 & 14.3 \\
\hline 5R17_PU2H6H_100 & $3 A$ & 25.0 & 0.5 & 100 & WEAK & 17 & 6.5 \\
\hline OR07_PU2H6H_100 & $2 F$ & 0.0 & 0.5 & 100 & WEAK & 7 & 7.6 \\
\hline OR07_PU2H6H_100 & $2 A$ & 0.0 & 0.5 & 100 & WEAK & 7 & 0.0 \\
\hline OR07__PU2H6H_100 & $3 F$ & 0.0 & 0.5 & 100 & WEAK & 7 & 7.6 \\
\hline 0R07_PU2H6H__100 & $3 A$ & 0.0 & 0.5 & 100 & WEAK & 7 & 0.0 \\
\hline 4R07_PU2H6H__200 & $2 F$ & 87.5 & 0.5 & 200 & WEAK & 7 & 40.8 \\
\hline 4R07_PU2H6H_200 & $2 A$ & 87.5 & 0.5 & 200 & WEAK & 7 & 12.7 \\
\hline 4R07_PU2H6H_200 & $3 F$ & 87.5 & 0.5 & 200 & WEAK & 7 & 24.4 \\
\hline 4R07_PU2H6H_200 & $3 A$ & 87.5 & 0.5 & 200 & WEAK & 7 & 15.4 \\
\hline 4R12_PU2H6H_200 & $2 F$ & 87.5 & 0.5 & 200 & WEAK & 12 & 40.2 \\
\hline 4R12_PU2H6H_200 & $2 A$ & 87.5 & 0.5 & 200 & WEAK & 12 & 21.3 \\
\hline 4R12_PU2H6H_200 & $3 F$ & 87.5 & 0.5 & 200 & WEAK & 12 & 23.1 \\
\hline 4R12_PU2H6H_200 & $3 A$ & 87.5 & 0.5 & 200 & WEAK & 12 & 16.1 \\
\hline 4R17__PU2H6H_200 & $2 F$ & 87.5 & 0.5 & 200 & WEAK & 17 & 47.3 \\
\hline 4R17__PU2H6H__200 & $2 A$ & 87.5 & 0.5 & 200 & WEAK & 17 & 21.8 \\
\hline 4R17__PU2H6H_200 & $3 F$ & 87.5 & 0.5 & 200 & WEAK & 17 & 29.0 \\
\hline 4R17_PU2H6H_200 & $3 A$ & 87.5 & 0.5 & 200 & WEAK & 17 & 20.5 \\
\hline $2 \mathrm{R} 07 \_\mathrm{PU} 2 \mathrm{H} 6 \mathrm{H} \_200$ & $2 F$ & 75.0 & 0.5 & 200 & WEAK & 7 & 42.4 \\
\hline 2R07_PU2H6H_200 & $2 A$ & 75.0 & 0.5 & 200 & WEAK & 7 & 20.7 \\
\hline 2R07_PU2H6H_200 & $3 F$ & 75.0 & 0.5 & 200 & WEAK & 7 & 24.9 \\
\hline 2R07_PU2H6H_200 & $3 A$ & 75.0 & 0.5 & 200 & WEAK & 7 & 15.8 \\
\hline 2R12_PU2H6H_200 & $2 F$ & 75.0 & 0.5 & 200 & WEAK & 12 & 44.7 \\
\hline 2R12_PU2H6H_200 & $2 A$ & 75.0 & 0.5 & 200 & WEAK & 12 & 31.0 \\
\hline 2R12_PU2H6H_200 & $3 F$ & 75.0 & 0.5 & 200 & WEAK & 12 & 24.3 \\
\hline 2R12_PU2H6H_2OO & $3 A$ & 75.0 & 0.5 & 200 & WEAK & 12 & 21.3 \\
\hline 2R17_PU2H6H_200 & $2 F$ & 75.0 & 0.5 & 200 & WEAK & 17 & 47.0 \\
\hline 2R17_PU2H6H_200 & $2 A$ & 75.0 & 0.5 & 200 & WEAK & 17 & 37.1 \\
\hline 2R17_PU2H6H_200 & $3 F$ & 75.0 & 0.5 & 200 & WEAK & 17 & 27.4 \\
\hline 2R17_PU2H6H_200 & $3 A$ & 75.0 & 0.5 & 200 & WEAK & 17 & 23.5 \\
\hline
\end{tabular}


Table VIII (3 of 7). Data Base for Side-On Fragment Impact Events (Continued)

For Impacts from $\mathrm{O}$ to $87.5 \%$ of the Distance from Fragment Center

to Fragment Tip (Non-Tip Cases)

\begin{tabular}{|c|c|c|c|c|c|c|c|}
\hline Data Set Name & $\begin{array}{l}\text { Stack } \\
\text { Location/ } \\
\text { FWD-AFT } \\
\text { Location }\end{array}$ & $\begin{array}{c}\text { Distance } \\
\text { From } \\
\text { Fragment } \\
\text { Center } \\
\%\end{array}$ & $\begin{array}{c}\text { Fragment } \\
\text { Thickness } \\
\text { INS }\end{array}$ & $\begin{array}{c}\text { Impact } \\
\text { Velocity } \\
\mathrm{m} / \mathrm{s}\end{array}$ & $\begin{array}{l}\text { Fuel } \\
\text { Type }\end{array}$ & $\begin{array}{c}\text { Potation } \\
\text { Rate } \\
\text { HZ }\end{array}$ & $\begin{array}{c}\text { Distortion } \\
\%\end{array}$ \\
\hline 3R07_PU2H6H_200 & $2 F$ & 500 & 05 & 200 & WEAK & 7 & 431 \\
\hline 3R07_PU2H6H_200 & $2 A$ & 500 & 05 & 200 & WEAK & 7 & 206 \\
\hline 3R07_PU2H6H_200 & $3 F$ & 500 & 05 & 200 & WEAK & 7 & 294 \\
\hline 3R07_PU2H6H_200 & $3 A$ & 500 & 05 & 200 & WEAK & 7 & 232 \\
\hline 3R12_PU2H6H_200 & $2 F$ & 500 & 05 & 200 & WEAK & 12 & 424 \\
\hline 3R12_PU2H6H_200 & $2 A$ & 500 & 05 & 200 & WEAK & 12 & 239 \\
\hline 3R12_PU2H6H_200 & $3 F$ & 500 & 05 & 200 & WEAK & 12 & 278 \\
\hline 3R12_PU2H6H_2OO & $3 A$ & 500 & 05 & 200 & WEAK & 12 & 183 \\
\hline 3R17_PU2H6H_200 & $2 F$ & 500 & 05 & 200 & WEAK & 17 & 431 \\
\hline 3R17_PU2H6H__2OO & $2 \mathrm{~A}$ & 500 & 05 & 200 & WEAK & 17 & 297 \\
\hline 3R17_PU2H6H_200 & $3 F$ & 500 & 05 & 200 & WEAK & 17 & 245 \\
\hline 3R17_PU2H6H_200 & $3 A$ & 500 & 05 & 200 & WEAK & 17 & 223 \\
\hline 5R07_PU2H6H_200 & $2 F$ & 250 & 05 & 200 & WEAK & 7 & 417 \\
\hline 5R07__PU2H6H_200 & $2 \mathrm{~A}$ & 250 & 05 & 200 & WEAK & 7 & 122 \\
\hline 5R07_PU2H6H_200 & $3 F$ & 250 & 05 & 200 & WEAK & 7 & 264 \\
\hline 5R07_PU2H6H_200 & $3 A$ & 250 & 05 & 200 & WEAK & 7 & 229 \\
\hline 5R12_PU2H6H_200 & $2 F$ & 250 & 05 & 200 & WEAK & 12 & 424 \\
\hline 5R12_PU2H6H_200 & $2 A$ & 250 & 05 & 200 & WEAK & 12 & 150 \\
\hline 5R12_PU2H6H_200 & $3 F$ & 250 & 05 & 200 & WEAK & 12 & 276 \\
\hline 5R12_PU2H6H_200 & $3 A$ & 250 & 05 & 200 & WEAK & 12 & 228 \\
\hline 5R17_PU2H6H_200 & $2 F$ & 250 & 05 & 200 & WEAK & 17 & 431 \\
\hline 5R17_PU2H6H_200 & $2 A$ & 250 & 05 & 200 & WEAK & 17 & 192 \\
\hline 5R17__PU2H6H_200 & $3 F$ & 250 & 05 & 200 & WEAK & 17 & 274 \\
\hline 5R17_PU2H6H_200 & $3 A$ & 250 & 05 & 200 & WEAK & 17 & 170 \\
\hline OR07_PU2H6H_200 & $2 F$ & 00 & 05 & 200 & WEAK & 7 & 426 \\
\hline OR07__PU2H6H_2OO & $2 A$ & 00 & 05 & 200 & WEAK & 7 & 180 \\
\hline 0R07_PU2H6H_200 & $3 F$ & 00 & 05 & 200 & WEAK & 7 & 286 \\
\hline 0R07_PU2H6H_200 & $3 A$ & 00 & 05 & 200 & WEAK & 7 & 161 \\
\hline 23_WP_3RO_255 & $2 F$ & 500 & 05 & 255 & WEAK & 0 & 420 \\
\hline 23_WP_3RO_255 & $2 A$ & 500 & 05 & 255 & WEAK & 0 & 90 \\
\hline 23_WP_3RO_255 & $3 F$ & 500 & 05 & 255 & WEAK & 0 & 280 \\
\hline 23_WP_3RO_255 & $3 A$ & 500 & 05 & 255 & WEAK & 0 & 150 \\
\hline 45_WP_3RO_330 & $4 F$ & 500 & 05 & 330 & WEAK & 0 & 360 \\
\hline 45_WP_3RO_330 & $4 A$ & 500 & 05 & 330 & WEAK & 0 & 290 \\
\hline 45_WP_3R0_330 & $5 F$ & 500 & 05 & 330 & WEAK & 0 & 320 \\
\hline 45_WP_3RO_330 & $5 A$ & 500 & 05 & 330 & WEAK & 0 & 250 \\
\hline 45_WP_3RO_255 & $4 F$ & 500 & 05 & 255 & WEAK & 0 & 320 \\
\hline 45_WP_3RO_255 & $4 A$ & 500 & 05 & 255 & WEAK & 0 & 240 \\
\hline 45_WP_3RO_255 & $5 F$ & 500 & 05 & 255 & WEAK & 0 & 200 \\
\hline 45_WP_3RO_255 & $5 A$ & 500 & 05 & 255 & WEAK & 0 & 100 \\
\hline
\end{tabular}


Table vil (A ofn. Data Base for Side-On Fragment mmpact Events (Continued)

For Impacts from 0 to $87.5 \%$ of the Distance from Fragment Center

to Fragment Tip (Non-Tip Cases)

\begin{tabular}{|c|c|c|c|c|c|c|c|}
\hline Data Set Name & $\begin{array}{l}\text { Stack } \\
\text { Location/ } \\
\text { FWD-AFT } \\
\text { Location }\end{array}$ & $\begin{array}{c}\text { Distance } \\
\text { From } \\
\text { Fragment } \\
\text { Center } \\
\% \\
\end{array}$ & $\begin{array}{c}\text { Fragment } \\
\text { Thickness } \\
\text { INS }\end{array}$ & $\begin{array}{c}\text { Impact } \\
\text { Velocity } \\
\mathrm{m} / \mathrm{s}\end{array}$ & $\begin{array}{l}\text { Fuel } \\
\text { Type }\end{array}$ & $\begin{array}{c}\text { Rotation } \\
\text { Rate } \\
\mathrm{HZ}\end{array}$ & $\begin{array}{c}\text { Distortion } \\
\% \\
\end{array}$ \\
\hline 45_WP_3RO_200 & $4 F$ & 500 & 05 & 200 & WEAK & 0 & 360 \\
\hline 45_WP_3RO_200 & $4 \mathrm{~A}$ & 500 & 05 & 200 & WEAK & 0 & 130 \\
\hline 45_WP_3RO_200 & $5 F$ & 500 & 05 & 200 & WEAK & 0 & 290 \\
\hline 45_WP_3RO_200 & $5 \mathrm{~A}$ & 500 & 05 & 200 & WEAK & 0 & 130 \\
\hline 45_WP_3R0_255 & $4 F$ & 500 & 05 & 255 & WEAK & 0 & 320 \\
\hline 45_WP_3RO_255 & $4 A$ & 500 & 05 & 255 & WEAK & 0 & 120 \\
\hline 45_WP_3RO_255 & $5 F$ & 500 & 05 & 255 & WEAK & 0 & 240 \\
\hline 45_WP_3RO_255 & $5 \mathrm{~A}$ & 500 & 05 & 255 & WEAK & 0 & 100 \\
\hline 23_SP_4R17_100 & $2 F$ & 875 & 05 & 100 & STRONG & 17 & 170 \\
\hline 23_SP_4R17_100 & $2 A$ & 875 & 05 & 100 & STRONG & 17 & 10 \\
\hline 23_SP_4R17_100 & $3 F$ & 875 & 05 & 100 & STRONG & 17 & 140 \\
\hline 23_SP_4R17_100 & $3 A$ & 875 & 05 & 100 & STRONG & 17 & 10 \\
\hline 23_SP_2R17_100 & $2 \mathrm{~F}$ & 755 & 05 & 100 & STRONG & 17 & 150 \\
\hline 23_SP_2R17_100 & $2 \mathrm{~A}$ & 755 & 05 & 100 & STRONG & 17 & 10 \\
\hline 23_SP_2R17_100 & $3 F$ & 755 & 05 & 100 & STRONG & 17 & 110 \\
\hline 23_SP_2R17_100 & $3 A$ & 755 & 05 & 100 & STRONG & 17 & 10 \\
\hline T23_SP_4R12_200 & $2 F$ & 875 & 075 & 200 & STRONG & 12 & 330 \\
\hline T23_SP_4R12_200 & $2 A$ & 875 & 075 & 200 & STRONG & 12 & 200 \\
\hline T23_SP_4R12_200 & $3 F$ & 875 & 075 & 200 & STRONG & 12 & 190 \\
\hline T23_SP_4R12_200 & $3 A$ & 875 & 075 & 200 & STRONG & 12 & 120 \\
\hline T23_SP_2R17_200 & $2 \mathrm{~F}$ & 755 & 075 & 200 & STRONG & 17 & 310 \\
\hline T23_SP_2R17_200 & $2 A$ & 755 & 075 & 200 & STRONG & 17 & 110 \\
\hline T23_SP_2R17_200 & $3 F$ & 755 & 075 & 200 & STRONG & 17 & 250 \\
\hline T23_SP_2R17_200 & $3 A$ & 755 & 075 & 200 & STRONG & 17 & 20 \\
\hline T23_SP_2R12_200 & $2 \mathrm{~F}$ & 750 & 075 & 200 & STRONG & 12 & 330 \\
\hline T23_SP_2R12_200 & $2 F$ & 750 & 075 & 200 & STRONG & 12 & 160 \\
\hline T23_SP_2R12_200 & $2 F$ & 750 & 075 & 200 & STRONG & 12 & 170 \\
\hline$T 23 \_S P \_2 R 12 \_200$ & $2 F$ & 750 & 075 & 200 & STRONG & 12 & 110 \\
\hline T45_SP_2R17_200 & $4 \mathrm{~F}$ & 750 & 075 & 200 & STRONG & 17 & 250 \\
\hline T45_SP_2R17_200 & $4 A$ & 750 & 075 & 200 & STRONG & 17 & 130 \\
\hline T45_SP_2R17_200 & $5 F$ & 750 & 075 & 200 & STRONG & 17 & 260 \\
\hline T45_SP_2R17_200 & $5 \mathrm{~A}$ & 750 & 075 & 200 & STRONG & 17 & 130 \\
\hline T23_SP_3R17_200 & $2 \mathrm{~F}$ & 500 & 075 & 200 & STRONG & 17 & 250 \\
\hline$T 23 \_S P \_3 R 17 \_200$ & $2 A$ & 500 & 075 & 200 & STRONG & 17 & 160 \\
\hline T23_SP_3R17_200 & $3 F$ & 500 & 075 & 200 & STRONG & 17 & 170 \\
\hline T23_SP_3R17_200 & $3 A$ & 500 & 075 & 200 & STRONG & 17 & 110 \\
\hline
\end{tabular}


Table VIII (5 of 7). Data Base for Side-On Fragment Impact Events (Continued)

For Impacts from 0 to $87.5 \%$ of the Distance from Fragment Center to Fragment Tip (Non-Tip Cases)

\begin{tabular}{|c|c|c|c|c|c|c|c|}
\hline Data Set Name & $\begin{array}{c}\text { Stack } \\
\text { Location/ } \\
\text { FWD-AFT } \\
\text { Location }\end{array}$ & $\begin{array}{c}\text { Distance } \\
\text { From } \\
\text { Fragment } \\
\text { Center } \\
\% \\
\end{array}$ & $\begin{array}{c}\text { Fragment } \\
\text { Thickness } \\
\text { INS } \\
\end{array}$ & $\begin{array}{c}\text { Impact } \\
\text { Velocity } \\
\mathrm{m} / \mathrm{s}\end{array}$ & $\begin{array}{l}\text { Fuel } \\
\text { Type }\end{array}$ & $\begin{array}{c}\begin{array}{c}\text { Rotation } \\
\text { Rate }\end{array} \\
\mathrm{HZ} \\
\end{array}$ & $\begin{array}{c}\text { Distortion } \\
\% \\
\end{array}$ \\
\hline T23_WP_3RD_200 & $2 \mathrm{~F}$ & 50.0 & 0.75 & 200 & WEAK & 0 & 53.0 \\
\hline T23_WP_3RO_200 & $2 A$ & 50.0 & 0.75 & 200 & WEAK & 0 & 27.0 \\
\hline T23_WP_3RO_200 & $3 \mathrm{~F}$ & 50.0 & 0.75 & 200 & WEAK & 0 & 31.0 \\
\hline T23_WP_3R0_200 & $3 A$ & 50.0 & 0.75 & 200 & WEAK & 0 & 23.0 \\
\hline T45_WP_3RO_200 & $4 \mathrm{~F}$ & 50.0 & 0.75 & 200 & WEAK & 0 & 35.0 \\
\hline T45_WP_3RO_200 & $4 A$ & 50.0 & 0.75 & 200 & WEAK & 0 & 17.0 \\
\hline T45_WP_3R0_200 & $5 F$ & 50.0 & 0.75 & 200 & WEAK & 0 & 27.0 \\
\hline T45_WP_3R0_200 & $5 A$ & 50.0 & 0.75 & 200 & WEAK & 0 & 19.0 \\
\hline T23_WP_3R0_255 & $2 F$ & 50.0 & 0.75 & 255 & WEAK & 0 & 50.0 \\
\hline T23_WP_3R0_255 & $2 A$ & 50.0 & 0.75 & 255 & WEAK & 0 & 45.0 \\
\hline T23_WP_3R0_255 & $3 F$ & 50.0 & 0.75 & 255 & WEAK & 0 & 27.0 \\
\hline T23_WP_3RO_255 & $3 A$ & 50.0 & 0.75 & 255 & WEAK & 0 & 28.0 \\
\hline T45_WP_3R0_255 & $4 \mathrm{~F}$ & 50.0 & 0.75 & 255 & WEAK & 0 & 33.0 \\
\hline T45_WP_3RO_255 & $4 A$ & 50.0 & 0.75 & 255 & WEAK & 0 & 33.0 \\
\hline T45_WP_3R0_255 & $5 F$ & 50.0 & 0.75 & 255 & WEAK & 0 & 27.0 \\
\hline T45_WP_3R0_255 & $5 \mathrm{~A}$ & 50.0 & 0.75 & 255 & WEAK & 0 & 25.0 \\
\hline T23_WP_3RO_330 & $2 F$ & 50.0 & 0.75 & 330 & WEAK & 0 & 56.0 \\
\hline T23_WP_3RO_330 & $2 A$ & 50.0 & 0.75 & 330 & WEAK & 0 & 28.0 \\
\hline T23_WP_3RO_330 & $3 F$ & 50.0 & 0.75 & 330 & WEAK & 0 & 25.0 \\
\hline T23_WP_3R0_330 & $3 A$ & 50.0 & 0.75 & 330 & WEAK & 0 & 4.0 \\
\hline T45_WP_3R0_330 & $4 \mathrm{~F}$ & 50.0 & 0.75 & 330 & WEAK & 0 & 35.0 \\
\hline T45_WP_3R0_330 & $4 \mathrm{~A}$ & 50.0 & 0.75 & 330 & WEAK & 0 & 11.0 \\
\hline T45_WP_3R0_330 & $5 F$ & 50.0 & 0.75 & 330 & WEAK & 0 & 26.0 \\
\hline T45_WP_3RO_330 & $5 A$ & 50.0 & 0.75 & 330 & WEAK & 0 & 13.0 \\
\hline T23_WP_4R12__200 & $2 F$ & 87.5 & 0.75 & 200 & WEAK & 12 & 51.0 \\
\hline T23_WP_4R12_200 & $2 A$ & 87.5 & 0.75 & 200 & WEAK & 12 & 35.0 \\
\hline T23_WP_4R12_200 & $3 F$ & 87.5 & 0.75 & 200 & WEAK & 12 & 22.0 \\
\hline T23_WP_4R12_200 & $3 A$ & 87.5 & 0.75 & 200 & WEAK & 12 & 13.0 \\
\hline T23_WP_4R17_200 & $2 \mathrm{~F}$ & 87.5 & 0.75 & 200 & WEAK & 17 & 51.0 \\
\hline T23_WP_4R17_200 & $2 \mathrm{~A}$ & 87.5 & 0.75 & 200 & WEAK & 17 & 15.0 \\
\hline T23_WP_4R17__200 & $3 F$ & 87.5 & 0.75 & 200 & WEAK & 17 & 27.0 \\
\hline T23_WP_4R17_200 & $3 A$ & 87.5 & 0.75 & 200 & WEAK & 17 & 00.0 \\
\hline T45_WP_4R17_200 & $4 \mathrm{~F}$ & 87.5 & 0.75 & 200 & WEAK & 17 & 37.0 \\
\hline T45_WP_4R17_200 & $4 A$ & 87.5 & 0.75 & 200 & WEAK & 17 & 13.0 \\
\hline T45_WP_4R17_200 & $5 F$ & 87.5 & 0.75 & 200 & WEAK & 17 & 38.0 \\
\hline T45_WP_4R17_200 & $5 A$ & 87.5 & 0.75 & 200 & WEAK & 17 & 11.0 \\
\hline T45_WP_2R17_200 & $4 \mathrm{~F}$ & 75.0 & 0.75 & 200 & WEAK & 17 & 36.0 \\
\hline T45_WP_2R17_200 & $4 \mathrm{~A}$ & 75.0 & 0.75 & 200 & WEAK & 17 & 13.0 \\
\hline T45_WP_2R17_200 & $5 F$ & 75.0 & 0.75 & 200 & WEAK & 17 & 33.0 \\
\hline T45_WP_2R17_200 & $5 A$ & 75.0 & 0.75 & 200 & WEAK & 17 & 20.0 \\
\hline
\end{tabular}


Table VIII (6 of 7). Data Base for Side-On Fragment Impact Events (Continued)

For Impacts from 0 to $87.5 \%$ of the Distance from Fragment Center

to Fragment Tip (Non-Tip Cases)

\begin{tabular}{|c|c|c|c|c|c|c|c|}
\hline Data Set Name & $\begin{array}{l}\text { Stack } \\
\text { Location/ } \\
\text { FWD-AFT } \\
\text { Location }\end{array}$ & $\begin{array}{c}\text { Distance } \\
\text { From } \\
\text { Fragment } \\
\text { Center } \\
\% \\
\end{array}$ & $\begin{array}{c}\text { Fragment } \\
\text { Thickness } \\
\text { INS }\end{array}$ & $\begin{array}{c}\text { Impact } \\
\text { Velocity } \\
\mathrm{m} / \mathrm{s}\end{array}$ & $\begin{array}{l}\text { Fuel } \\
\text { Type }\end{array}$ & $\begin{array}{c}\begin{array}{c}\text { Rotation } \\
\text { Rate }\end{array} \\
\mathrm{HZ} \\
\end{array}$ & $\begin{array}{c}\text { Distortion } \\
\% \\
\end{array}$ \\
\hline T23_WP_R17__200 & $2 F$ & 0.00 & 0.75 & 200 & WEAK & 17 & 51.0 \\
\hline T23_WP_R17_200 & $2 A$ & 0.00 & 0.75 & 200 & WEAK & 17 & 27.0 \\
\hline T23_WP_R17_200 & $3 F$ & 0.00 & 0.75 & 200 & WEAK & 17 & 27.0 \\
\hline T23_WP_R17_200 & $3 A$ & 0.00 & 0.75 & 200 & WEAK & 17 & 21.0 \\
\hline T23_WP_R17_100 & $2 F$ & 0.00 & 0.75 & 100 & WEAK & 17 & 9.0 \\
\hline T23_WP_R17_100 & $2 A$ & 0.00 & 0.75 & 100 & WEAK & 17 & 3.0 \\
\hline T23_WP_R17_100 & $3 F$ & 0.00 & 0.75 & 100 & WEAK & 17 & 8.0 \\
\hline$T 23 \_W P \_R 17 \_100$ & $3 A$ & 0.00 & 0.75 & 100 & WEAK & 17 & 2.0 \\
\hline \multicolumn{8}{|c|}{$\begin{array}{c}\text { For Impacts from } 87.5 \%-100 \% \text { of the Distance from Fragment Center } \\
\text { to Fragment Tip (Tip Cases) }\end{array}$} \\
\hline $\mathrm{R} 07$ _PU $2 \mathrm{H} 6 \mathrm{H}-100$ & $2 F$ & 100.0 & 0.5 & 100 & WEAK & 7 & 16.3 \\
\hline R07__PU2H6H__100 & $2 A$ & 100.0 & 0.5 & 100 & WEAK & 7 & 9.4 \\
\hline R07_PU2H6H_100 & $3 F$ & 100.0 & 0.5 & 100 & WEAK & 7 & 20.0 \\
\hline R07_PU2H6H_100 & $3 A$ & 100.0 & 0.5 & 100 & WEAK & 7 & 6.3 \\
\hline R12_PU2H6H_100 & $2 F$ & 100.0 & 0.5 & 100 & WEAK & 12 & 22.0 \\
\hline R12_PU2H6H__100 & $2 A$ & 100.0 & 0.5 & 100 & WEAK & 12 & 12.7 \\
\hline R12_PU2H6H_100 & $3 F$ & 100.0 & 0.5 & 100 & WEAK & 12 & 37.8 \\
\hline R12_PU2H6H_L 100 & $3 A$ & 100.0 & 0.5 & 100 & WEAK & 12 & 16.0 \\
\hline $\mathrm{R} 17 \_\mathrm{PU} 2 \mathrm{H} 6 \mathrm{H} \_100$ & $2 F$ & 100.0 & 0.5 & 100 & WEAK & 17 & 42.6 \\
\hline R17_PU2H6H_100 & $2 A$ & 100.0 & 0.5 & 100 & WEAK & 17 & 13.9 \\
\hline R17__PU2H6H_100 & $3 F$ & 100.0 & 0.5 & 100 & WEAK & 17 & 41.1 \\
\hline $\mathrm{R} 17 \_\mathrm{PU} 2 \mathrm{H} 6 \mathrm{H} \_100$ & $3 A$ & 100.0 & 0.5 & 100 & WEAK & 17 & 23.3 \\
\hline R07_PU2H6H_200 & $2 F$ & 100.0 & 0.5 & 200 & WEAK & 7 & 43.5 \\
\hline R07_PU2H6H_200 & $2 A$ & 100.0 & 0.5 & 200 & WEAK & 7 & 12.9 \\
\hline R07__PU2H6H_2OO & $3 F$ & 100.0 & 0.5 & 200 & WEAK & 7 & 40.6 \\
\hline $\mathrm{RO} 7 \_\mathrm{PU} 2 \mathrm{H} 6 \mathrm{H} \_200$ & $3 A$ & 100.0 & 0.5 & 200 & WEAK & 7 & 20.6 \\
\hline R12_PU2H6H_200 & $2 F$ & 100.0 & 0.5 & 200 & WEAK & 12 & 52.5 \\
\hline R12_PU2H6H_200 & $2 A$ & 100.0 & 0.5 & 200 & WEAK & 12 & 12.5 \\
\hline R12_PU2H6H_200 & $3 F$ & 100.0 & 0.5 & 200 & WEAK & 12 & 38.4 \\
\hline $\mathrm{R} 12$ PU2H6H_200 & $3 A$ & 100.0 & 0.5 & 200 & WEAK & 12 & 20.1 \\
\hline R17_PU2H6H_200 & $2 F$ & 100.0 & 0.5 & 200 & WEAK & 17 & 56.0 \\
\hline $\mathrm{R} 17 \_\mathrm{PU} 2 \mathrm{H} 6 \mathrm{H} \_200$ & $2 A$ & 100.0 & 0.5 & 200 & WEAK & 17 & 10.6 \\
\hline R17_PU2H6H_200 & $3 F$ & 100.0 & 0.5 & 200 & WEAK & 17 & 38.8 \\
\hline R17_PU2H6H_200 & $3 A$ & 100.0 & 0.5 & 200 & WEAK & 17 & 21.8 \\
\hline 45_WP_R17_200 & $4 F$ & 100.0 & 0.5 & 200 & WEAK & 17 & 50.0 \\
\hline 45_WP_R17_200 & $4 A$ & 100.0 & 0.5 & 200 & WEAK & 17 & 33.0 \\
\hline 45_WP_R17_200 & $5 F$ & 100.0 & 0.5 & 200 & WEAK & 17 & 32.0 \\
\hline 45_WP_R17_200 & $5 A$ & 100.0 & 0.5 & 200 & WEAK & 17 & 18.0 \\
\hline 45_l $\quad R \_150$ & $4 F$ & 100.0 & 0.5 & 150 & WEAK & 0 & 16.1 \\
\hline 45_Wr_R_-150 & $4 A$ & 100.0 & 0.5 & 150 & WEAK & 0 & 6.2 \\
\hline 45_WP_R_150 & $5 F$ & 100.0 & 0.5 & 150 & WEAK & 0 & 12.9 \\
\hline 45_WP_R_150 & $5 A$ & 100.0 & 0.5 & 150 & WEAK & 0 & 7.7 \\
\hline
\end{tabular}


Table VIII (7 of 7). Data Base for Side-On Fragment Impact Events (Continued)

For Impacts from $87.5 \%-100 \%$ of the Distance from Fragment Center to Fragment Tip (Tip Cases)

\begin{tabular}{|c|c|c|c|c|c|c|c|}
\hline Data Set Name & $\begin{array}{l}\text { Stack } \\
\text { Location/ } \\
\text { FWD-AFT } \\
\text { Location }\end{array}$ & $\begin{array}{c}\text { Distance } \\
\text { From } \\
\text { Fragment } \\
\text { Center } \\
\%\end{array}$ & $\begin{array}{c}\text { Fragment } \\
\text { Thickness } \\
\text { INS }\end{array}$ & $\begin{array}{c}\text { Impact } \\
\text { Velocity } \\
\mathrm{m} / \mathrm{s}\end{array}$ & $\begin{array}{l}\text { Fuel } \\
\text { Type }\end{array}$ & $\begin{array}{c}\begin{array}{c}\text { Rotation } \\
\text { Rate }\end{array} \\
\mathrm{HZ}\end{array}$ & $\begin{array}{c}\text { Distortion } \\
\qquad \\
\%\end{array}$ \\
\hline 45_WP_R_250 & $4 F$ & 1000 & 05 & 250 & WEAK & 0 & 442 \\
\hline 45_WP_R_250 & $4 A$ & 1000 & 05 & 250 & WEAK & 0 & 200 \\
\hline 45_WP_R_250 & $5 F$ & 1000 & 05 & 250 & WEAK & 0 & 273 \\
\hline 45_WP_R_250 & $5 \mathrm{~A}$ & 1000 & 05 & 250 & WEAK & 0 & 161 \\
\hline 45_WP_R_300 & $4 F$ & 1000 & 05 & 300 & WEAK & 0 & 442 \\
\hline 45_WP_R_300 & $4 \mathrm{~A}$ & 1000 & 05 & 300 & WEAK & 0 & 304 \\
\hline 45_WP_R__300 & $5 F$ & 1000 & 05 & 300 & WEAK & 0 & 218 \\
\hline 45_WP_R_300 & $5 A$ & 1000 & 05 & 300 & WEAK & 0 & 217 \\
\hline 45_WP_R_350 & $4 F$ & 1000 & 05 & 350 & WEAK & 0 & 442 \\
\hline 45_WP_R_350 & $4 A$ & 1000 & 05 & 350 & WEAK & 0 & 316 \\
\hline 45_WP_R_350 & $5 F$ & 1000 & 05 & 350 & WEAK & 0 & 346 \\
\hline 45_WP_R_350 & $5 A$ & 1000 & 05 & 350 & WEAK & 0 & 183 \\
\hline T23_WP_R17__200 & $2 F$ & 1000 & 075 & 200 & WEAK & 17 & 870 \\
\hline$T 23 \_W P \_R 17 \_200$ & $2 A$ & 1000 & 075 & 200 & WEAK & 17 & 170 \\
\hline T23_WP_R17_200 & $3 F$ & 1000 & 075 & 200 & WEAK & 17 & 460 \\
\hline T23_WP_R17_200 & $3 A$ & 1000 & 075 & 200 & WEAK & 17 & 000 \\
\hline T45_WP_R17_200 & $4 F$ & 1000 & 075 & 200 & WEAK & 17 & 470 \\
\hline T45_WP_R17__200 & $4 \mathrm{~A}$ & 1000 & 075 & 200 & WEAK & 17 & 110 \\
\hline T45_WP_R17_200 & $5 F$ & 1000 & 075 & 200 & WEAK & 17 & 380 \\
\hline T45_WP_R17_200 & $5 A$ & 1000 & 075 & 200 & WEAK & 17 & 000 \\
\hline T23_WP_R17_ 100 & $2 F$ & 1000 & 075 & 100 & WEAK & 17 & 570 \\
\hline T23_WP_R17__100 & $2 A$ & 1000 & 075 & 100 & WEAK & 17 & 150 \\
\hline T23_WP_R17_100 & $3 F$ & 1000 & 075 & 100 & WEAK & 17 & 290 \\
\hline T23_WP_R17_100 & $3 A$ & 1000 & 075 & 100 & WEAK & 17 & 180 \\
\hline T23_WP_R_100 & $2 F$ & 1000 & 075 & 100 & WEAK & 0 & 77 \\
\hline T23_WP_R_100 & $2 \mathrm{~A}$ & 1000 & 075 & 100 & WEAK & 0 & 22 \\
\hline T23_WP_R_ 100 & $3 F$ & 1000 & 075 & 100 & WEAK & 0 & 77 \\
\hline$T 23 \_W P \_R \_100$ & $3 A$ & 1000 & 075 & 100 & WEAK & 0 & 22 \\
\hline T23_WP_R_150 & $2 F$ & 1000 & 075 & 150 & WEAK & 0 & 217 \\
\hline T23, WP_R_150 & $2 A$ & 1000 & 075 & 150 & WEAK & 0 & 77 \\
\hline T23_WP_R_150 & $3 F$ & 1000 & 075 & 150 & WEAK & 0 & 227 \\
\hline$T 23 \_W P \_R_{-} 150$ & $3 A$ & 1000 & 075 & 150 & WEAK & 0 & 94 \\
\hline T23_SP_R07_200 & $2 F$ & 1000 & 005 & 200 & STRONG & 7 & 150 \\
\hline T23_SP_R07_200 & $2 A$ & 1000 & 005 & 200 & STRONG & 7 & 30 \\
\hline T23_SP_R07_200 & $3 F$ & 1000 & 005 & 200 & STRONG & 7 & 210 \\
\hline T23_SP_R07__200 & $3 A$ & 1000 & 005 & 200 & STRONG & 7 & 80 \\
\hline T23_SP_R17__200 & $2 F$ & 1000 & 075 & 200 & STRONG & 17 & 920 \\
\hline T23_SP_R17_200 & $2 A$ & 1000 & 075 & 200 & STRONG & 17 & 30 \\
\hline T23_SP_R17_200 & $3 F$ & 1000 & 075 & 200 & STRONG & 17 & 270 \\
\hline T23_SP_R17_200 & $3 A$ & 1000 & 075 & 200 & STRONG & 17 & 000 \\
\hline$T 45 \_S P \_R 17 \_200$ & $4 F$ & 1000 & 075 & 200 & STRONG & 17 & 300 \\
\hline T45_SP_R17__200 & $4 A$ & 1000 & 075 & 200 & STRONG & 17 & 90 \\
\hline T45_SP_R17_200 & $5 F$ & 1000 & 075 & 200 & STRONG & 17 & 270 \\
\hline$T 45 \quad S P=R 17=200$ & $5 A$ & 1000 & 075 & 200 & STRONG & 17 & 20 \\
\hline
\end{tabular}


fragment rotation rate, translational velocity, and stack position and fragment impact location. Much of the following description was taken from A. Mowery's memo on the treatment of that data base. It should be noted that this data base was generated on quadrant sized fragments and that the calculation set contained equivalent fragment translational velocity variations ranging from 100 to $350 \mathrm{~m} / \mathrm{s}$. Rotation rates of $0,7,12$, and $17 \mathrm{~Hz}$ were investigated prior to determining that fueled clad distortion resulting from impacts over the majority of the fragment was a function only of point velocity. Six impact points on the fragment were considered. These were $0,25,50,75,87.5$ and 100 percent of the fragment radius. Fragment impacts at 100 percent of fragment radius were called tip impacts. In this case, the tip of the fragment was aligned with the centeriine of the module in the number two stack position. The other variable used in the calculational set was the module position. Results were calculated for the $2,3,4$ and 5 module positions. The position 1 module was not calculated directly and was always used as a concentrated mass simulant because of difficulty in modeling the heat source support system. It was assumed that module position 2 will produce distortion equivalent of position 1. Figure 35 shows a plot of the data base for the 2 and 3 positions in the stack. These results are typical of the cases studied. The equation shown below was used to fit the results shown in Table VIII, and is shown graphically as the nominal curve in Figure 35.

$$
D(p, v, f / a)=D m\left[1-\exp \left(-a\left(\frac{v-v o}{100}\right)^{n}\right)\right]
$$

Where $D$ is the clad distortion as a function of module position.

$p$, point fragment velocity, $v$, and forward or aft clad, f/a.

$\mathrm{Dm}$ is the maximum clad distortion over the velocity range.

$v$ is the point fragment velocity.

$v_{0}$ is the velocity offset below which there is no clad damage.

$a$ and $n$ are fit constants. 


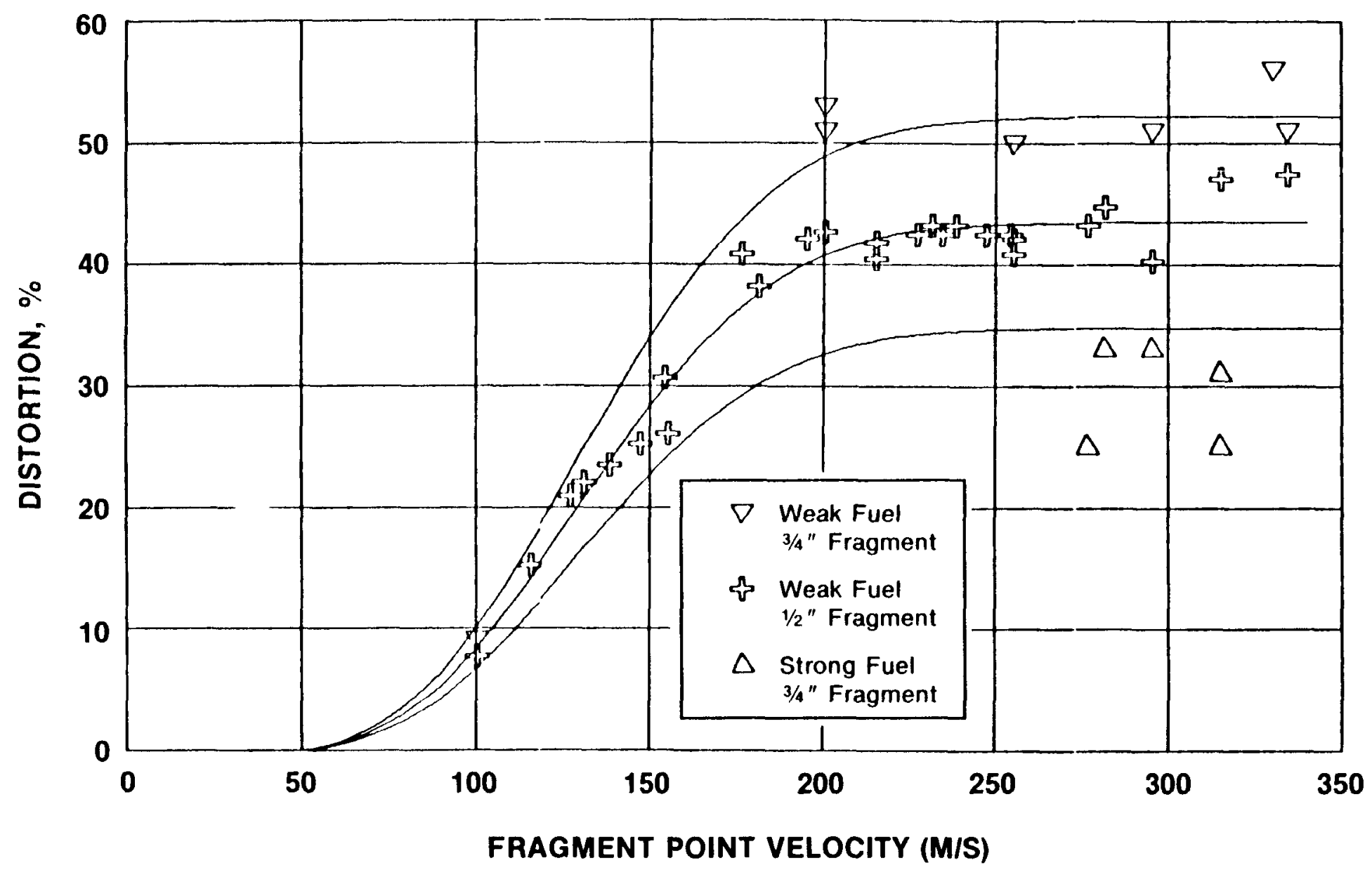

Figure 35. Position 2 and 3 Fueled Clad Distortion as a Function of Fragment Thickness, Velocity and Plutonia Mechanical Properties 
Fit parameters were generated for each module position assuming that position 1 was equivalent to position 2 . Fore and aft clads were also treated. Separate fits were developed for non-tip and tip fragment impacts. Impact at the fragment tip was assumed to be any impact between 0.875 and 1.00 of the fragment length. Each quadrant sized fragment has a radius of $4.7 \mathrm{ft}$, the fragment tip is therefore, about 6 inches wide. A least squares fit of the hydrocode results was prepared by $R$. Vaughn of NUS. These fits are shown in Table IX for non-tip impact cases and in Table $X$ for tip impact cases. The sigma shown in the tables is a measure of the accuracy of the fit to the hydrocode results. It is not an indication of the overall uncertainty of one sigma. Note that grouping of the hydrocode results was required because functional relations were not generated for every module position. Groupings were therefore required to provide missing velocity dependent functions. The following is a description of the manner in which the hydrocode results were fit to functional relations.

Non-Tip/Fwd Clads - Functional form was selected from the 2 nd position results and the $\mathrm{Dm}$ taken as the average of the values above $200 \mathrm{~m} / \mathrm{s}$. Reason: A functional relation was not available for position 4 and 5 and 2 provided an adequate fit for 3 .

Non-Tip/Aft Clads - Functional form selected from 3 rd position results and treated as above for similar reasons.

Tip-Forward Clads - Second position distortions were unique so the least squares fit was used directly. Position 4 was the best available curve fit so that functional form was used for 3 and 5 with best estimates of Dm.

Tip-Aft clads - Adequate results were available for a reasonable least squares fit so the NUS fit parameters are listed. 
Table IX. Summary of Parameters Used in Equation (1) for Non-Tip Cases Impact with Fragment Inner Surface ( 0 to $87.5 \%$ of Radius)

\begin{tabular}{|l|cccc|cccc|}
\hline $\begin{array}{l}\text { Stacked } \\
\text { Position }\end{array}$ & \multicolumn{3}{|c|}{ Forward Clad } & \multicolumn{4}{c|}{ Aft Clad } \\
\hline \multirow{2}{*}{ p1 $=p 2$} & Dm & $-\mathbf{a}$ & $\mathbf{n}$ & Sigma & Dm & $-\mathbf{a}$ & $\mathbf{n}$ & Sigma \\
p3 & 43.5 & 1.08 & 2.40 & 2.0 & 27.5 & 0.46 & 2.04 \\
p4 & 27.1 & 1.08 & 2.40 & & 21.3 & 0.46 & 2.04 \\
p5 & 34.0 & 1.08 & 2.40 & & 29.0 & 0.46 & 2.04 \\
& 26.2 & 1.08 & 2.44 & & 25.0 & 0.46 & 2.04 \\
\hline
\end{tabular}


Table X. Summary of Parameters Used in Equation (1) for Tip Cases Impact with Fragment Tip (87.5\% to $100 \%$ of Radius)

\begin{tabular}{|l|cccc|cccc|}
\hline $\begin{array}{l}\text { Stacked } \\
\text { Position }\end{array}$ & \multicolumn{3}{|c|}{ Forward Clad } & \multicolumn{5}{c|}{ Aft Clad } \\
\hline \multirow{2}{*}{$p 1=p 2$} & $\mathrm{Dm}$ & $-\mathbf{a}$ & $\mathrm{n}$ & Sigma & $\mathrm{Dm}$ & $-\mathbf{a}$ & $\mathrm{n}$ & Sigma \\
$\mathrm{p3}$ & 58.3 & 0.43 & 2.76 & & 12.5 & 0.90 & 3.76 & 1.1 \\
$\mathrm{p4}$ & 39.4 & 0.43 & 2.76 & & 21.4 & 0.21 & 4.29 & 1.2 \\
$\mathrm{p5}$ & 47.0 & 0.43 & 2.76 & 2.3 & 34.7 & 0.17 & 2.53 & 1.4 \\
& 32.0 & 0.43 & 2.76 & & 19.1 & 0.50 & 2.23 & 1.7 \\
\hline
\end{tabular}


It was noted that further simplification of the clad distortion relations for non-tip impacts could be realized without significant loss of accuracy. If forward clads in positions 3,4 , and 5 were combined, the range of results would be covered by the 10 percent one sigma uncertainty in the calculations. The aft clad deformations could be adequately described by a single equation with an average $\mathrm{Dm}$ and the functional parameters listed in Table $x$. A similar treatment could be applied to the forward clad fragment tip impact by combining positions 3, 4 and 5 with an average om using the functional parameters in Table $x$. For aft clads, a single set of average parameters would adequately describe the hydrocode results.

The FGT-4 and LFT-2 results indicate that the plateaus observed in the predicted distortions at higher velocities (Figure 35 ) are real. It is speculated that these plateaus are caused by the movement of the forward part of the aeroshell into the space previously occupied by the CBCF insulation. The effect of this is to fill the volume into which the fueled clads can expand. This limits the maximum diametrial growth of the fueled clads. This hypothesis was tested against the experimental results. In the LFT-2 tests it was noted that at the higher velocities $(212 \mathrm{~m} / \mathrm{s})$ the diameter of the fueled clads did not increase proportionally. In some cases this diameter was not greatly different than the original diameter (in one case it was less than the original diameter), while the fueled clads height and length were observed to change significantly. A summary of the LFT results (this test used urania fueled clads) was presented in Table VI for reference. It is seen that the fueled clad height and length changes are significantly different in the 100 and $200 \mathrm{~m} / \mathrm{s}$ cases; however. the diameters, as a result of the hydrostat produce by the adjunct modules, are nearly equal. Further it is observed that the post impact shape of these clads is different from that noted in the SVT and FGT tests. The exact cause of this difference is speculative; however, it should be noted that the hydrocode predicted diameter behavior correlated very well with the behavior observed in the SVT, FGT and LFT events. Comparison of the postimpact geometries shown in Figures 27 and 28 with the observations presented previously in Table $V I$ is instructive in this regard. 


\section{Edge-On Impacts by SRM Fragments}

It was shown in Section II. C. that peak distortion occurred at a 10 degree angle of attack for edge-on impacts. A number of urania and plutonia edge-on impact calculations were performed to calibrate the model against the edge-on test results. The configuration used for this calculation is shown in Figure 36. The analytical model which was used is really only valid for Ulysses geometry impacts. The Galileo impact geometry (the geometry which was tested) requires that the centerline of the SRM and the centerline of the RTG be parallel. This will produce an edge-on impact such that the edge of the fragment is coincident with all 18 forward fueled clads on one side of the RTG. In the configuration modeled, the edge of the SRM fragment hits only two fueled clads in the leading GIS. This produces a significantly different impact orientation than would occur in the test. Several attempts were made to make the available model more applicable to the Galileo geometry. The most appropriate was to set to zero the $y$-velocity of the upper and lower surfaces of the module being impacted. Calculations performed in this manner still do not account for the transverse displacement of the face of the aeroshell as would occur in the Galileo geometry impact. As a result, it is expected that the predicted distortions will be significantly greater than those observed in the LFT-5. Models which had the proper geometry for the Galileo could be configured but were not undertaken at this time because of the uncertainty of the fragment orientation which will actually occur given the results of the wing and the fuselage transit tests. The results of the edge-on impact distortion predictions are summarized in Table XI. Detailed post-impact geometries for plutonia fueled clads are shown in Figure 37 for initial velocities of 100 and $200 \mathrm{~m} / \mathrm{s}$ respectively.

It should be noted that significant releases are predicted from edge-on impacts; however, the probability that impacts will occur in this exact orientation is extremely low. In addition, the calculations show that. based on distortion/release criteria developed by others, most release will be confined to the forward fueled clads and that the aft fueled clads will be contiguous for the purposes of defining a source term. If fragments 


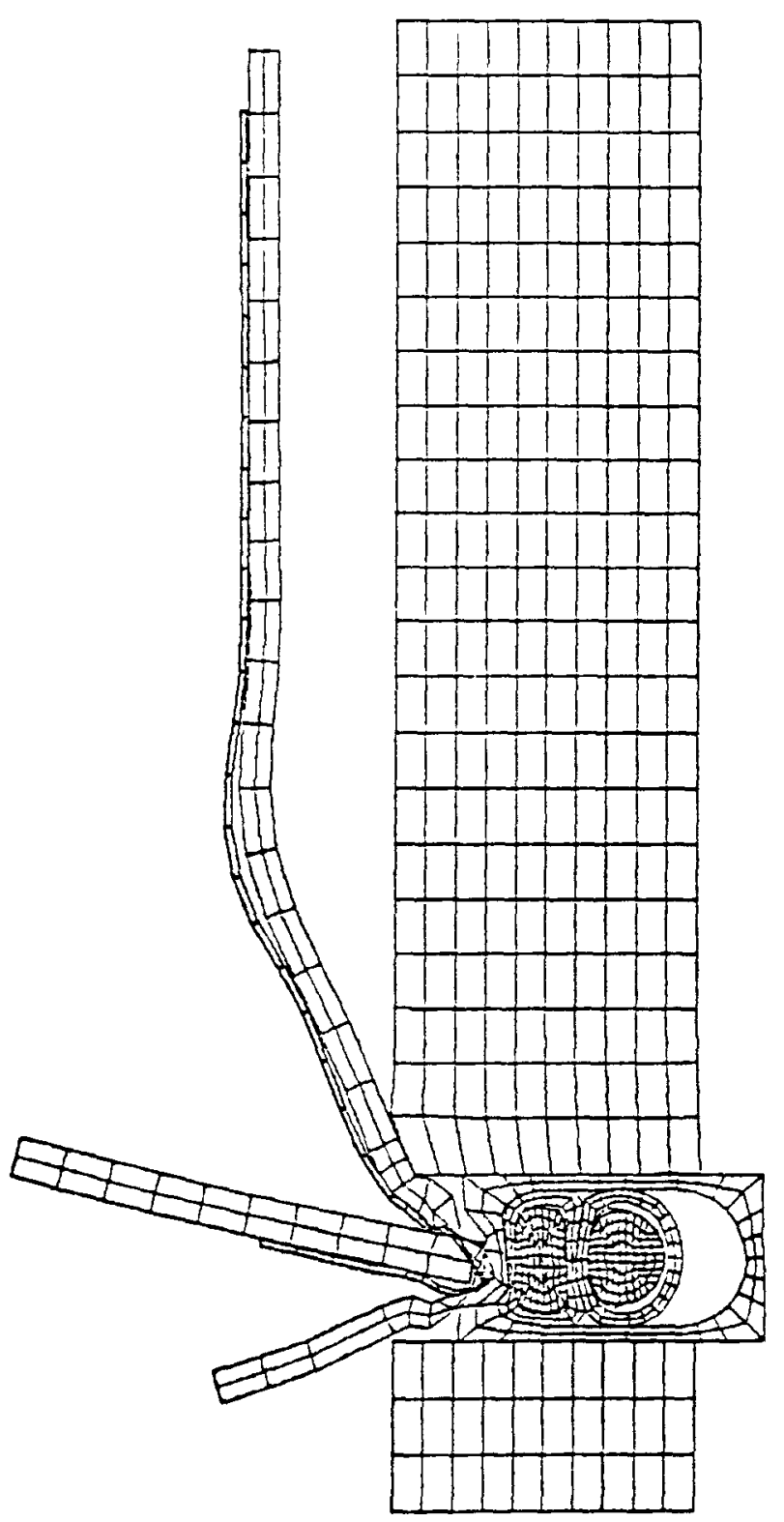

Figure 36. Geometry Resulting from the Edge-On Impact at $100 \mathrm{~m} / \mathrm{s}$ of a Quadrant Sized SRM Fragment on a GPHS RTG in a Ulysses Configuration 
Table XI. Effect of Boundary Constraints, Fuel Type, and Velocity on the Fueled Clad Distortion Resulting from SRB Edge-On Impacts on the Ulysses RTG

\begin{tabular}{|l|l|c|c|c|}
\hline Fuel Type & \multicolumn{1}{|c|}{$\begin{array}{c}\text { Boundary } \\
\text { Constraint }\end{array}$} & $\begin{array}{c}\text { Fragment } \\
\text { Velocity } \\
\text { m/s }\end{array}$ & $\begin{array}{c}\text { Fwd Clad } \\
\text { Distortion } \\
\%\end{array}$ & $\begin{array}{c}\text { Aft Clad } \\
\text { Distortion } \\
\%\end{array}$ \\
\hline PU2H6H & NONE & 100 & 121 & 14 \\
PU2H6H & YVEL(Zero) & 100 & 100 & 21 \\
U6H11H(1) & YVEL(Zero) & 100 & 64 & 5 \\
PU2H6H & YVEL(Zero) & 200 & 305 & 64 \\
\hline
\end{tabular}

(1) Urania simulant case run for test. Predictions for this case included for reference (See Table VII for test results). 


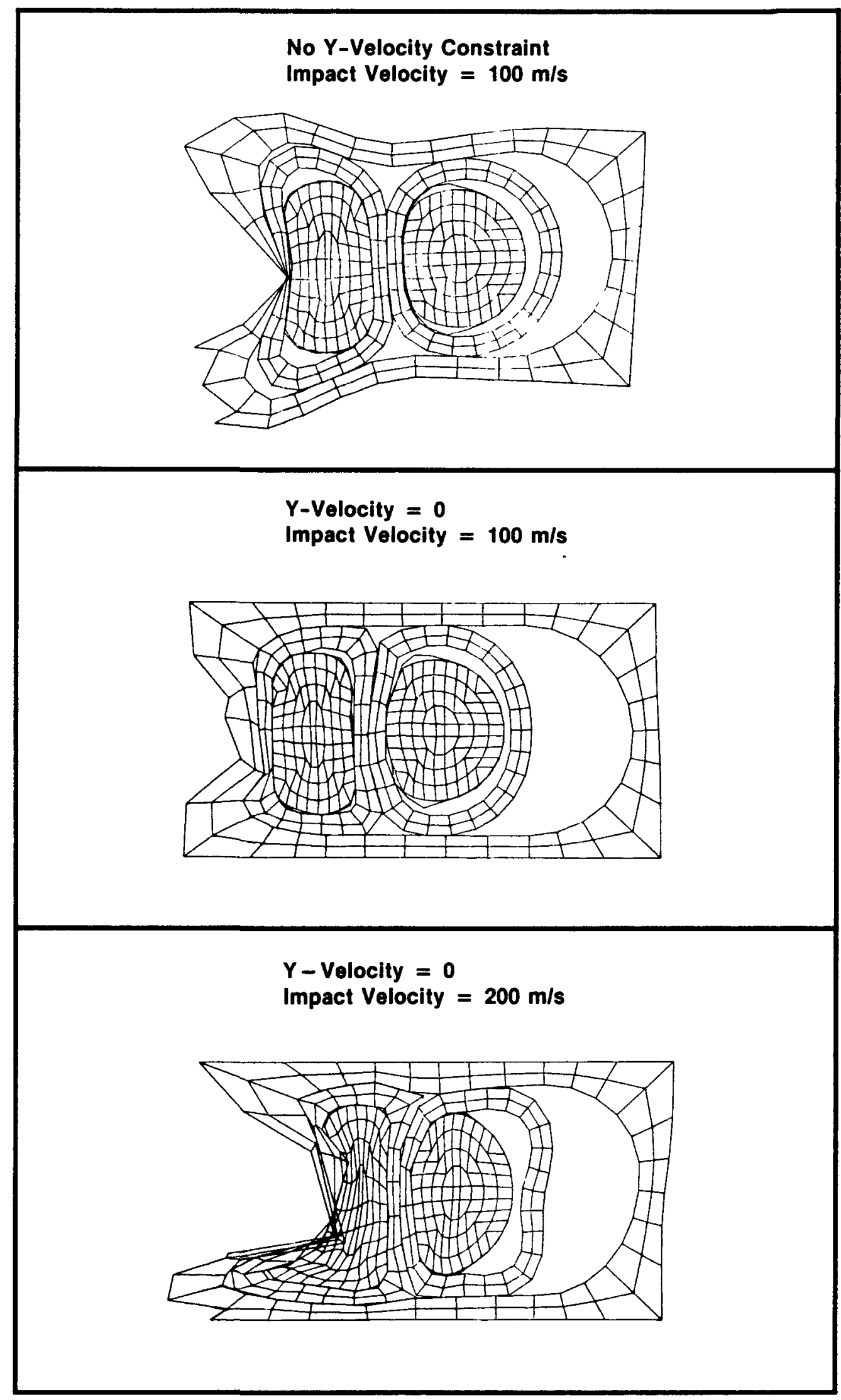

Figure 37. Effects of Boundary Constraint and Velocity on the Fueled Clad Post-Impact Geometry Resulting from the Edge.On Impact of an SRM Fragment on a Ulyeses RTG 
impact the module in the calculated orientation at velocities of more than $200 \mathrm{~m} / \mathrm{s}$, some release from the aft fueled clads may occur based on the predicted distortions. However, fragment velocities of this magnitude occur only at late MET and the consequences of these releases may not be great.

\section{RTG - Bay Door Impacts}

Calculations were performed to predict the results of intact RTG impacts on the STS-Bay Doors at $365 \mathrm{~m} / \mathrm{s}$. The results of these calculations are presented in Table XII. Typical post impact geometry is shown in Figure 38 .

\section{Bare Module - Bay Door Impacts}

Calculations were performed to predict the results of various velocity impacts of individual modules on the STS-Bay Doors. These impacts would occur in those cases in which the modules were ejected from the RTG within the Bay (explosive disassembly of the RTG). This action was modeled as an acceleration of the modules and subsequent impact on simulated STS-Bay Doors having two assumed areal densities. The results of these calculations are presented in Table XIII. Typical post-impact geometry is presented in Figure 39.

\section{Bare Fueled Clad - Bay Door Impacts}

Calculations were performed to predict the results of various velocity impacts of bare fueled clads on STS-Bay Doors having two areal densities. This event results from the case in which the graphite was stripped from the fueled clads by an explosion which did not disassemble the STS-Bay. This scenario is considered unrealistic in that the RTG housing and aeroshell are considerably more robust than the bay doors. The calculations were performed, however, and the results of these calculations are presented in Table XIV. Typical post-impact geometries are presented in Figure 40. 
Table XII. Fueled Clad Distortion Resulting from the Impact of an Intact Galileo RTG on the STS-Bay Doors(1) at 365 M/S

\begin{tabular}{|c|c|c|}
\hline $\begin{array}{c}\text { Stacked } \\
\text { Position }\end{array}$ & \multicolumn{2}{|c|}{ Distortion } \\
\hline & Forward Clad & Aft Clad \\
& $\%$ & $\%$ \\
2 & 9.3 & 0.0 \\
3 & 6.1 & 0.0 \\
4 & 6.2 & 0.0 \\
5 & 7.1 & 0.0 \\
\hline
\end{tabular}

(1)Areal Density $=3.46 \mathrm{lb} / \mathrm{ft}^{2}$ 


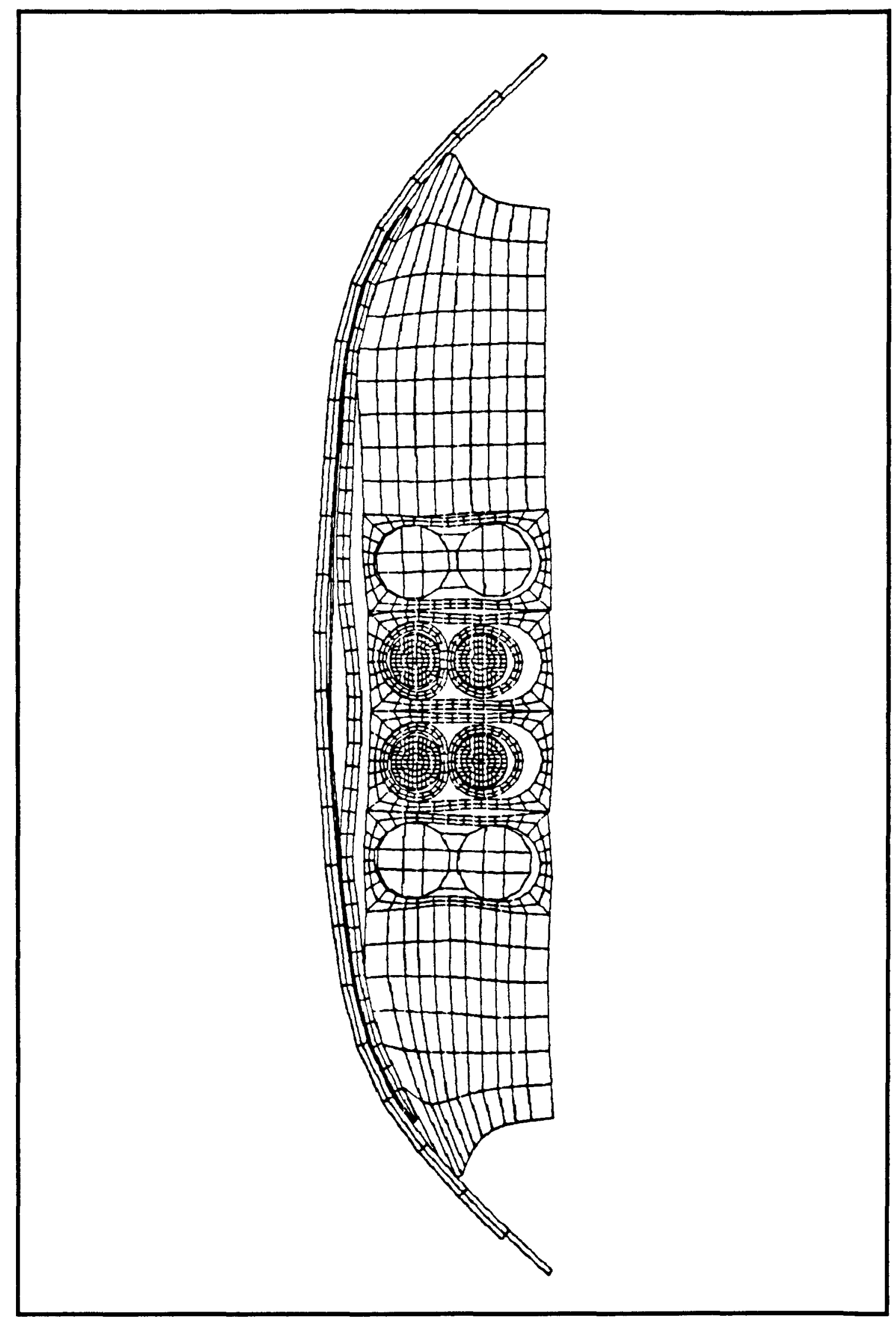

Figure 38. Post-Impact Geometry of the Galileo RTG After Impact on the STS-Bay Doors at $365 \mathrm{~m} / \mathrm{s}$ 
Table XIII. Fueled Clad Distortion Resulting from Bare Module STS-Bay Door(1) Impacts

\begin{tabular}{|ccc|}
\hline $\begin{array}{c}\text { Impact } \\
\text { Velocity } \\
\text { m/s }\end{array}$ & $\begin{array}{c}\text { Fwd Clad } \\
\text { Distortion } \\
\%\end{array}$ & $\begin{array}{c}\text { Aft Clad } \\
\text { Distortion } \\
\%\end{array}$ \\
335 & 37.5 & 10 \\
365 & 65.0 & 10 \\
\hline
\end{tabular}

(1) Areal Density $=3.46 \mathrm{lb} / \mathrm{ft}^{2}$ 


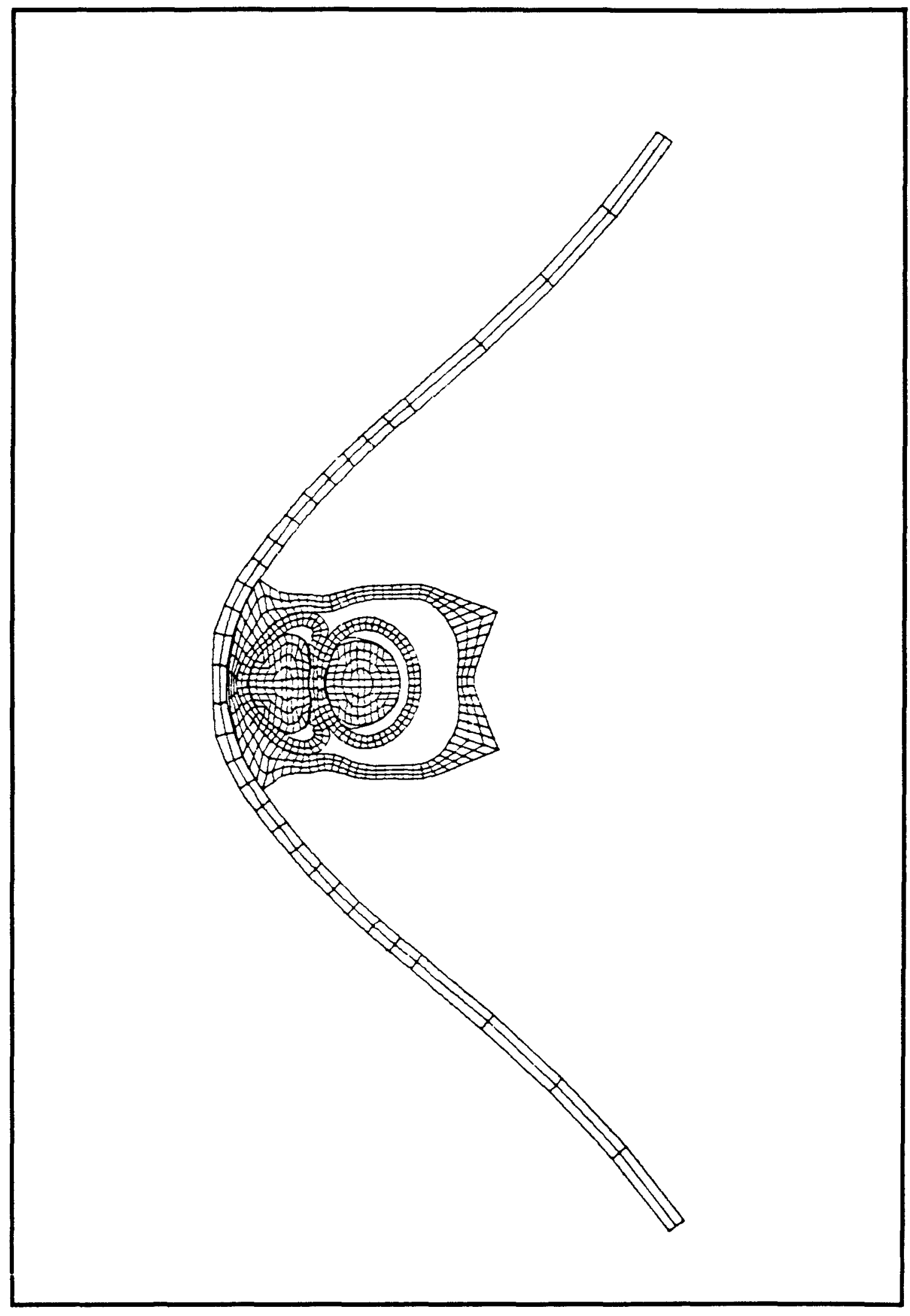

Figure 39. Post-Impact Geometry of a GPHS Module After Impact on the STS-Bay Doors at $335 \mathrm{~m} / \mathrm{s}$ 
Table XIV. Fueled Clad Distortion Resulting from a Bare Clad Impact on the STS-Bay Door ${ }^{(1)}$ at Two Velocities

\begin{tabular}{|cc|}
\hline $\begin{array}{c}\text { Impact Velocity } \\
\mathrm{m} / \mathrm{s}\end{array}$ & $\begin{array}{c}\text { Clad Distortion } \\
\%\end{array}$ \\
335 & 43 \\
365 & 55 \\
\hline
\end{tabular}

(1) Areal Density $=3.46 \mathrm{lb} / \mathrm{ft}^{2}$ 


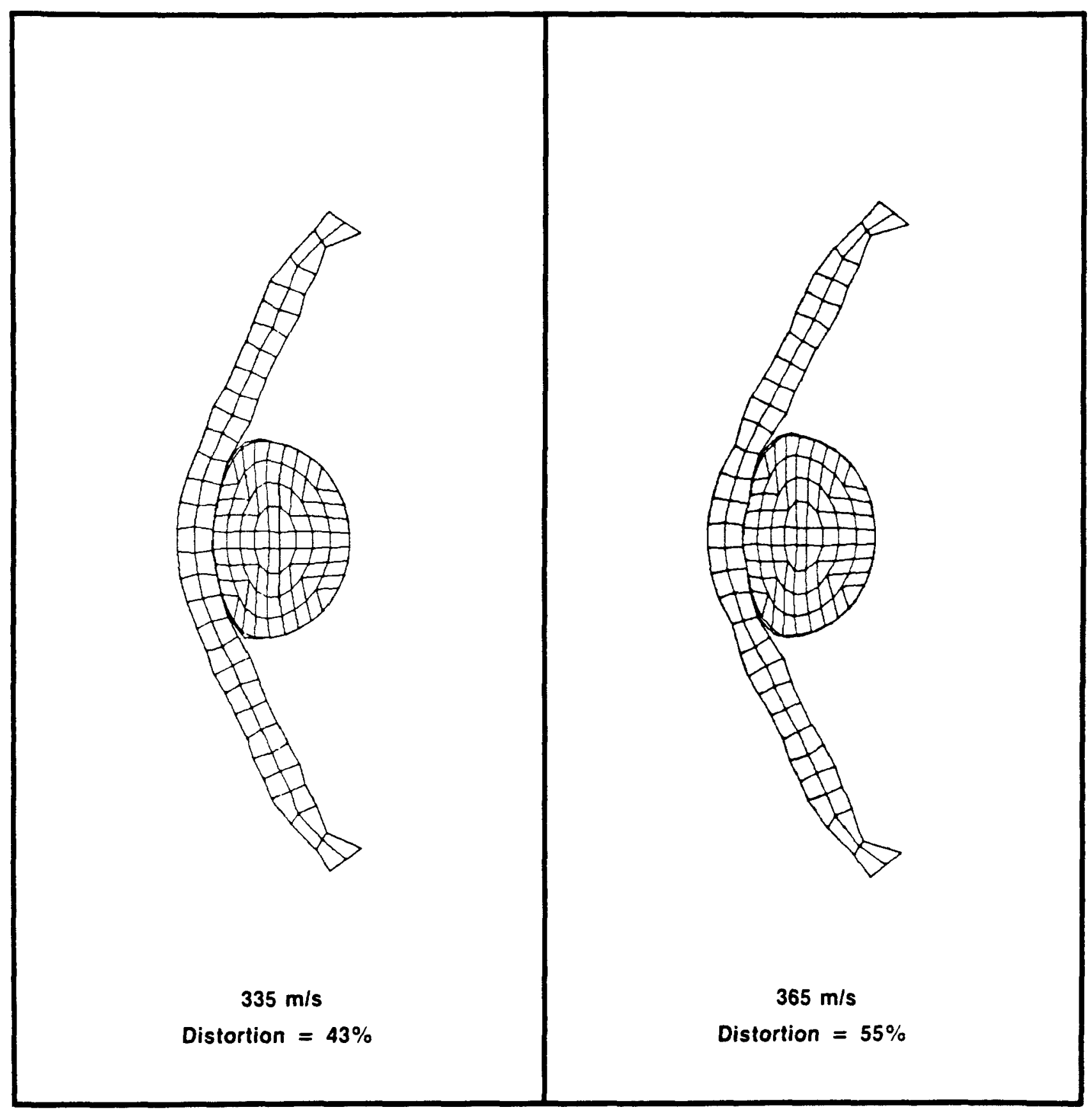

Figure 40. Post-Impact Geometry of a Bare GPHS Fueled Clad After Impact on the STS-Bay Doors at 335 and 365 ands 


\section{Bare GIS Impacts on Concrete}

Calculations were performed to predict the distortion of plutonia fueled clads which impact concrete while still in the Ground Impact Shell (GIS). This event could occur in early aborts in which the aeroshell was stripped either by collisions with shrapnel or the STS structure. It could also occur in reentry cases in which the aeroshell failed and released the GIS. The results of these calculations are presented in Table XV. Typical post impact geometries are presented in Figure 41 for two impact velocities.

\section{End-On Impacts of an Intact RTG}

Large fueled clad deformation will occur if the RTG impacts at its terminal velocity in an end-on configuration on hard surfaces such as concrete or steel. Lesser amounts of deformation will occur if the RTG impacts a softer surface such as wet sand. The end-on impact analyses were limited in the number of modules which could be modeled at one time. This came about because of the code limitation which allows only 20 impact polygons to be used. As a result, the strategy which was used in modeling the side-on fragment impacts had to be applied. This strategy modeled two modules in fine detail and simulated the rest of the stack with mass mockups. The end-on impacts were modeled with point mass mock-ups so that inertial hard points adjacent to the fine zoned modules would provide the proper stress concentrations. The remainder of the stack was modeled as a distributed mass having the mechanical properties of poco graphite. As in the case of the side-on model, the finely zoned modules were analyses in the second, third, forth, and fifth locations. In all cases it was assumed that the number one module would be distorted by locally high stress concentrations brought about by the sharp edges of the RTG stack spider. A summary of fueled clad distortion as a function of the nature of the impact surface, impact velocity, and the module position in the stack is shown in Table XVI. Somewhat more distortion occurs when impacting steel than concrete; however, this difference should wash out by the fifth stack position. Impacts on sand show that large amounts of distortion are limited to the first two stack locations. These observations were all made for 
Table XV. Fueled Clad Distortion Resulting from Bare GIS Impact on Concrete at Two Velocities

\begin{tabular}{|c|c|}
\hline $\begin{array}{l}\text { Impact Velocity } \\
\mathrm{m} / \mathrm{s}\end{array}$ & $\begin{array}{c}\text { Clad Distortion } \\
\%\end{array}$ \\
\hline 63 & 51 \\
\hline 70 & 58 \\
\hline
\end{tabular}




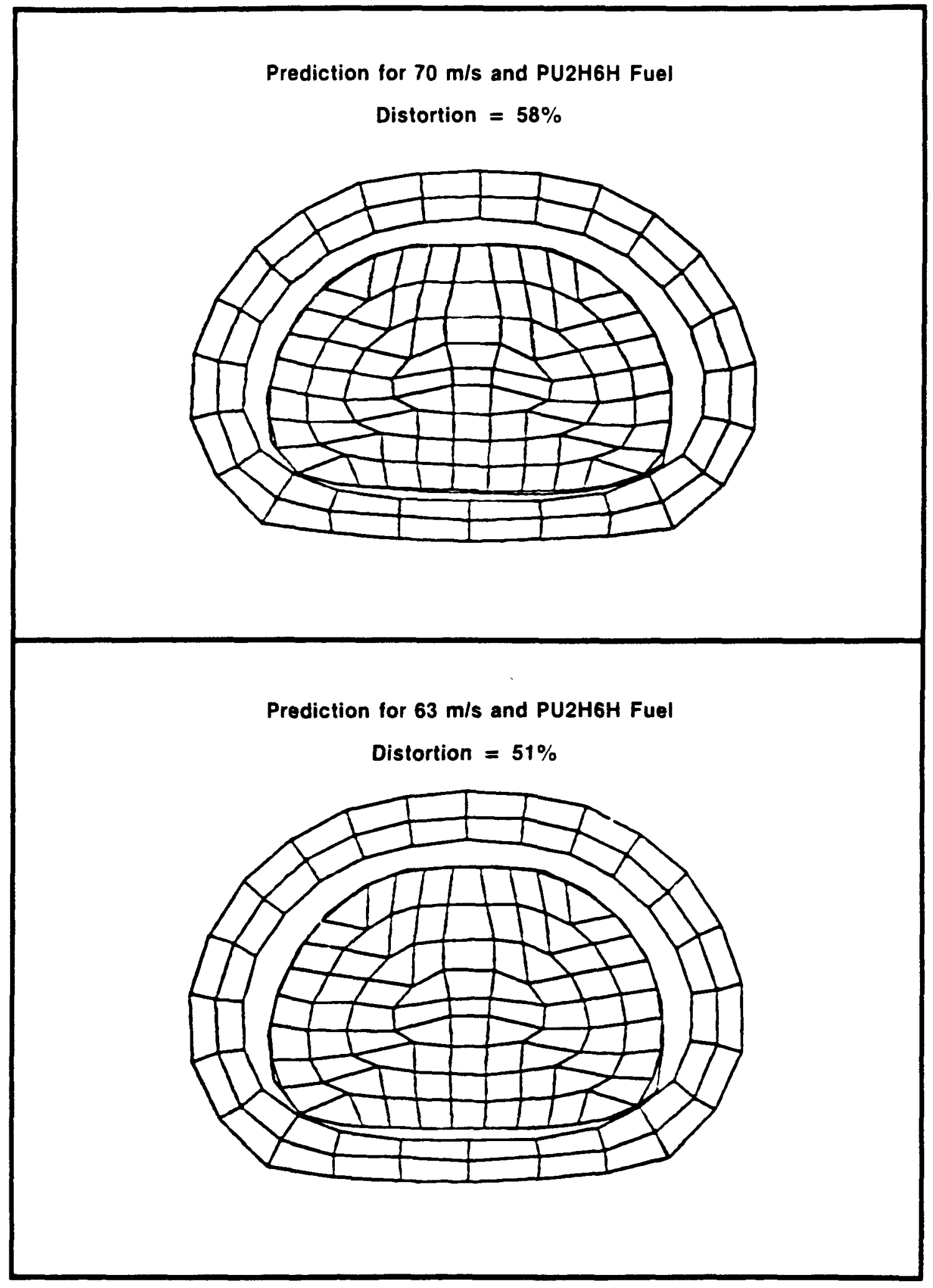

Figure 41. Post-Impact Geometry of a Bare GIS After Impact on a Concrete at 63 and $70 \mathrm{~m} / \mathrm{s}$ 
Table XVI. RTG End-On Impacts on Concrete and Wet Sand at Various Velocities

\begin{tabular}{|lccc|}
\hline Target & $\begin{array}{c}\text { Impact } \\
\text { Velocity } \\
\text { m/s }\end{array}$ & $\begin{array}{c}\text { Stack Position 2 } \\
\text { Distortion }\end{array}$ & $\begin{array}{c}\text { Stack Position 3 } \\
\text { Distortion }\end{array}$ \\
Concrete & 55 & $\%$ & $\%$ \\
Concrete & 70 & 36 & 39 \\
Concrete & 85 & 52 & 52 \\
Concrete & 100 & 74 & 67 \\
Concrete & 120 & 101 & 77 \\
Steel & 120 & 123 & 102 \\
Wet Sand & 120 & 130 & 109 \\
\hline
\end{tabular}


terminal velocity impacts. Additional calculations were preformed at reduced impact velocity to simulate the case in which the STS does not achieve the height necessary for the RTG to reach terminal velocity before impacting the reference surface. Post-impact geometries for two impact velocities and two target materials are shown in Figure 42 .

\section{E. Distortion Resulting From Multiple Impacts of a Bare Fueled Clad}

The material presented in this section summarizes the results of an effort designed to determine the response of a bare GPHS fueled clad to multiple impacts on the same clad surface. The first impact response was developed in the BCI steel impact geometry. This response is shown for a typical case in Figure 43 . The secondary impact was on a $4 \times 4$ inch concrete target. This response is shown for a typical case in Figure 44 .

A matrix of cases was run to determine the sensitivity of GPHS fueled clad secondary impact distortion to initial distortion. The results of this sensitivity study are presented in Table XVII and figure 45. A curve showing the expected distortion from a concrete-only impact is also presented in figure 45 . This curve is useful in determining what the effects of individual impacts would be. For example, two $40 \mathrm{~m} / \mathrm{s}$ concrete impacts would produce an additive distortion of 48 percent $(24+24$ from the concrete-only curve), while a 24 percent distortion initial impact followed by a $40 \mathrm{~m} / \mathrm{s}$ concrete impact would produce a calculated distortion of 39 percent $(24+15$; interpolated from the sensitivity plot). Two concrete impacts at $50 \mathrm{~m} / \mathrm{s}$ would add to a total distortion of 61 percent while an interpolation of the sensitivity plot curve shows a predicted distortion of 50 percent. Two $45 \mathrm{~m} / \mathrm{s}$ secondary impact tests were run on fueled clads having 13 and 24 percent average initial distortion. The results of these tests are plotted as diamonds on figure 45 . The test results show that, within the experimental accuracy, the distortion resulting from the secondary impact is not a strong function of initial distortion. Given that there is some initial disruption of the fuel, the secondary impact distortion seems to be primarily a function of the secondary impact velocity. This is not surprising since the area of the impact face is 


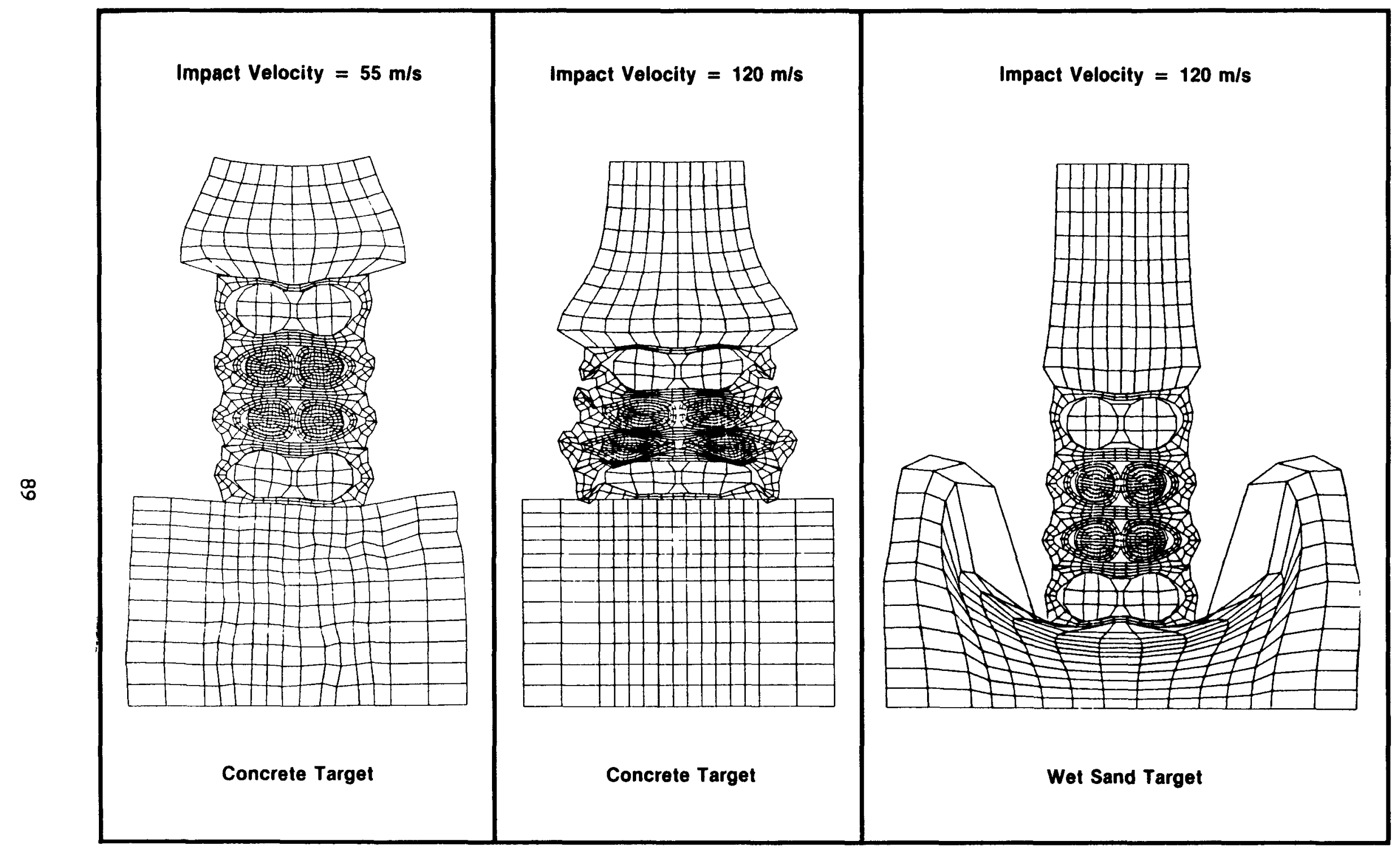

Figure 42. Effect of Impact Velocity and Target Material on the Post Impact Geometry of a Galileo RTG Undergoing an Intact, End-On Impact 
WP_30

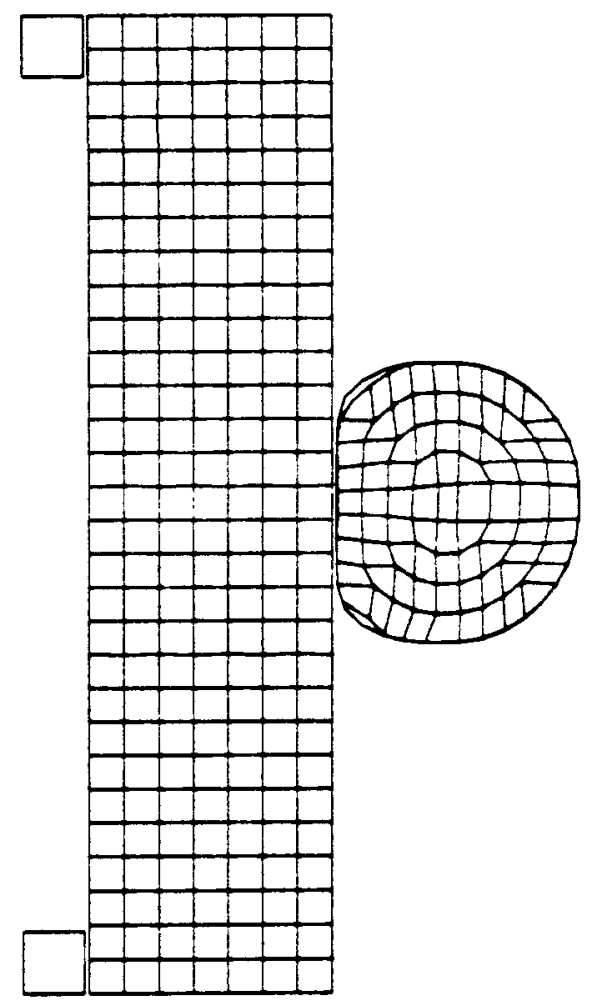

Figure 43. Typical Initial Distortion Geometry Resulting from the Impact of a Bare Fueled Clad on a BCl Target at $30 \mathrm{~m} / \mathrm{s}$ 
WP_30_40_CNC

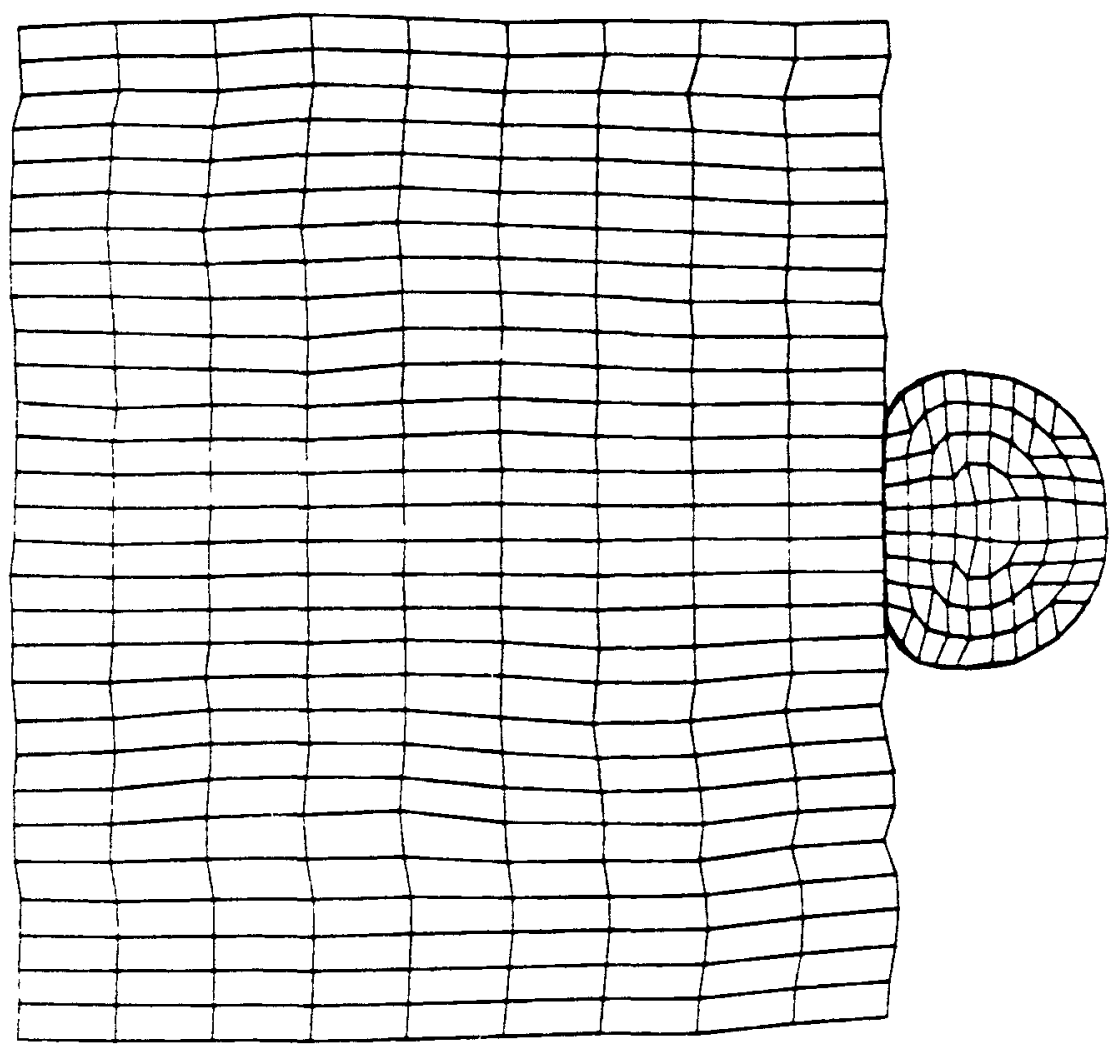

Figure 44. Typical Distortion Resulting from Secondary Impact on Concrete on an Initially Distorted Bare Fueled Clad 
Table XVII.

\begin{tabular}{|c|c|c|c|c|}
\hline Data Set Name & $\begin{array}{c}\text { Steel } \\
\text { Impact } \\
\text { Velocity } \\
\text { M/S }\end{array}$ & $\begin{array}{c}\text { Distortion } \\
\\
\%\end{array}$ & $\begin{array}{l}\text { Concrete } \\
\text { Impact } \\
\text { Velocity } \\
\text { M/S }\end{array}$ & $\%$ \\
\hline $\begin{array}{l}\text { WP_20 } \\
\text { WP_20_40_CNC } \\
\text { WP_20_45_CNC } \\
\text { WP_20_50_CNC } \\
\text { WP_20_60_CNC }\end{array}$ & $\begin{array}{l}20 . \\
20 . \\
20 . \\
20 . \\
20 .\end{array}$ & $\begin{array}{l}10.5 \\
10.5 \\
10.5 \\
10.5 \\
10.5\end{array}$ & $\begin{array}{l}-\overline{40 .} \\
45 . \\
50 . \\
60 .\end{array}$ & $\begin{array}{l}- \\
28.4 \\
33.0 \\
36.6 \\
45.5\end{array}$ \\
\hline $\begin{array}{l}\text { WP_30 } \\
\text { WP_30_40_CNC } \\
\text { WP_30_45_CNC } \\
\text { WP_30_50_CNC } \\
\text { WP_30_60_CNC }\end{array}$ & $\begin{array}{l}30 . \\
30 . \\
30 . \\
30 . \\
30 .\end{array}$ & $\begin{array}{l}17 . \\
17 . \\
17 . \\
17 . \\
17 .\end{array}$ & $\begin{array}{l}- \\
40 . \\
45 . \\
50 . \\
60 .\end{array}$ & $\begin{array}{l}- \\
34.8 \\
38.9 \\
43.2 \\
51.2\end{array}$ \\
\hline $\begin{array}{l}\text { WP_40 } \\
\text { WP_40_40_CNC } \\
\text { WP_40_45_CNC } \\
\text { WP_40_50_CNC } \\
\text { WP_40_60_CNC }\end{array}$ & $\begin{array}{l}40 \\
40 \\
40 \\
40 \\
40\end{array}$ & $\begin{array}{l}28.2 \\
28.2 \\
28.2 \\
28.2 \\
28.2\end{array}$ & $\begin{array}{l}- \\
40 \\
45 \\
50 \\
60\end{array}$ & $\begin{array}{l}- \\
43.2 \\
46.8 \\
49.5 \\
58.0\end{array}$ \\
\hline $\begin{array}{l}\text { WP_50 } \\
\text { WP_50_40_CNC } \\
\text { WP_50_50_CNC } \\
\text { WP_50_60 }\end{array}$ & $\begin{array}{l}50 . \\
50 . \\
50 . \\
50 .\end{array}$ & $\begin{array}{l}38.4 \\
38.4 \\
38.4 \\
38.4\end{array}$ & $\begin{array}{l}\overline{40 .} \\
50 . \\
60 .\end{array}$ & $\begin{array}{l}\overline{51.6} \\
58.2 \\
66.5\end{array}$ \\
\hline $\begin{array}{l}\text { WP_20_CNC } \\
\text { WP_40_CNC } \\
\text { WP_45_CNC } \\
\text { WP_50_CNC } \\
\text { WP_60_CNC }\end{array}$ & $\begin{array}{l}- \\
\overline{-} \\
- \\
-\end{array}$ & $\begin{array}{l}- \\
- \\
- \\
-\end{array}$ & $\begin{array}{l}20 . \\
40 . \\
45 . \\
50 . \\
60 .\end{array}$ & $\begin{array}{r}8.4 \\
24.3 \\
28.8 \\
30.3 \\
40.3\end{array}$ \\
\hline $\begin{array}{l}\text { WP_35 } \\
\text { WP_35_40_CNC } \\
\text { WP_35_45_CNC } \\
\text { WP_35_50_CNC } \\
\text { WP_35_60_CNC }\end{array}$ & $\begin{array}{l}35.0 \\
35.0 \\
35.0 \\
35.0 \\
35.0\end{array}$ & $\begin{array}{l}22.4 \\
22.4 \\
22.4 \\
22.4 \\
22.4\end{array}$ & $\begin{array}{l}\overline{40} \\
45 \\
50 . \\
60 .\end{array}$ & $\begin{array}{l}-\overline{36.6} \\
39.7^{*} \\
38.1^{*} \\
53.8^{*}\end{array}$ \\
\hline
\end{tabular}

- Concrete target spalled at $50 \mathrm{~m} / \mathrm{s}$ but not at $45 \mathrm{~m} / \mathrm{s}$. 


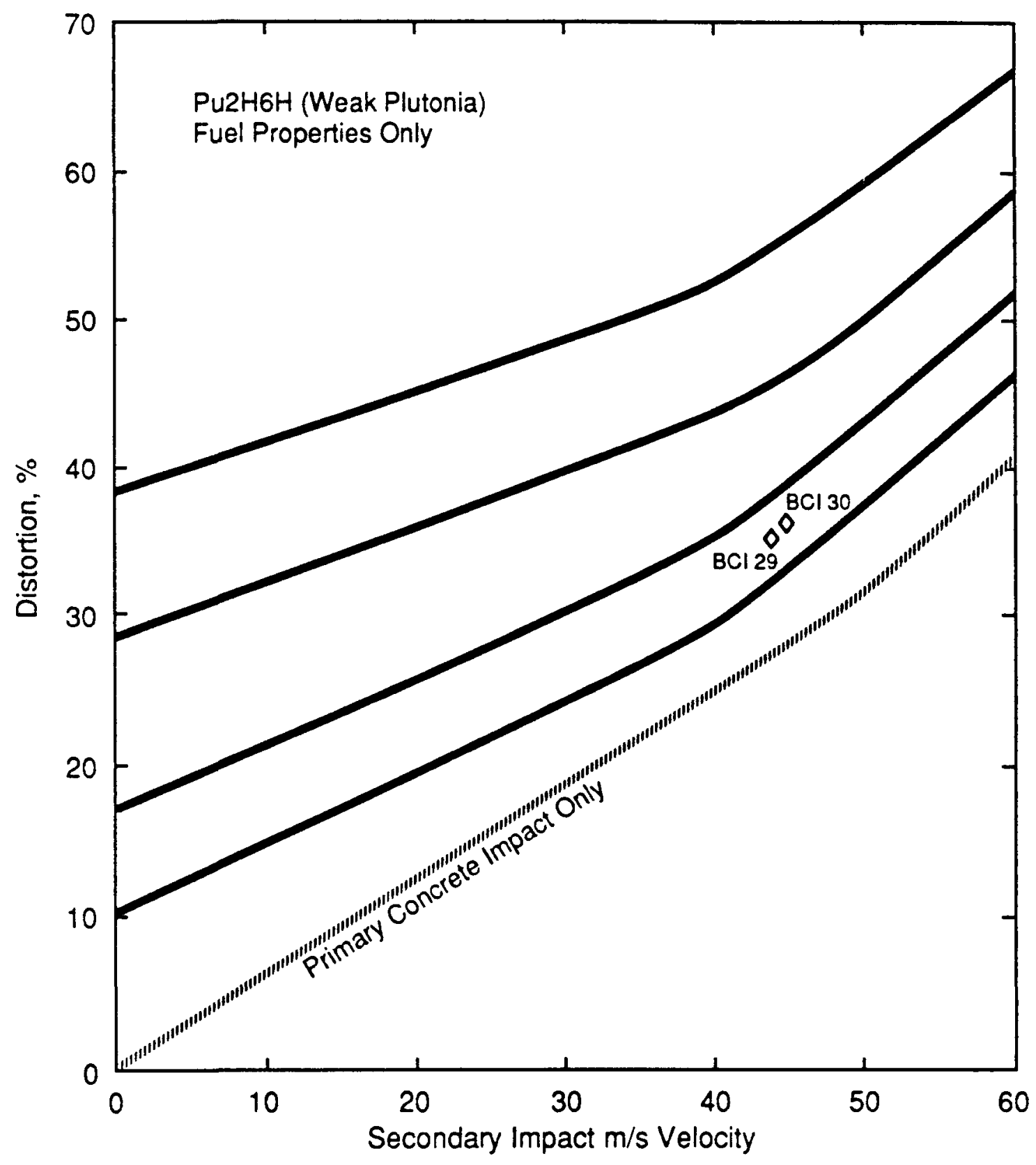

Figure 45. Effect of Initial Bare Fueled Clad Distortion on Cummulative Distortion Following a Same Surface Secondary Impact on Concrete ${ }^{(1)}$

(1) Initial Distortion Created by Impact on a Steel Target having $\mathrm{BCl}$ Geometry $\mathrm{BCl} 29$ Initial Distortion was $13 \%$ while $\mathrm{BCl} 30$ was $26 \%$ 
greatly increased from the line contact which is a characteristic of all primary impacts.

It should be noted that the analytical methods predicted the distortion resulting from a secondary impact at $45 \mathrm{~m} / \mathrm{s}$ on concrete of a fueled clad having an initial distortion of 13 percent to be 35 percent. A similar calculation for a fueled clad having an initial distortion of 24 percent predicted the distortion resulting from a $45 \mathrm{~m} / \mathrm{s}$ secondary impact on concrete to be 43 percent. The average measured distortions were 36 and 37 percent respectively. The agreement between the analytically predicted and measured distortions appears to be well within the uncertainty of the calculations and the test material responses.

The results of these analyses do not speak to fuel release. The use of a single distortion vs. release curve ignores the physical fact that clad failure is pathway dependent. No attempt to assess this dependence has been made; however, it is interesting to note that the directly applicable test results obtained to date had final distortions of $\sim 37$ percent and released no fuel. The referenced data points are the diamonds plotted on the analytical sensitivity curves shown in figure 45 . These results are consistent with the authors' long stated view that, for low rates of momentum transfer, fueled clads will accommodate 40 percent distortion before cracking through. 


\section{REFERENCES}

(1) Eck, Marshall and Meera Mukunda. (1988) "Predicting the Velocity and Azimuth of Fragments Generated by the Range Destruction or Random Failure of Rocket Casings and Tankage." 39th Congress of the International Astronautical Federation, held in Bangalore, India, 10-14 October 1988 .

(2) Rogers, William, Chairman, et. al. Report of the Presidential Commission on the Space Shuttle Challenger Accident. Washington, D.C. June, 1966.

(3) Zocher, Roy, (1988). Personal Communication. Los Alamos National Laboratory, Los Alamos, New Mexico, September 1988.

(4) Timoshenko, S. Theory of Plates and Shells. McGraw-Hill Book Company, Inc. New York, 1940. 